\title{
Applications of Photoinduced Phenomena in Supramolecularly Arranged Phthalocyanine Derivatives: A Perspective
}

\author{
Simona Bettini ${ }^{1,2}$, Ludovico Valli ${ }^{2,3, *(\mathbb{D})}$ and Gabriele Giancane ${ }^{2,4}$ (D) \\ 1 Department of Engineering of Innovation, University of Salento, Via per Monteroni, 73100 Lecce, Italy; \\ simona.bettini@unisalento.it \\ 2 National Interuniversity Consortium for Materials Science and Technology, INSTM, Via Giuseppe Giusti, \\ 9, 50121 Florence, Italy; gabriele.giancane@unisalento.it \\ 3 Department of Biological and Environmental Sciences and Technologies, University of Salento, \\ Via per Monteroni, 73100 Lecce, Italy \\ 4 Department of Cultural Heritage, University of Salento, Via D. Birago, 64, 73100 Lecce, Italy \\ * Correspondence: ludovico.valli@unisalento.it
}

Academic Editor: Simona Collina

Received: 17 July 2020; Accepted: 13 August 2020; Published: 16 August 2020

\begin{abstract}
This review focuses on the description of several examples of supramolecular assemblies of phthalocyanine derivatives differently functionalized and interfaced with diverse kinds of chemical species for photo-induced phenomena applications. In fact, the role of different substituents was investigated in order to tune peculiar aggregates formation as well as, with the same aim, the possibility to interface these derivatives with other molecular species, as electron donor and acceptor, carbon allotropes, cyclodextrins, protein cages, drugs. Phthalocyanine photo-physical features are indeed really interesting and appealing but need to be preserved and optimized. Here, we highlight that the supramolecular approach is a versatile method to build up very complex and functional architectures. Further, the possibility to minimize the organization energy and to facilitate the spontaneous assembly of the molecules, in numerous examples, has been demonstrated to be more useful and performing than the covalent approach.
\end{abstract}

Keywords: sensors; fluorescence; time-resolved spectroscopy; UV-Vis; Charge-transfer; energy-transfer; supramolecular assembly; $\pi-\pi$ interaction; hydrogen bonds; photocatalysis; solar cells; photodynamic therapy; fullerene; carbon allotropes; cyclodextrins; PDI; micelles

\section{Introduction}

The awareness that Nature brings into play disparate templates to fabricate complex macromolecules, such as proteins or DNA, has prompted scientists to investigate novel low-dimensional synthetic multi-molecular assemblies. Consequently, through the last decades remarkable amount of research has been dedicated to the preparation of bio-inspired hybrid supramolecular assemblies in consideration of their appealing and multifaceted applications in areas covering biology, chemistry, materials science, medicine, physics, from catalysis [1] to organic thin field-effect transistors [2], from cosmetics [3] to drugs [4], from imaging [5] to inks [3], from photovoltaic [6] to other energy-conversion devices [7], from sensing [8] to theranostics [9], from opto-electronics [10] to anticancer photodynamic therapy [11], from non-linear optics devices [12] to data storage systems [13]. Supramolecular assemblies can be described as hierarchical structures where each component is important to determine characteristics, employment and functionalities. So the idea of joining together different functionalities within the identical nanoassemblies has gained great attention [14]. Moreover, Ariga et al. have even introduced the concept of "nanoarchitectonics" [15]. 
In order to associate the diverse moieties of such multimodular structures, various approaches are available (used individually and independently or in combination) and, among them, the ones enabling thorough management of molecular architecture are the most employed: dispersion forces [16], electrostatic attractions [11], hydrogen-bonding interactions [17], hydrophobic effects [18], Langmuir-Blodgett [19] and Langmuir-Schäfer [20] techniques, Layer-by-Layer transfer [21], metal to ligand coordination [22], $\pi-\pi$ stacking interactions [23], physical evaporation [24] and ultra-high vacuum methods [25], self-assembly [26], van der Waals interactions [27], and so on. These are some of the preferred means for the preparation of supramolecular and multimodular structures with tunable characteristics. In general such non-covalent interactions ensure the chance of generating stiff and distinct assemblies with anisotropic properties. In fact it is possible to modulate supramolecular assemblies structure through several parameters such as the central metal ion in the macrocycle [28], the construction methods [29], the ionic strength [30], pH [31], the presence of electro-donating or withdrawing functionalizations on the periphery [28], the solvent [32], the steric hindrance [33], the thermal treatments [34], etc. Such a novel approach allows, in several fields of applications of these hybrid structures, the prospects of amalgamation of multimodal procedures with the ultimate goal of accomplishing a synergistic effect [35].

Among the molecular building blocks for the fabrication of such structures, hefty tetrapyrrolic macrocycles, such as porphyrins, porphyrazines, phthalocyanines and other analogues (18 $\pi$-electrons aromatic macrocycles), play a role of primary importance due to their properties (rigidity, chance to deposit thin films, stability, extended conjugated $\pi$-electron cloud, intrinsic conductivity, light absorption capability with extinction coefficients of the order of magnitude of $10^{5} \mathrm{~cm}^{-1} \mathrm{M}^{-1}$, long-lived fluorescence, redox activity, possibility to host uncoupled electrons on the central metal ion or in the aromatic cloud, rich electrochemistry, modulation of their characteristics through peripheral functionalization or variation of the central metal atom cation and so on). All these peculiarities allow to confer definite physico-chemical characteristics which are of paramount importance to manipulate the performance and interactions of these macrocycles as molecular Legos in supramolecular networks. The best instances of this engineering and regulation in supramolecular assemblies also this time come from biological networks where different components integrate to bring about indispensable and fundamental processes for living organisms.

Herein, our review is focused on phthalocyanines (Scheme 1) and their applications in supramolecular assemblies in mainly four areas: charge and energy transfer, photocatalysis, photodynamic therapy and chemical sensors. The rationale of our choice resides in the more intense absorption of phthalocyanines above $550 \mathrm{~nm}$ (body tissues are moderately transparent in this wavelength range), superior photochemical and thermal stability in comparison with porphyrins [36].

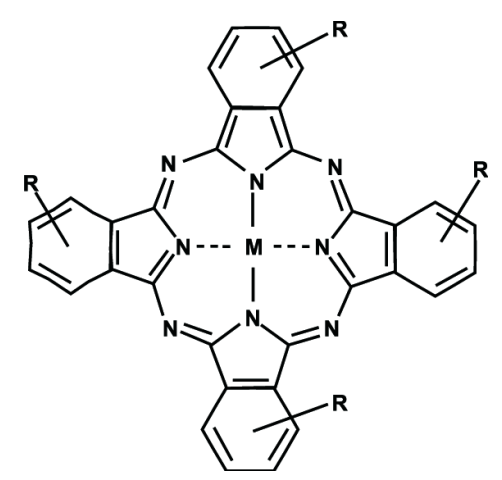

Scheme 1. General structure of the phthalocyanine macroring, where $\mathrm{M}$ is the central metal ion or $\mathrm{H}_{2}$ in the case of the free base. $\mathrm{R}$ is the potential functionalization on the phthalocyanine periphery.

Among compounds used in hybrid supramolecular structures in association with phthalocyanines, it is possible to cite antibodies [37], carbohydrates [38], carbon allotropes (fullerenes [39], graphene [40], nanotubes [7], etc.), cellulose nanocrystals [41], cucurbit[n]uril [42], cyclodextrins [43], DNA [44], 
liposomes [45], metal or oxide nanoparticles [46], peptides [47], perylene bisimides [48], polyaromatic compounds [49], polyoxometalates [50], protein cages [51], etc. All these substances in association with phthalocyanines in supramolecular structures permit to face the well-known tendency of these macroheterocycles to form large stacking aggregates-head to tail J type or face to face H-type stackings-(and consequently low-solubility, quenching of fluorescence and depletion of singlet dioxygen production in some areas of applications) and even offer the possibility to induce reversible conversion from aggregated to disassembled forms and vice-versa.

\section{Pcs-Based Supramolecular Assemblies for Sensing Applications}

In an interesting paper [52], Jiang and collaborators have proposed the unusual realization of an assembly capable of identifying different chiral analytes, such as amino acids and sugars. The strategy has been to couple a tetrapyrrolic moiety, such as a phthalocyanine derivative, with a biomacromolecule; the first one bears four 15-crown-5 ethers (Figure 1A) which coassemblies with two biomacromolecules, a negatively charged DNA or poly(L-lysine). The crown-ether has a dual function: to induce amphiphilic properties and pliability to the macrocycle, while the other two components have to relocate optical activity to the co-assemblies. Such supramolecular assemblies have been fabricated by both the Langmuir-Blodgett (LB) [53,54] and the Langmuir-Schäfer (LS) techniques [52] since the Coulombic interaction between species with opposite charges allows the transfer of robust dyads; in this case with the presence of the amphiphilic phthalocyanine floating on the water surface and DNA or poly(L-lysine) dissolved in the subphase. The surface pressure vs. area per molecule curves already gave indications of the interaction at the air-water interface between the biomacromolecules and the phthalocyanine. The UV-Vis spectra of the LS films of the pure phthalocyanine evidence an unequivocal hypsochromic shift suggesting the presence of $\mathrm{H}$-aggregates; such a shift becomes even larger when poly(L-lysine) is inserted in the LS films. Next also circular dichroism (CD) investigations were carried out; it is worth to observe that, even though the phthalocyanine is not optically active, the fabricated LS films evidence CD signals. The generation of supramolecular chiral assemblies has been also checked in LS films transferred with DNA and poly(L-lysine). In particular in this last case a positive Cotton effect has been discovered in the Q-band; but it is absolutely discrepant from that observed for the pure phthalocyanine film thus suggesting a modification of the supramolecular architecture of the composite multilayer. The positive charges in poly(L-lysine) corroborate the effective interaction existing with the phthalocyanine even at the air-water interface. Further AFM, XRD and FT-IR investigations [52] confirmed the origination of a weak chirality when films of the pure phthalocyanine were deposited; but, on the other side, the presence of poly(L-lysine) induces the handover of biomaterials chirality to the phthalocyanine coassemblies.

Moreover the composite poly(L-lysine)/phthalocyanine multilayers display good fluorescence characteristics upon irradiation at $470 \mathrm{~nm}$ suggesting that the polypeptide inhibits macrocycle dense packing and so also fluorescence quenching. The most remarkable result is the observation that the interaction of these films with amino acids in aqueous media permits to detect not only the amino acids themselves but even to distinguish enantiomers of several of them. In the case of acidic amino acids (aspartic and glutamic acids and proline) the ability to discriminate between the corresponding Land D-enantiomers has been exhibited: in fact, above all in the instances of glutamic and aspartic acids, the L-enantiomers provoke a notable fluorescence enhancement, while the D-enantiomers an evident contraction. In the case of proline the phenomenon is less pronounced, but always observable.

Otherwise, basic amino acids do not influence fluorescence; the most immediate rationale is that their interaction with poly(L-lysine) is really faint. Different is the case of aromatic amino acids, such as phenylalanine and histidine, since a reduction of fluorescence has been observed for both stereoisomers. This observation has prompted the investigation of the corresponding fluorescence quenching rate: it has been observed that $\mathrm{D}$-phenylalanine fastens fluorescence quenching in comparison with the slower phenomenon detected in the case of $\mathrm{L}$-phenylalanine. The rationale is that the aromatic amino acid propagation within the composite films depends on the chirality. 
Another consideration is that the significant presence of hydroxyl groups in carbohydrate molecules potentially could ensure the thorough interaction with the phthalocyanine/poly(L-lysine) composite films and thus induce changes in the fluorescence of the macrocycle. D-galactose, D-glucose and D-mannose were used in aqueous solutions and the immersion of the LS multilayers has provoked a remarkable quenching of fluorescence, even though their discrimination by steady-state fluorescence is not possible. Hence the same approach already described for the aromatic amino acids has been employed; and in fact the investigation of the fluorescence quenching rate allows distinguishing D-glucose with the fastest rate from D-galactose and D-mannose which has the slowest rate.

Figure $1 \mathrm{~B}$ illustrates the rationale given by the authors about the possible mechanism involved in the sensing discrimination of enantiomers. In the case of D- and L-glutamic acid (a molecule which doesn't exhibit peculiar photophysical characteristics) it appears straightforward to propose that the fluorescence variations directly derives from changes in macrocycle aggregation. It has been suggested that D-glutamic acid could induce a more significant aggregation of the phthalocyanine molecules; in contrast, L-glutamic acid molecule contribute to slightly move away the macroring molecules. Further analysis by AFM, CD, and UV-Vis spectroscopy are consistent with these conclusions [52].
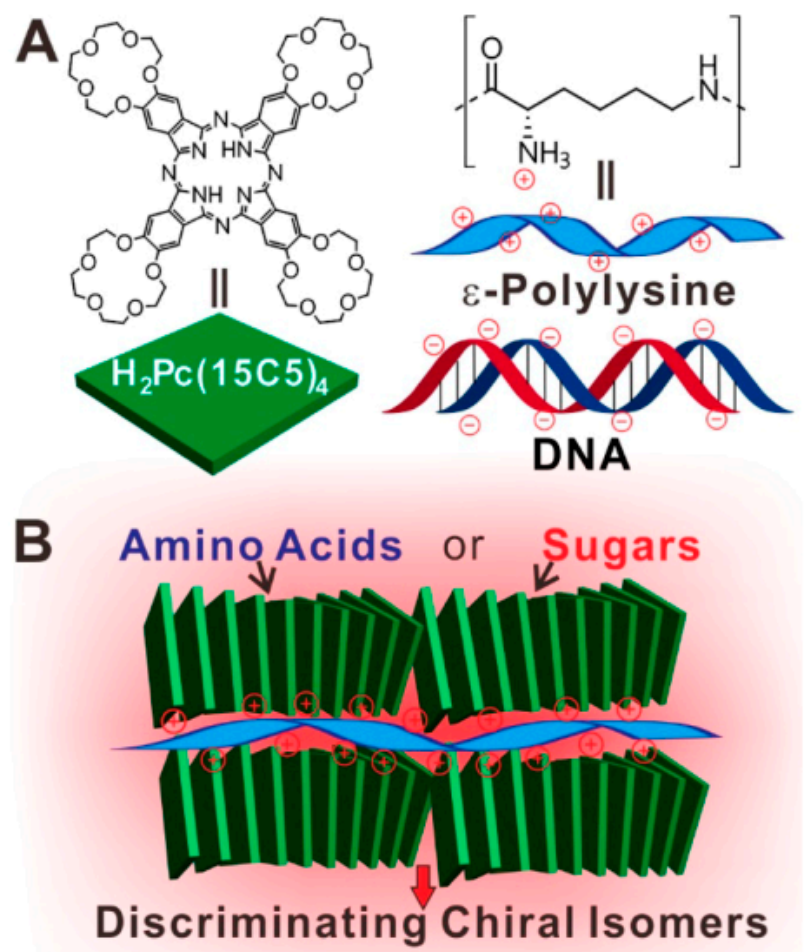

Figure 1. (A) Chemical structure of the tetrasubstituted 15-crown-5 ethers phthalocyanine derivative and the two biomolecules. (B) Schematic representation of the formation of Pc/poly(L-lysine) assemblies. Reprinted with permission from ref. [52]. Copyright 2017 American Chemical Society.

In a paper by Zhu et al. the possibility to detect nucleic acids was investigated above all considering the usual approach already employed for their revelation (addition of fluorescent probes) [55]. In fact the fluorescence of nucleic acids is poor and can be enhanced through the interaction with peculiar dyes. The work proposed by C. Zhu et al. was stimulated by a research by Gurrieri et al. [56] who explored the supramolecular aggregates of an anionic porphyrin derivative with polylysine for the recognition of DNA.

Zhu et al. have used tetracarboxyaluminum phthalocyanine $\left(\mathrm{AlC}_{4} \mathrm{PC}\right)$ which displays intense fluorescence in the NIR wavelength range; the presence of the negative charges permits thorough interaction with polylysine (a polycationic polypeptide) with a $\mathrm{pKa}$ of 9.9 , thus inducing also absorption 
(at $686 \mathrm{~nm}$ ) and fluorescence (at $701 \mathrm{~nm}$ ) suppression. But the most important observation is that upon the successive interaction with nucleic acids the former fluorescence is retrieved. This analysis has prompted the suggestion of this approach for the realization of chemical sensors of nucleic acids with fluorescence excitation and emission in the NIR range in order to preserve biomaterials from more energetic irradiation. The active layers of these sensors have exhibited excellent responsiveness, speed and stability.

During the investigations also the influence of $\mathrm{pH}$ has been controlled; best results were obtained buffering the system at $\mathrm{pH}=6.73$ by hexamethylenetetramine- $\mathrm{HCl}$ buffer solutions. As a further control, also the effect of the $\mathrm{AlC}_{4} \mathrm{Pc} /$ polylysine concentration ratio was examined; the best performances were observed when both concentrations were fixed at $10^{-7} \mathrm{M}$.

Another straightforward observation concerned the effect of ionic strength whose value obviously influences the $\mathrm{AlC}_{4} \mathrm{Pc}$ /polylysine interaction considering its electrostatic origin. In the case of sodium chloride the upper limit for the salt concentration is $20 \mathrm{mM}$.

Finally, as far as selectivity is concerned, the data from investigations are summed up in Table 1.

Table 1. Checked interfering elements used to evaluate the device selectivity. Adapted from ref. [55].

\begin{tabular}{|c|c|c|}
\hline Foreign Substances & Maximum Concentration (ng $\mathrm{mL}^{-1}$ ) & Relative Error Caused (\%) \\
\hline $\mathrm{Ba}^{2+}\left(\mathrm{Cl}^{-}\right)$ & 500 & -4.1 \\
\hline $\mathrm{Mn}^{2+}\left(\mathrm{Cl}^{-}\right)$ & 200 & -2.2 \\
\hline $\mathrm{Fe}^{3+}\left(\mathrm{Cl}^{-}\right)$ & 200 & -5.0 \\
\hline $\mathrm{Mg}^{2+}\left(\mathrm{Cl}^{-}\right)$ & 100 & -3.1 \\
\hline $\mathrm{Zn}^{2+}\left(\mathrm{Cl}^{-}\right)$ & 50 & -4.8 \\
\hline $\mathrm{Cd}^{2+}\left(\mathrm{Cl}^{-}\right)$ & 50 & -4.1 \\
\hline $\mathrm{Ca}^{2+}\left(\mathrm{Cl}^{-}\right)$ & 50 & -4.2 \\
\hline $\mathrm{Hg}^{2+}\left(\mathrm{Cl}^{-}\right)$ & 30 & -3.9 \\
\hline $\mathrm{Co}^{2+}\left(\mathrm{Cl}^{-}\right)$ & 15 & -4.5 \\
\hline DL- $\alpha$-Aminopropionic acid & 8000 & +4.8 \\
\hline L-Phenylalanine & 2000 & -4.5 \\
\hline Glysine & 2000 & -4.6 \\
\hline L-Lyrosine & 2000 & +3.4 \\
\hline L-Arginine & 2000 & -4.9 \\
\hline$\gamma-\operatorname{IgG}$ & 500 & -3.6 \\
\hline HAS & 200 & +4.9 \\
\hline BSA & 200 & -4.8 \\
\hline CTAB & 400 & -5.0 \\
\hline SDBS & 400 & -1.7 \\
\hline Triton X-100 & 400 & -0.2 \\
\hline
\end{tabular}

ctDNA: $50 \mathrm{ng} \mathrm{mL} \mathrm{m}^{-1}$.

Achadu and Nyokong have proposed functional composites of graphene quantum dots (GQDs) and $\mathrm{Co}$ (II) pyrene-substituted phthalocyanine ( $\mathrm{CoPc})$ as selective and sensitive moieties for cyanide ions $\left(\mathrm{CN}^{-}\right)$, a severely harmful anion [57]. GQDs have been extensively used because of their biocompatibility and photoluminescence properties and since their $\pi$-electron cloud and surface pendant groups allow functionalization by other materials. GQDs' nanoconjugates with tetrapyrrolic macrocycles were already used by the authors in other studies and GQDs' fluorescence was quenched by phthalocyanines 
and porphyrins. Cyanide ions have been demonstrated the only ones able to switch on the fluorescence of GQDs.

The first investigations concerned GQDs (synthesized by a hydrothermal procedure) whose emission, upon irradiation at $340 \mathrm{~nm}$, was observed at $445 \mathrm{~nm}$ with a 0.31 quantum yield and a 5.7 ns lifetime.

The GQDs-CoPc composites have been prepared by addition of GQDs to CoPc [57]; a bathochromic shift by $10 \mathrm{~nm}$ of the phthalocyanine $Q$ band has been registered, from 706 to $716 \mathrm{~nm}$, while the pattern of the spectrum was remarkably influenced by GQDs thus suggesting the thorough interaction between the dots and the macrocycles.

Studies by transmission electron microscopy (TEM) have evidenced another typical behavior: the generation of phthalocyanines $\pi-\pi$ aggregates onto GQDs. Moreover the generation of the GQDs-CoPc hybrids is accompanied by the fluorescence "turn OFF" of GQDs with a prompt suggestion of an energy transfer in a donor-acceptor dyad but the most important following discovery is that fluorescence is restored by interaction of the composite material with cyanide ions, $\mathrm{CN}^{-}$. The dependence of the fluorescence intensity on $\mathrm{CN}^{-}$concentration is linear in the interval $0-50 \mathrm{nM}$ and can be expressed by the following Equation (1):

$$
\frac{\Delta F}{F_{0}}=1+K\left[\mathrm{CN}^{-}\right]
$$

where $F$ and $F_{0}$ are the fluorescence intensities in the presence and absence of $\mathrm{CN}^{-}$ions and $K$ is the fluorescence constant. The limit of detection for cyanide ions has been calculated to be $0.5 \mathrm{nM}$.

The proposed rationale (Figure 2) for the interaction among the cyanide ions and the GQDs-CoPc hybrids entails the binding of the $\mathrm{CN}^{-}$ion to cobalt central metal atom thus spacing GQDs and CoPcs out. This separation remarkably hinders the energy transfer and consequently reawakens the fluorescence of GQDs. The gradually enhanced bathochromic shift of the CoPc Q-band in UV-Vis absorption spectroscopy to a greater extent supports the axial ligation of cyanide ions to the Cobalt atoms.

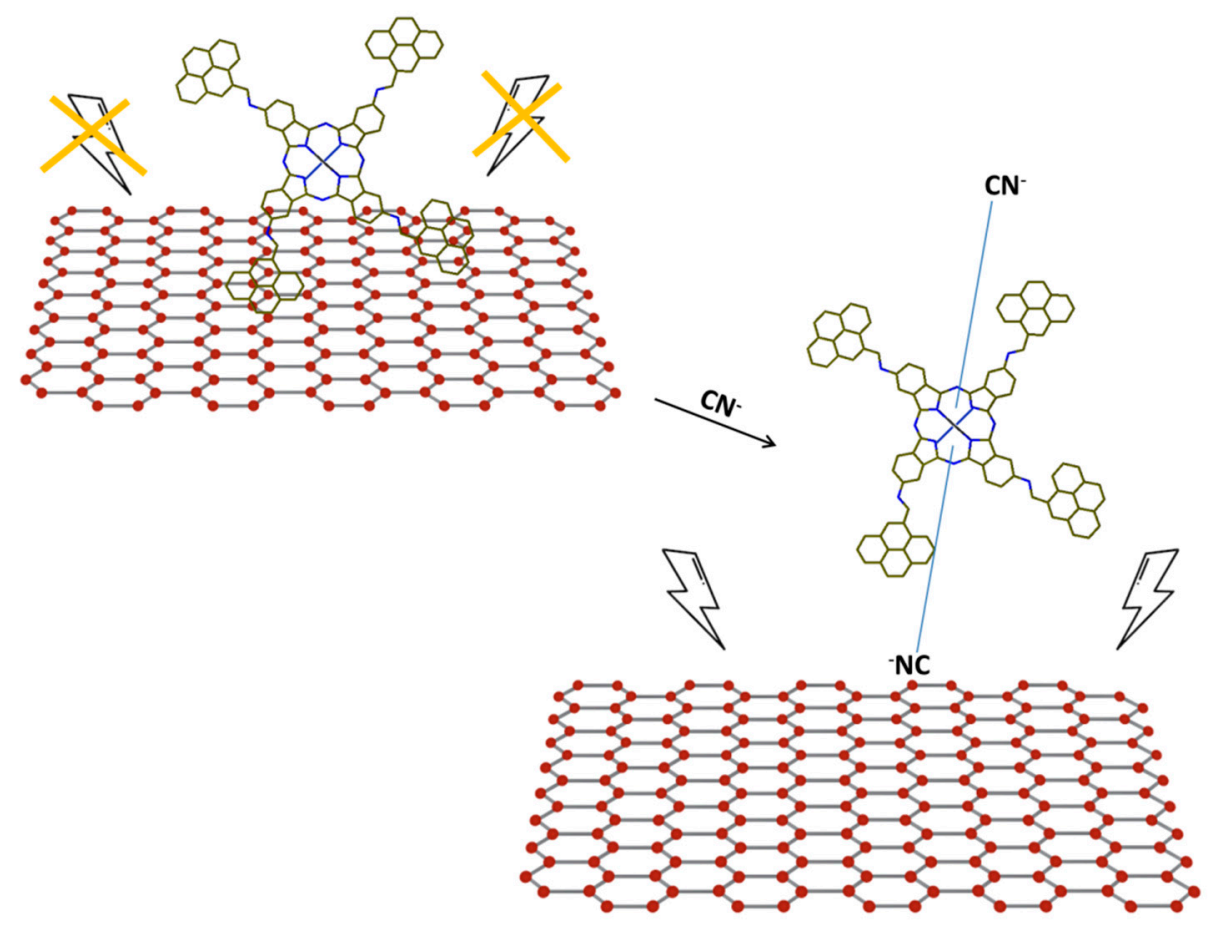

Figure 2. Scheme of the $\mathrm{CN}^{-}$sensing mechanism by supramolecular assembly GQDs-CoPc proposed in the Ref [57]. 
In order to check the selectivity of the GQDs-CoPc hybrids towards the cyanide ion a long series of anions have been experimented: $\mathrm{F}^{-}, \mathrm{Cl}^{-}, \mathrm{Br}^{-}, \mathrm{I}^{-}, \mathrm{H}_{2} \mathrm{PO}_{4}^{-}, \mathrm{HSO}_{4}^{-}, \mathrm{NO}_{3}^{-}, \mathrm{ClO}_{4}^{-}, \mathrm{SCN}^{-}, \mathrm{CH}_{3} \mathrm{COO}^{-}$, $\mathrm{HSO}_{3}{ }^{-}, \mathrm{SO}_{4}{ }^{2-}$ and $\mathrm{CO}_{3}{ }^{2-}$; their perturbation to the response to cyanide ion is conspicuously lower as an additional confirmation of the chemical sensor selectivity [57].

\section{Pcs-Based Supramolecular Assemblies for Photovoltaic Applications}

Unlike porphyrins, tetrapyrrolic macrocycles often associated to phthalocyanines for their chemical and physical features [58,59] and for the functionalization approaches usually employed [60], Pcs show both electron donor and electron acceptor characteristics depending on the chemical species they are interfaced. Further, photoinduced phenomena can be tuned changing the phthalocyanine central metal atom $[61,62]$.

In this section, supramolecularly assembled dyads formed by phthalocyanines acting as electron donor compounds will be considered and examined. In fact, the relevant light harvesting of Pcs derivatives, even higher than that one of porphyrin derivatives, ensures an efficient electron excitation under visible illumination and, if coupled with suitable molecules, efficient electron donor features. Charge transfer mechanism in conjugated compounds is strongly limited by the binding energy of the lowest singlet excitation (about $0.4 \mathrm{eV}$ ) $[63,64]$. In this class of organic compound, the photo-generated exciton is a thermodynamically stable specie, so the charge separation (CS) step appears forbidden or not-favored. On the contrary, the charge transfer (CT) process can be obtained using electron donor and electron acceptor species in both multi-layered and blended geometries. In this approach, photons are absorbed by the donor and/or acceptor species. In the case that most of irradiating photons are absorbed by the electron donor species, an electron-hole couple is formed on this compound as a consequence of the promotion of $\pi$-electrons from the HOMO to the LUMO level (Figure 3). In order to separate the hole-electron pair, the exciton has to move up to reach the interface with the acceptor element [65].

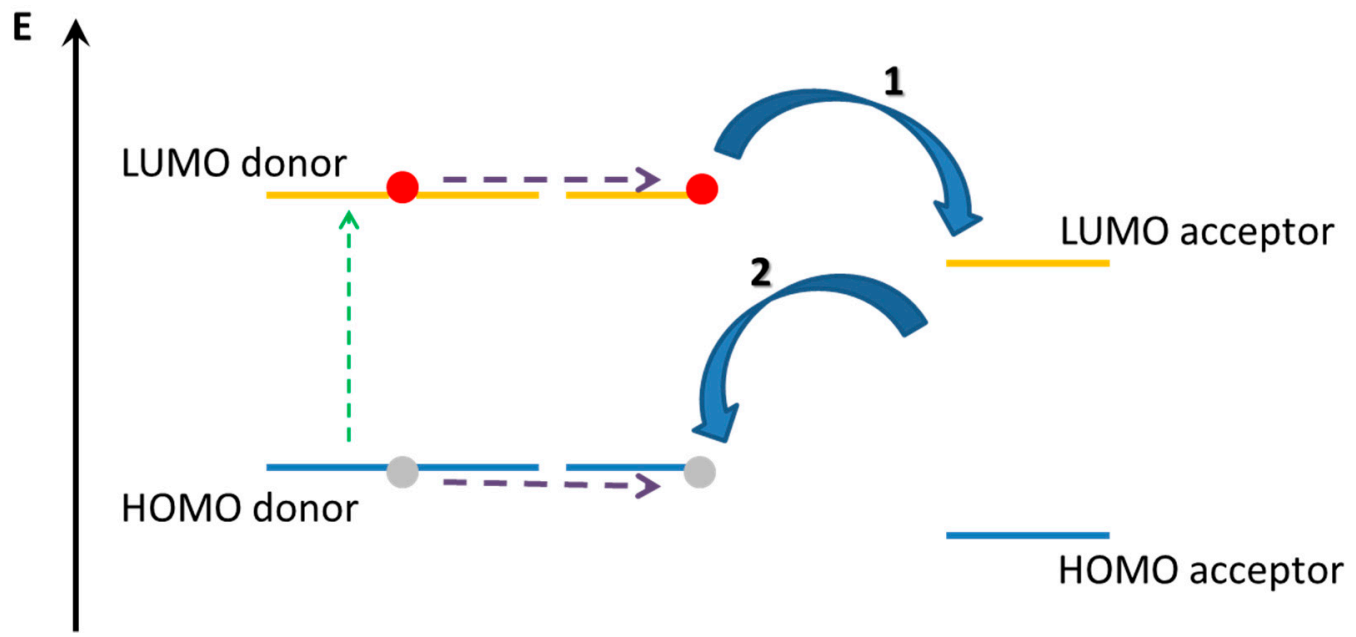

Figure 3. Energy levels of electron donor and electron acceptor during the electron-hole couple formation and separation.

Then, the electron promoted in the LUMO level of the donor element is transferred on the LUMO level of the acceptor compound, leaving the hole in the HOMO level of the donor (the charge separation process is indicated with the arrow labeled as 1). This process, known as photon-induced electron-transfer, converts light into electric charges. Obviously, in order to obtain an electric current is mandatory to overcome the Coulombic attractive force and to ensure an efficient migration of the separated charges toward the two electrodes. Furthermore, it is necessary that the species obtained after the charge separation step has the lowest energy configuration than any intermolecular excited state. Again, as highlighted in Figure 3, the recombination charge process (represented by the arrow 
labeled as 2 in Figure 3) competes with the charge separation and the equilibrium between these two mechanisms is strongly influenced by the molecular parameters. In this context, as well as the deposition techniques and parameters, the self-assembly of donor-donor and donor-acceptor molecules represents a successful approach to maximize the charge separation process.

Hierarchical organization across all length scales is considered a relatively simple approach able to mimic the natural photosynthesis. Supramolecular chemistry, in fact, allows to build up extremely complex structures bringing multifaceted features [66].

For example, the effect of the relative position between a free-based phthalocyanine $\left(\mathrm{H}_{2} \mathrm{Pc}_{\mathrm{C}}\right.$ and a perylene bisimide (PDI) on the charge separation and charge recombination was considered. The electronic coupling, which is particularly influenced by the molecular disorder, was demonstrated to exponentially decrease when the intermolecular distance increases [65]. The role of the molecular orientation was evaluated and it was concluded that the use of planar structures can be detrimental if compared to spherical (or pseudo-spherical) structures like $\mathrm{C}_{60}$.

Nevertheless, the appropriate energetic levels of Pcs and PDI prompted Guldi's and Torres' research teams to propose several photo-active system based on the Pcs-PDI dyad. The electronic communication between Pcs and PDI was already used to carry out $\mathrm{TiO}_{2}$-based dye sensitized solar devices and Forster resonant energy transfer from PDI to Pcs was used to enhance the spectral range of photon absorption up to blue region of the visible spectrum [67,68]. Starting from these evidences, a supramolecular three-dimensional Pcs (in the role of electron donor)-PDI (as electron acceptor) photo-active layer was built up [69]. In particular, a Pc functionalized with a ditopic melanine moiety supramolecularly binds a bifunctional PDI by means of hydrogen bonds (Figure 4). As highlighted by UV-Vis and fluorescence measurements, a complex formed by two Pcs and one PDI derivative linked by hydrogen bonds is obtained.

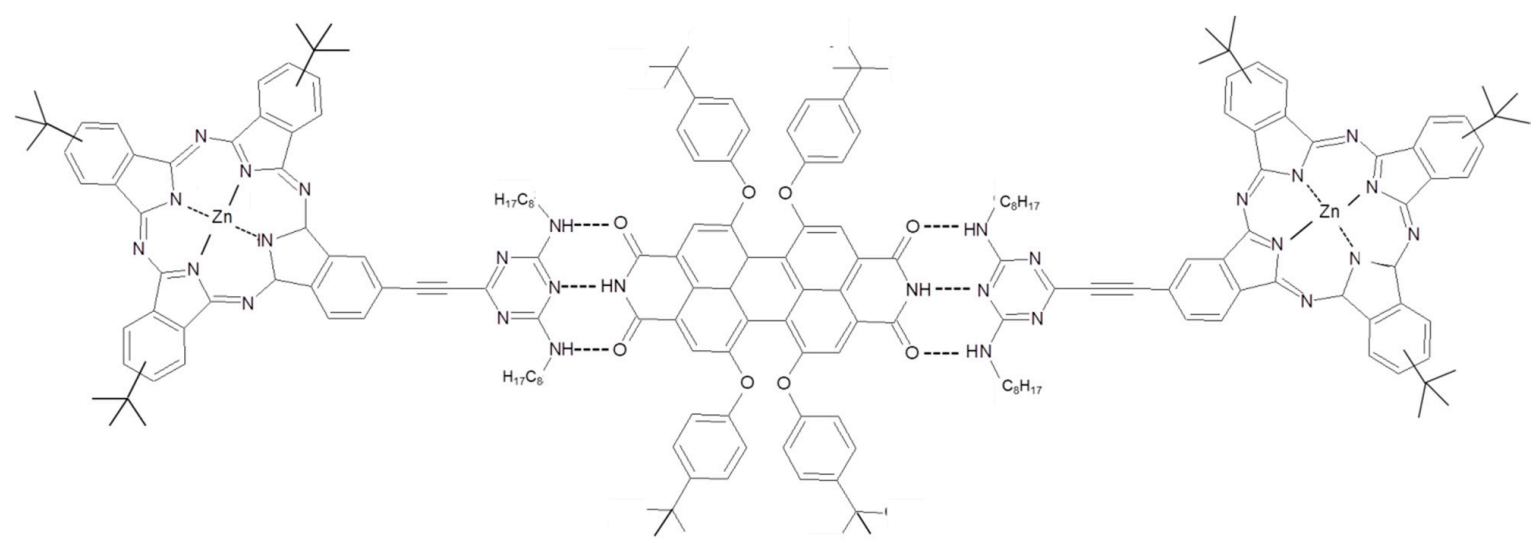

Figure 4. Chemical structure of Pc and PDI reported in the reference [69].

Similarly a molecular assembly was obtained by the same authors by linking a ruthenium metallated Pc with a functionalized PDI by means of covalent binding [70]. Even in this case, the supramolecular approach appears more versatile since it allows to modulate the donor:acceptor ratio and to deeper investigate the photon-induced communication between the two species. Nevertheless, in both approaches, as reported by the authors, it was not possible to evidence any charge transfer reaction from PCs and PDIs. This issue was overcome by the modification of the PCs substituents [71]. In particular, the phthalocyanine (a free-base in this contribution) is still asymmetrically substituted with a melanine unit, but the methyl group is now substituted with an alkanethiole on the Pc periphery (Figure 5). 


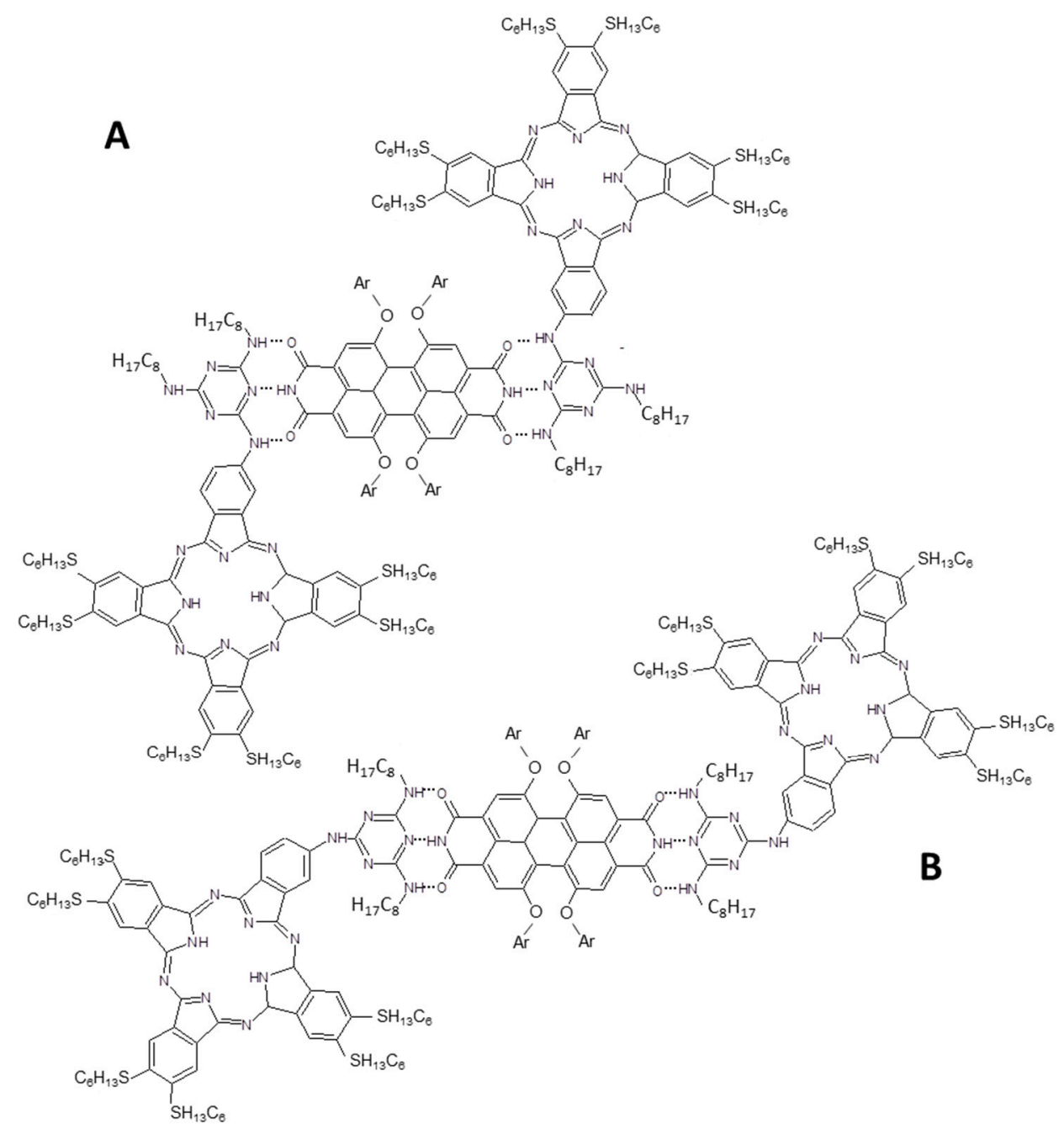

Figure 5. Melanine substituted Pc used to form the supramolecular assembly with functionalized PDI derivative [71]. In (A,B) the two possible supramolecular configurations are reported according to the authors' rationale [71].

Two different configurations can be theoretically adopted by the supramolecular adduct made by two Pcs and a PDI derivative but the authors highlighted that type A in Figure 5 is favored. The supramolecular adduct, driven by hydrogen bonds, was characterized by ${ }^{1} \mathrm{H}-\mathrm{NMR}$, steady-state and transient absorption spectroscopy. It is very interesting that no charge and/or energy transfer is observed when the PCs units are excited to their absorption maximum, on the contrary when PDI moiety is opportunely excited a thermodynamically favored charge separation is induced from PDI to Pc derivatives. The excited electron on the LUMO level of PDI leaves a hole in the valence band that is filled by an electron from Pc and a charge separated state with a lifetime of about 8 ns was measured by laser flash photolysis.

Two systems represented by PDI derivatives/ZnPc substituted were characterized by Sastre, Fukuzumi and collaborators. The authors used a different approach to obtain two supramolecular adducts: a dyad formed by the octaepoxy substituted $\mathrm{ZnPcs}$ and an imidazolyl bis- and mono-substituted perylene bisimide, reported in Figure 6A,B, respectively [72].

The imidazole substituents interact with the central metal atom inducing the formation of the supramolecular adducts. The formation of a $\mathrm{ZnPc} / \mathrm{PDI} \mathrm{B}$ and a triad PDI A/ZnPc/PDI A was demonstrated and confirmed by means of UV-Vis and fluorescence titration; furthermore ${ }^{1} \mathrm{H}-\mathrm{NMR}$ suggests a stable enough formation of the dyad and triad and lifetimes of the separated charge state of about $9.8 \mathrm{~ns}$ for the triad and about $3 \mathrm{~ns}$ for the supramolecular dyad. 


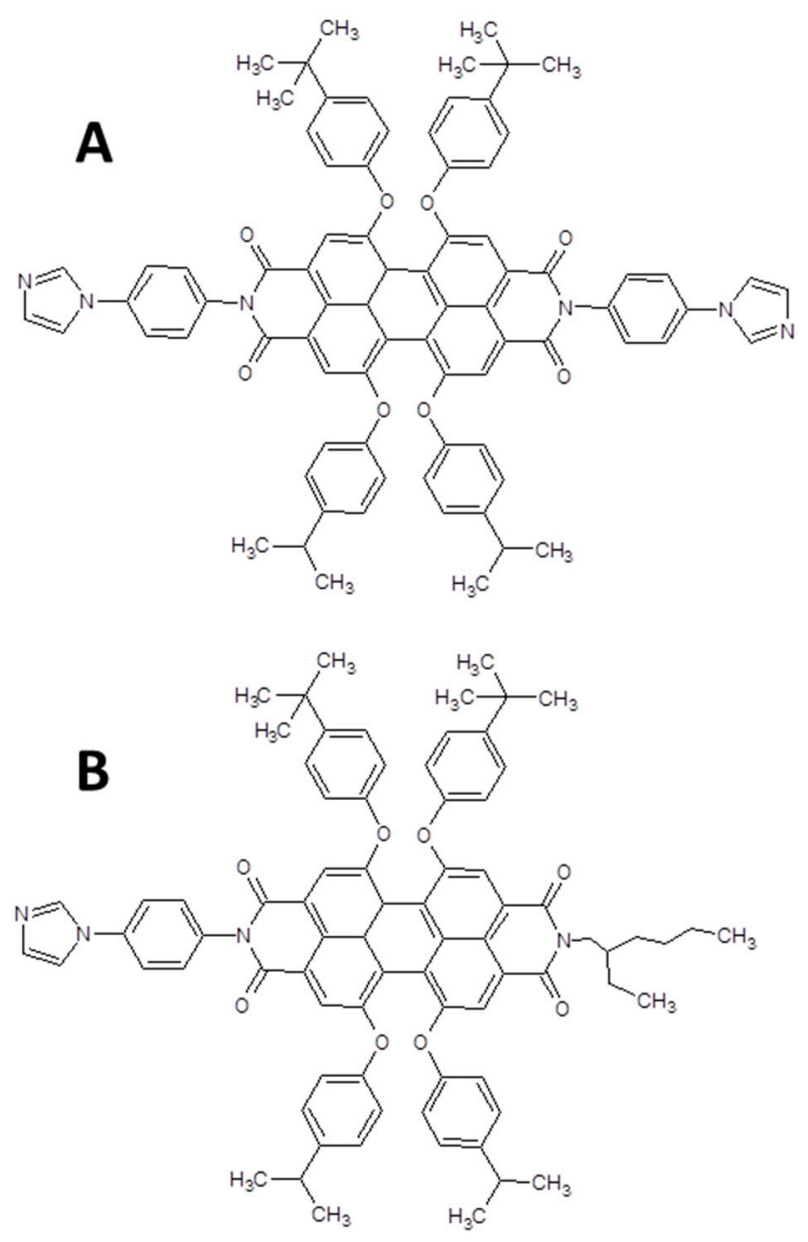

Figure 6. Chemical structures of the bis-(A) and mono (B) substituted PDIs used to form the supramolecular adducts with the $\mathrm{ZnPc}$ reported in the reference [72].

Even electrostatic interaction coupled with $\pi-\pi$ stacking allows to build up supramolecular assemblies [73,74]. A supramolecular dyad between a tetrasulfonated $\mathrm{Zn}$ phthalocyanine and a perylene dimide derivative reported in Figure 7A is formed in [48]. The authors evidenced the formation of well-known elongated 1D structures of perylene derivatives [21,75] that were affected when PDI is dissolved in water in presence of the sulfonated porphyrin. DLS analysis suggests that large aggregates of PDI/Pcs are formed under the action of $\pi-\pi$ and ionic interactions. Fluorescence and UV-Vis studies of PDI solutions in presence of increasing concentration of the anionic ZnPc derivative were used to determinate the binding constant (about $3 \times 10^{4} \mathrm{M}^{-1}$ ) and to evidence the energy transfer process from $\mathrm{ZnPcs}$ to the singlet-excited state of PDI. The electron transfer between the two species was further confirmed by electrochemical measurements.

Asymmetrically substituted perylene imide (PyPMI) (Figure 7B) was used to simultaneously supramolecularly bind a $\mathrm{ZnPc}$ and $\mathrm{TiO}_{2}$ to build up a dye sensitized solar cell [76]. Pyridine substituent interacts with the $\mathrm{Zn}$ atom of Pc derivative and the anhydride termination was used to anchor the supramolecular $\mathrm{ZnPc} / \mathrm{PyPMI}$ dyad on the $\mathrm{TiO}_{2}$ surface. Even though the UV-Vis spectrum of the dyad is a linear combination of the UV-Vis spectra of the two dyes, the IPCE\% of the $\mathrm{ZnPc} /$ perylene imide dyad is $40 \%$ higher than the sum of the devices obtained using $\mathrm{ZnPc}$ and perylene imide separately. The authors proposed that an electron transfer is induced from PyPMI to $\mathrm{TiO}_{2}$. On the other side, when $\mathrm{ZnPc}$ is excited the electron is transferred on PyPMI and it is followed by a charge transfer on $\mathrm{TiO}_{2}$. It allows to increase the charge separation (localized on $\mathrm{ZnPc}$ and $\mathrm{TiO}_{2}$ ) and to maximize all the cell parameters. 
A
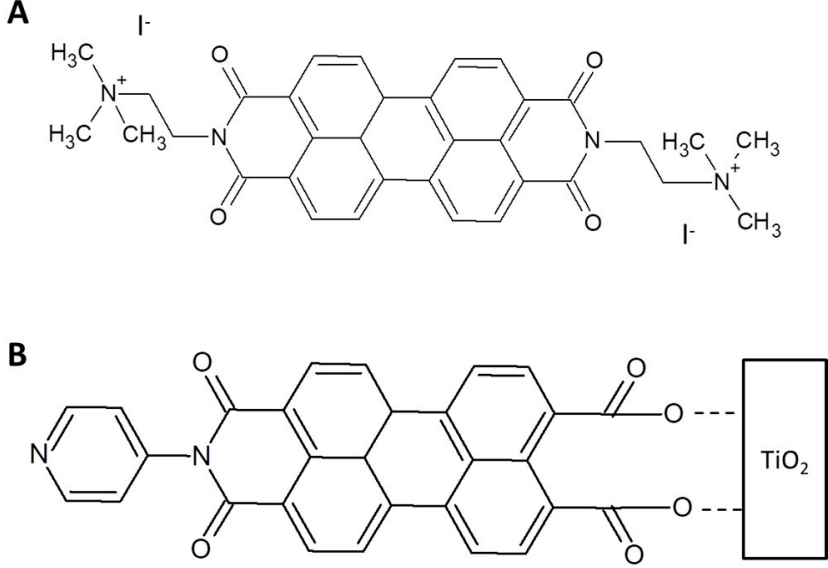

Figure 7. (A) Double charged PDI derivative used to form the photoactive dyad with ZnPc. (B) Asymmetrically substituted perylene imide linked to $\mathrm{TiO}_{2}$ to build up a dye sensitized solar cell [76].

Anyway, the most used electron acceptors coupled with Pcs belong to the fullerene family. In fact, the chemical configuration of $C_{60}$ and $C_{70}$ allows to these compounds to accept up to six electrons [77], minimizing the reorganization energy. Not functionalized $C_{60}$ and $C_{70}$ were demonstrated to be able to form supramolecular adducts with tetra-butyl $\mathrm{Pc}_{\mathrm{c}}$ in toluene by means of dipole-dipole interaction. Energy transfer was theoretically predicted and experimentally demonstrated by transient absorption spectroscopy [78]. Same functionalization was added on a $\mathrm{Zn}$ metallated Pc and the interaction with $\mathrm{C}_{60}$ and $\mathrm{C}_{70}$ was evaluated in toluene and dichlorobenzene, confirming the results previously produced [79]. Both static and dynamic quenching were observed in presence of $C_{60}$ and $C_{70}$. Higher binding constant was measured for the complex $\mathrm{C}_{70} / \mathrm{ZnPc}$ and the proposed mechanism for the formation of the supramolecular adduct was the electrostatic interaction between the electron clouds of the two compounds. Ab initio calculation was used to evidence that, in the ground state, the HOMO level is located on Pc while the LUMO level is placed on the fullerene moiety of the complex. Furthermore, theoretical calculation of formation heat suggested that the formation of $\mathrm{C}_{70} / \mathrm{ZnPc}$ is more favored than the supramolecular complex $\mathrm{C}_{60} / \mathrm{ZnPc}$ (about $-1.3 \mathrm{kcal} \mathrm{mol}^{-1}$ and $-0.6 \mathrm{kcal} \mathrm{mol}^{-1}$ for $\mathrm{C}_{70}$ and $\mathrm{C}_{60}$, respectively). In any case, theoretical simulations were not able to predict the photoinduced charge transfer and the energy transfer appears energetically favored. Size selection in the formation of non-covalent complexes with $C_{60}$ and $C_{70}$ was achieved inserting long alkyl chains on the Pc periphery [80]. In particular, eight octyloxy groups attached to the Pc periphery $(2,3,9,10,16,17,23,24$-octakis(octyloxy)-29H,31H-phthalocyanine) were used to form a branched structure. The authors report that the supramolecular adduct is formed both in presence of $\mathrm{C}_{60}$ and in presence of $\mathrm{C}_{70}$, even though NMR in toluene highlighted that a larger binding constant is obtained for the supramolecular adduct obtained with $C_{70}$. Theoretical studies suggest that the supramolecular adduct $\mathrm{C}_{70} / \mathrm{ZnPc}$ is formed in the so-called side-o configuration with a strong involvement of the substituents in the adduct formation.

A similar approach was used to build-up a Pc/fullerene supramolecular adduct using an octopus-like metallated phthalocyanine functionalization (Figure 8) [81]. Even in this case, a higher affinity was observed towards $C_{70}$ than $\mathrm{C}_{60}$ both by means of theoretical and experimental proofs [81].

From an applicative point of view, the use of not functionalized $C_{60}$ and $C_{70}$ presents the main drawback of the self-aggregation phenomenon. Two possible approaches are mainly used to minimize the self-aggregation of fullerene: 1) the functionalization of the bucky-ball carbon allotrope, 2) the use of chemical compounds, such as polymers, to disperse them. The last approach was proposed by Jurow and co-workers in [82]. The authors functionalized a commercial fluorurated zinc phthalocyanine with thioalkane e thiofluoroalkane group. The presence of florurated substituents enhances the interaction of Pcs with $\mathrm{C}_{60}$ inducing the formation of supramolecular nanostructures [83]. The ratio $\mathrm{C}_{60} / \mathrm{Pc}$ is crucial, 
in this case, to preserve the supramolecular formation and the uniform covering of ITO (and glasses) substrate when the supramolecular assemblies are transferred by the electrode immersion method.

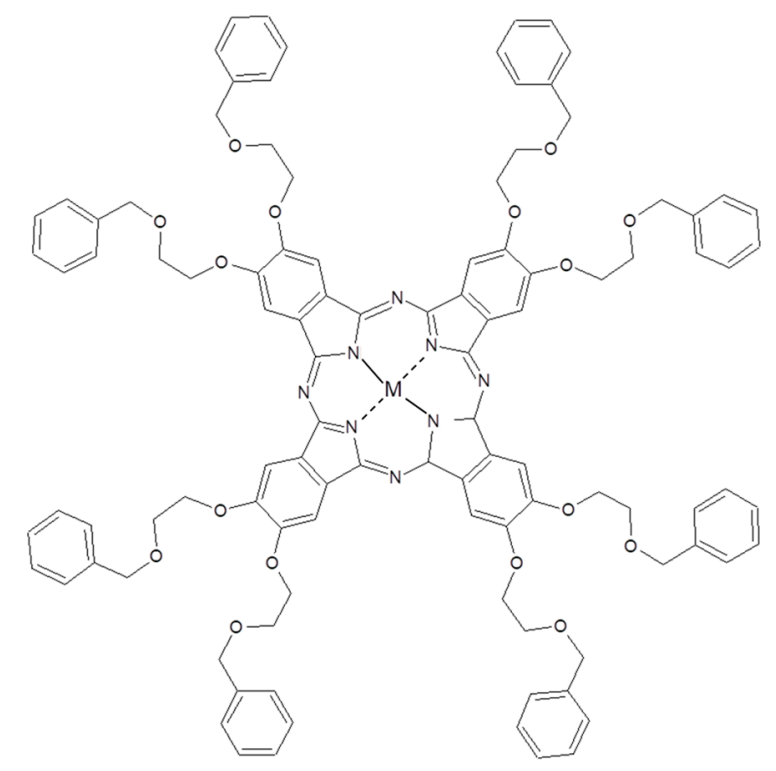

Figure 8. Chemical structure of $(2,3,9,10,16,17,23,24$-octakis(octyloxy))-29H,31H-phthalocyanine used in [81].

Inserting a lithium cation into the $\mathrm{C}_{60}$ cage $\left(\mathrm{Li}^{+} @ \mathrm{C}_{60}\right)$ was possible to assemble a supramolecular adduct with three carboxylated phthalocyanines (Figure 9) [84].

The supramolecular assembly in dimethylsulfoxide:benzonitrile $(v / v)=1: 1$ was studied by means of spectroscopic techniques. For the Pcs in Figure 9B,C a complex formed by 2 fullerenes and a Pc is obtained and the binding constants were estimated about $10^{12} \mathrm{M}^{-2}$ for both of them. When Pc in Figure $9 \mathrm{~A}$ is used, a complex formed by one fullerene derivative and one phthalocyanines is obtained and the binding constant appears strongly reduced. Photoinduced charge transfer from functionalized Pcs B and $\mathrm{C}$ and $\left(\mathrm{Li}^{+} @ \mathrm{C}_{60}\right)_{2}$ was observed and important parameters, such as reorganization energy and electronic coupling, were estimated. Then, Pcs $/\left(\mathrm{Li}^{+} @ \mathrm{C}_{60}\right)_{2}$ assemblies were transferred on an optically transparent electrode by electrochemical method. High incident photon to converted electron (IPCE) values indicate that an intense photocurrent takes place after the light irradiation.

Another example of dendritic substituted Pc is shown in [85] where a donor/acceptor supramolecular dyad is obtained coupling a $\mathrm{ZnPc}$ functionalized with 18-crown substituents and a $\mathrm{C}_{60}$ derivative bearing an ammonium head group (Figure 10). The $-\mathrm{NH}_{3}{ }^{+}$group is crucial to prevent the formation of large aggregates of $\mathrm{C}_{60}$ as well as the crown substituents limit the aggregation of Pc molecules. The authors demonstrated that a 1:1 ratio of $\mathrm{C}_{60} / \mathrm{Pc}$ is supramolecularly formed by means of $\pi-\pi$ interactions, charge transfer and crown substituents that play a cooperative role in the supramolecular assembling. In fact, increasing the numbers of crown-substituents on the Pcs periphery, $\mathrm{C}_{60} / \mathrm{Pc}$ assembly is formed bearing one fullerene and four phthalocyanine derivatives. 

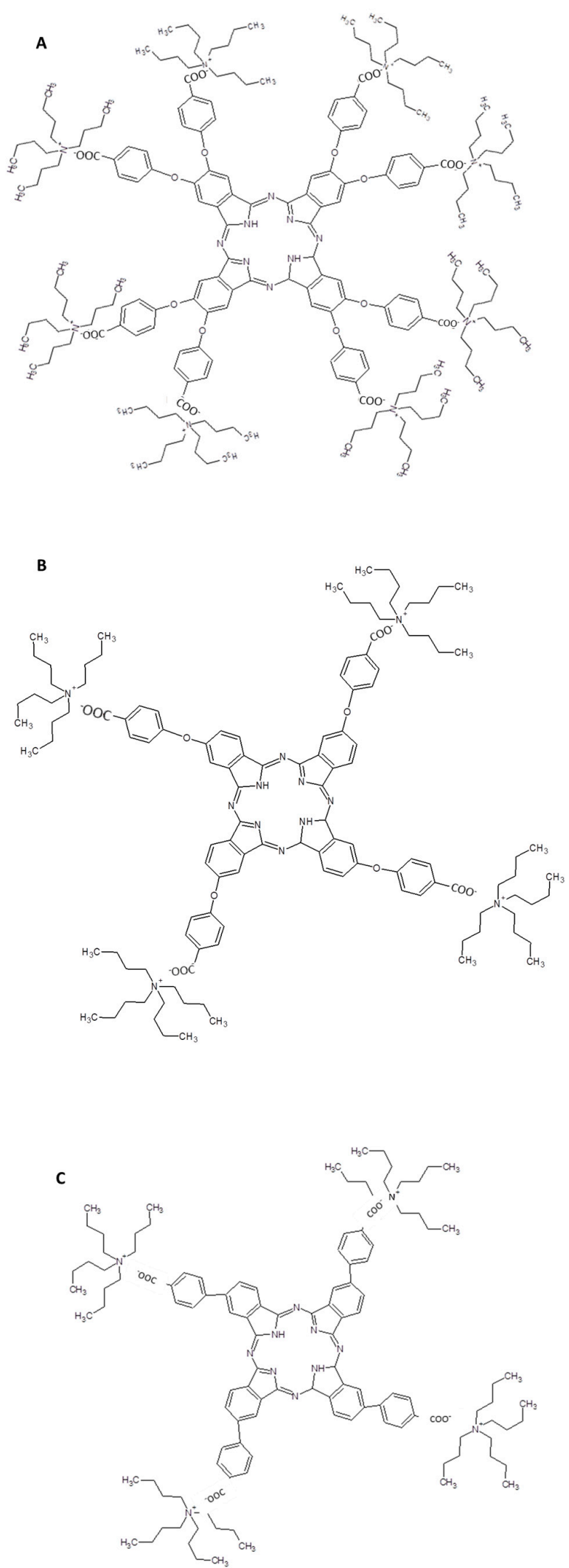

Figure 9. Chemical structures of the three carboxylated phthalocyanines used to form the electrostatically bounded supramolecular dyads with $\mathrm{Li}^{+} @ \mathrm{C}_{60}$ [84]. (A-C) are the three phthalocyanine derivatives used to form complexes with fullerenes. 


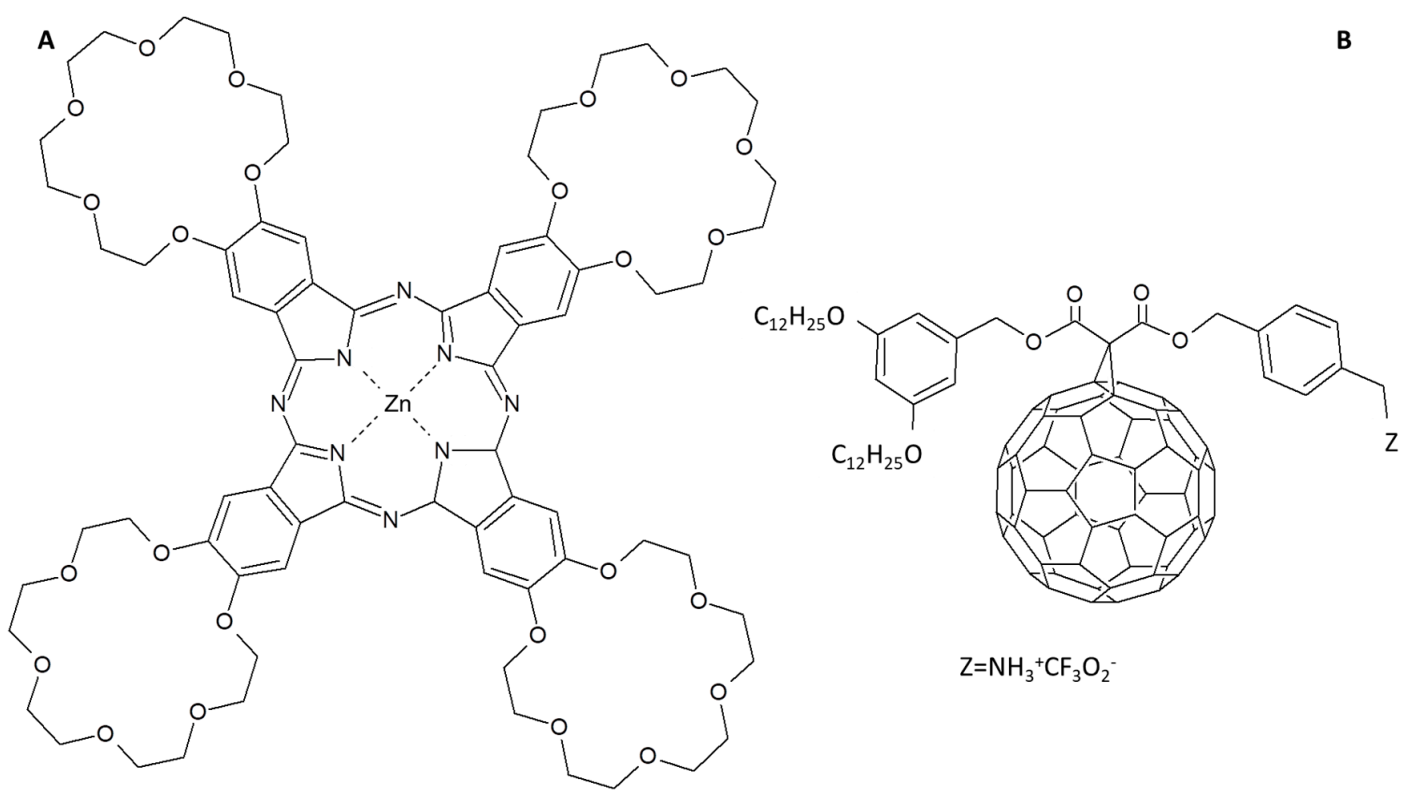

Figure 10. (A) 18-crown tetra functionalized $\mathrm{ZnPc}$ and (B) $\mathrm{C}_{60}$ derivative chemical structures [85].

In the supramolecular dyad represented by RuPc/squaraine derivative/RuPc reported in Figure 11, a photoinduced intramolecular charge transfer process within the fragments of the assembly was observed in toluene, THF, and dichloro-methane. In particular, by means of photophysical studies, the authors evidenced the formation of radical ion pair state RuPc-squaraine ${ }^{\bullet-}-\mathrm{RuPc}^{\bullet+}$ with a very long lifetime (24 $\mu \mathrm{s})$ [86]. When the supramolecular assembly is blended with the well-known PCBM in a ratio $1: 4$ a solar cell with a relatively low efficiency of about $0.3 \%$ under solar simulator irradiation was obtained.

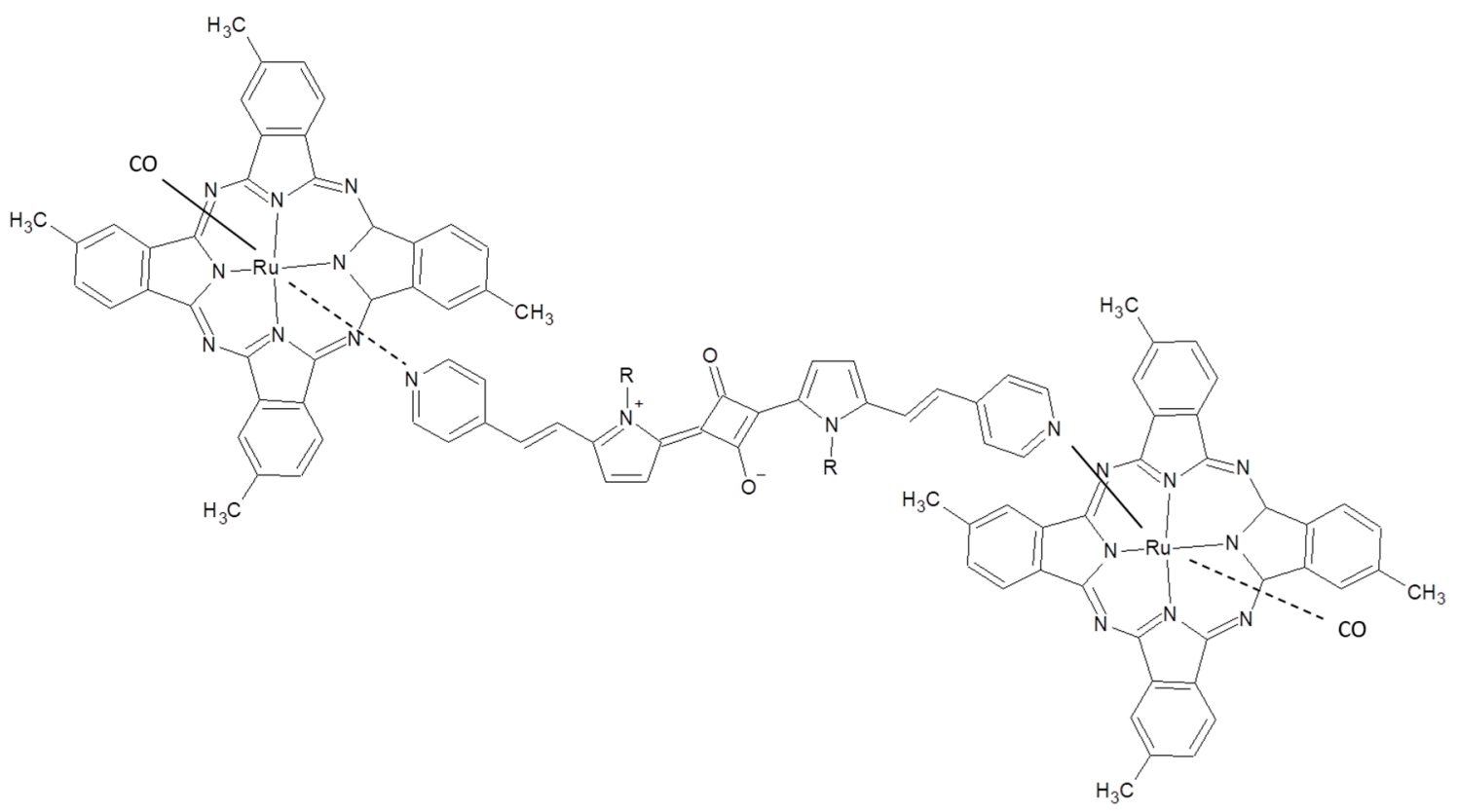

Figure 11. RuPc/squaraine derivative/RuPc photoactive supramolecular assembly reported in [86].

The role of induced order by self-assembled Pcs in a blend with PCBM was investigated in [87]. It was demonstrated that the supramolecular preferential arrangement induced by a fluoride atom attached to the Pc central gallium atom increases the PCE from a very low $0.03 \%$ to $0.4 \%$ (in the first case a $-\mathrm{OH}$ is linked to the $\mathrm{Ga}$ central atom). 
Moreover, the highest number of contributions about the formation of supramolecular aggregates of phthalocyanines and $\mathrm{C}_{60}$ derivatives is related to the use of the well-known fulleropyrrolidines [88]. In Figure $12, \mathrm{C}_{60}$ fulleropyrrolidine chemical structure is reported.

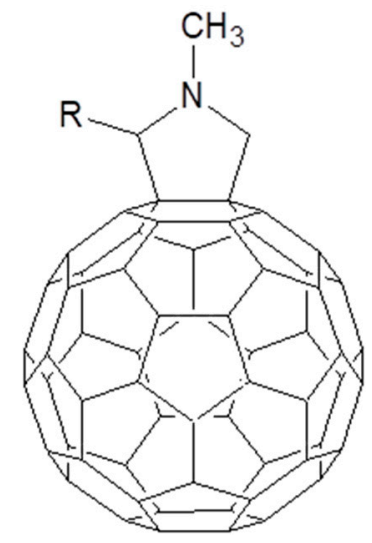

Figure 12. $\mathrm{C}_{60}$ fulleropyrrolidine chemical structure.

Before examining the large number of fulleropyrrolidines used to promote supramolecular assemblies with Pcs for photoinduced charge transfer and charge separation, it is useful to consider a contribution by Sariciftci and collaborators that clearly evidences the role of pyridine functionalization on $\mathrm{C}_{60}$ and how it influences the photovoltaic response of a device using it as an electron acceptor [89]. In particular, the performances of a solar cell where a ZnPc and 3-pyridyl functionalized fulleropyrrolidine were compared with those ones of an equivalent device where the PCBM was used as electron acceptor. The pyridyl substituent is able to complex the $\mathrm{Zn}$ atom of the $\mathrm{ZnPc}$ as testified by the enhancement of solubility of the metallated phthalocyanine in dichloromethane. Then, the authors transferred a layer of $\mathrm{ZnPc}$, by means of thermal evaporation, on the top of an ITO/PEDOT:PSS substrate. In order to compare the performance of PCBM and pyridyl functionalized $\mathrm{C}_{60}$, the two fullerenes derivatives were spun on the top of ZnPc layer. All the cell parameters (short circuit current, open circuit voltage and fill factor) are higher for the solar cell based on the pyridyl functionalized $C_{60}$ [90]. It is a consequence of the high $\pi$-electrons overlap of the donor and acceptor species obtained when the supramolecular adduct is formed. Furthermore, the higher solubility of the fulleropyrrolidine/ZnPc complex leads to a higher interface between the donor and acceptor species.

The photodevice efficiency was further enhanced, from $1.5 \%$ to $2 \%$ under 1.5 AM solar simulator illumination, when a blend of the same fullerene derivative and the organic polymer poly((2-methoxy-5-(3,7-dimethyloctyloxy)-p-phenylene)vinylene (briefly named MDMO-PPV) is used [91]. The authors evidenced that a very small amount of fulleropyrrolidine mixed with PCBM ( $2 \%$ and $98 \%$, respectively) is enough to double the device efficiency in presence of MDMO-PPV.

The interaction between the pyridyl substituent and the zinc central atom of the phthalocyanine was largely used to form photoactive dyads and triads. For example, a supramolecular assembly between the $\mathrm{C}_{60}$ derivative in Figure 13A and the $\mathrm{ZnPc}$ in Figure 13B was obtained by means of the pyridine- $\mathrm{Zn}$ atom interaction [92]. The $\mathrm{ZnPc}$ is covalently functionalized with a BODIPY (4,4-difluoro-4-bora-3a,4a-diaza-s-indacene) able to transfer energy, after appropriate irradiation, to the $\mathrm{ZnPc}$ core. It allows to extend the photon absorption spectrum to almost the complete visible range. So, the BODIPY acts as energy donor toward the ZnPc that works as energy acceptor. When the $\mathrm{C}_{60}$ derivative supramolecularly binds the BODIPY functionalized ZnPc, the photoexcitation of BODIPY is immediately followed by an energy transfer on ZnPc moiety and then by the formation of BODIPY-ZnPc ${ }^{\bullet+} / \mathrm{C}^{\circ} 0^{\bullet-}$ radical-ion pair state. 
A

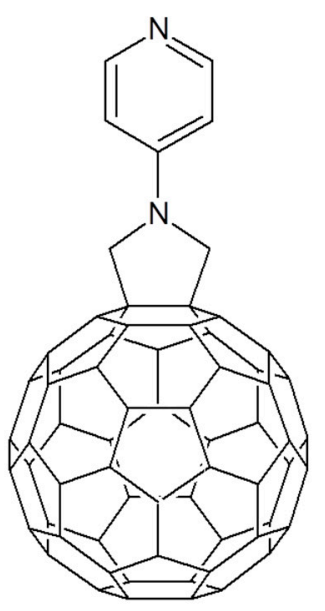

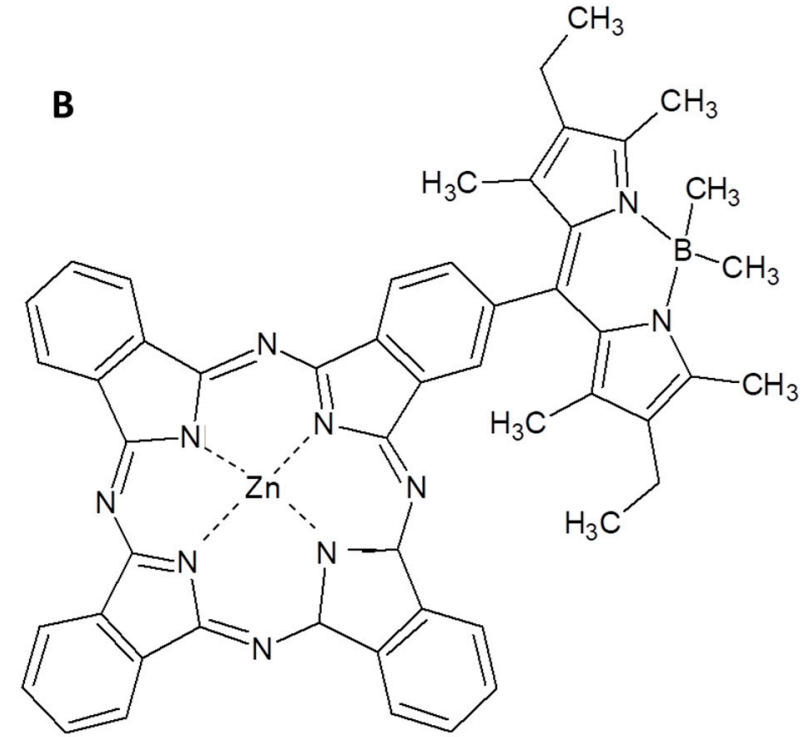

Figure 13. (A) Pyridine functionalized fulleropyrrolidine and (B) BODIPY-substituted ZnPc proposed in [92].

A remarkable achievement is the charge separated state lifetime that reaches $40 \mathrm{~ns}$ in toluene, 8 times longer than the system $\mathrm{C}_{60} / \mathrm{ZnPc}$ without the BODIPY moiety. This enhancement was explained by the authors as a consequence of the anodic shift of the oxidation potential of the ZnPc when linked to the BODIPY. This phenomenon induces a shift of the driving force of charge recombination into the Marcus inverted region, retarding the radical anion recombination. Furthermore, attaching a porphyrin to a BODIPY it was possible to obtain an antenna complex able to capture light and to efficiently transfer energy on $\mathrm{ZnPc}$ [93]. In presence of a phenylimidazole-functionalized fulleropyrrolidine the electron is transferred from $\mathrm{Pc}_{\mathrm{c}}$ to $\mathrm{C}_{60}$ derivatives that is supramolecularly linked to the $\mathrm{Zn}$ atom of Pc.

The inclusion of one or two corannulene functionalizations was another strategy used by the same authors to increase the charge separation lifetime [94]. The hydrophobic nature of corannulene stabilizes the charged state in polar solvents and improves the delocalization of the charges in one-electron oxidized ZnPc by means of $\pi$-electron cloud extension.

Another method to enhance the charge separated state lifetime is to increase the distance between the two species of the supramolecularly arranged Pc-fullerene derivative assembly. The lifetime of the charge separated state in a supramolecular dyad $\mathrm{C}_{60} / \mathrm{ZnPc}$ was increased from $2.5 \mathrm{~ns}$ up to $4.8 \mathrm{~ns}$ simply using a phenylimidazole functionalization in place of a pyridine on a fulleropyrrolidine [95]. In the sake of truth, the functionalization influences the assembly formation as evidenced by the different binding constant estimated for pyridine- and phenylimidazole- functionalized fulleropyrrolidine (10 $0^{4}$ and $10^{5} \mathrm{M}^{-1}$ respectively).

A more complex system was assembled by Fukuzumi, D'Souza and co-workers to mimic a bacterial photoreaction center: a supramolecular assembly of two ZnPcs in co-facial configuration and a fullerene derivative was proposed [96]. ZnPc was functionalized with 4 crown ether units (see Figure 10A) and a sandwich-type structure was obtained by the action of $\mathrm{K}^{+}$(Figure $14 \mathrm{~A}$ ). $\mathrm{C}_{60}$ brings two chemical groups that are in charge to bind the phthalocyanines: a pyridine group able to coordinate the $\mathrm{ZnPc}$ central atom and an alkyl ammonium cation that electrostatically interacts with the crown ether group (Figure 14). Then, a supramolecular assembly formed by two co-facial phthalocyanines and two fullerenes (one on each side of the $\mathrm{Pc} / 4 \mathrm{~K}^{+} / \mathrm{Pc}_{\mathrm{c}}$ sandwich) is obtained. Charge separated state lifetime was measured in $6.7 \mu$ s and it is significantly longer than the charge separated state lifetime recorded for analogous assemblies [97]. 
A

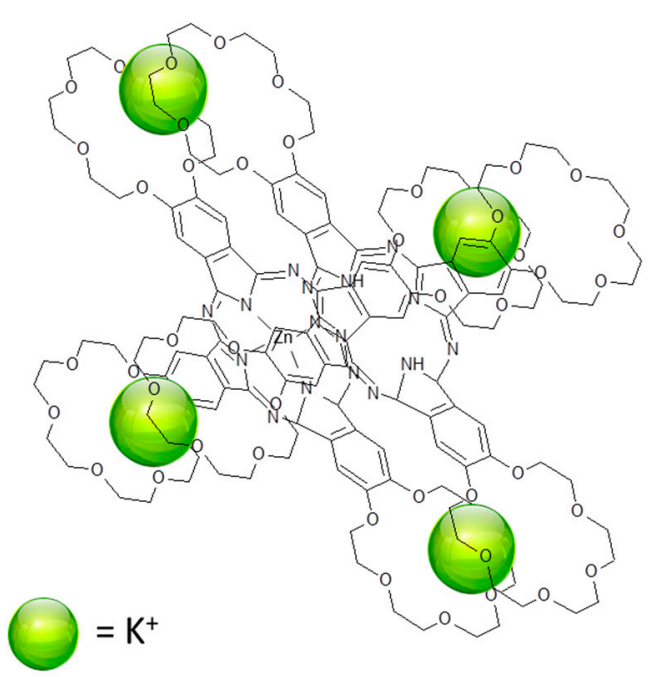

B

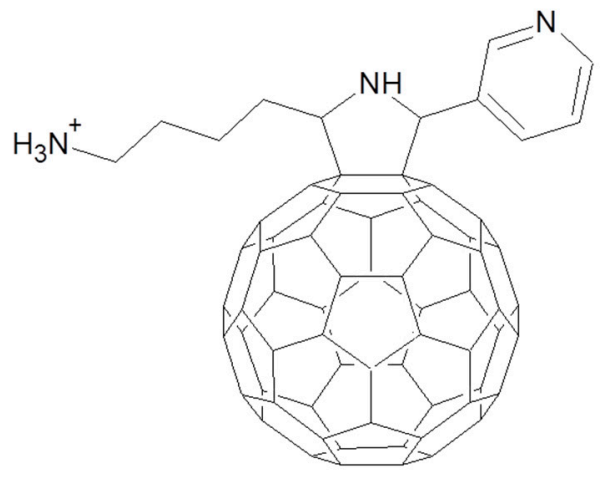

Figure 14. (A) ZnPcs derivative sandwich formed by the action of $\mathrm{K}^{+}$. (B) $\mathrm{C} 60$ derivative used to form the triad with (A) according to [97].

Even though ZnPcs are the most used metallophthalocyanines for obtaining charge and energy transfer towards acceptor molecules, the central metal atom, as well as the substituent chemical groups [17], can be changed in order to modify the spectroscopic and electronic features of the macrocycle and exploiting different methods to realize supramolecular assemblies. For example, a fulleropyrrolidine that brings a catechol substituent is used to chelate the titanium central atom of a tert-butyl Ti(IV) phthalocyanine [98] and a charge-separation is photoinduced in the dyad.

Photoinduced charge transfer phenomena with very interesting applications for photovoltaic devices were recently studied in a supramolecular architecture formed by two differently functionalized ZnPcs reported in Figure 15 [99]. A mixture of compound 1 and $\mathbf{2}$ in ratio 1:1 exhibits very interesting properties both in $\mathrm{CHCl}_{3}$ solution and when spun-coated and annealed on solid support. The mixture of $\mathbf{1}$ and $\mathbf{2}$ in proper ratio is able to build up a supramolecular structure formed by a highly ordered liquid crystal donor-acceptor system. In particular, the conjugated substituents of the Pcs not only are crucial for the special aggregation of the superstructure, but they also represent the building blocks for obtaining an antenna system able to absorb energy from photons and to transfer it to the central part of $\mathrm{ZnPc}$. In a cascade process, the energy transfer is followed by a charge transfer and separation toward fulleropyrrolidine derivative linked to the $\mathrm{ZnPcs}$.

Another case where covalently bonded fulleropyrrolidine derivative and ZnPcs form supramolecular aggregates with unique features is reported in [100]. The supramolecular formation of tubular structures of $\mathrm{C}_{60} / \mathrm{ZnPc}$ gives to the nanostructures interesting photo-induced properties. In fact, ultrafast charge separation $\left(10^{12} \mathrm{~s}^{-1}\right)$ and slow charge recombination $\left(10^{3} \mathrm{~s}^{-1}\right)$ processes characterize the supramolecular tubular aggregates. It is worth observing that the charge recombination mechanism for the supramolecular aggregates is deeply shifted in the Marcus inverted region. In fact, the lifetime of charge separated state appears six order of magnitude longer for the nanotubes aggregates than for the monomeric form of the covalent bounded $\mathrm{C}_{60} / \mathrm{ZnPc}$ dyad. 


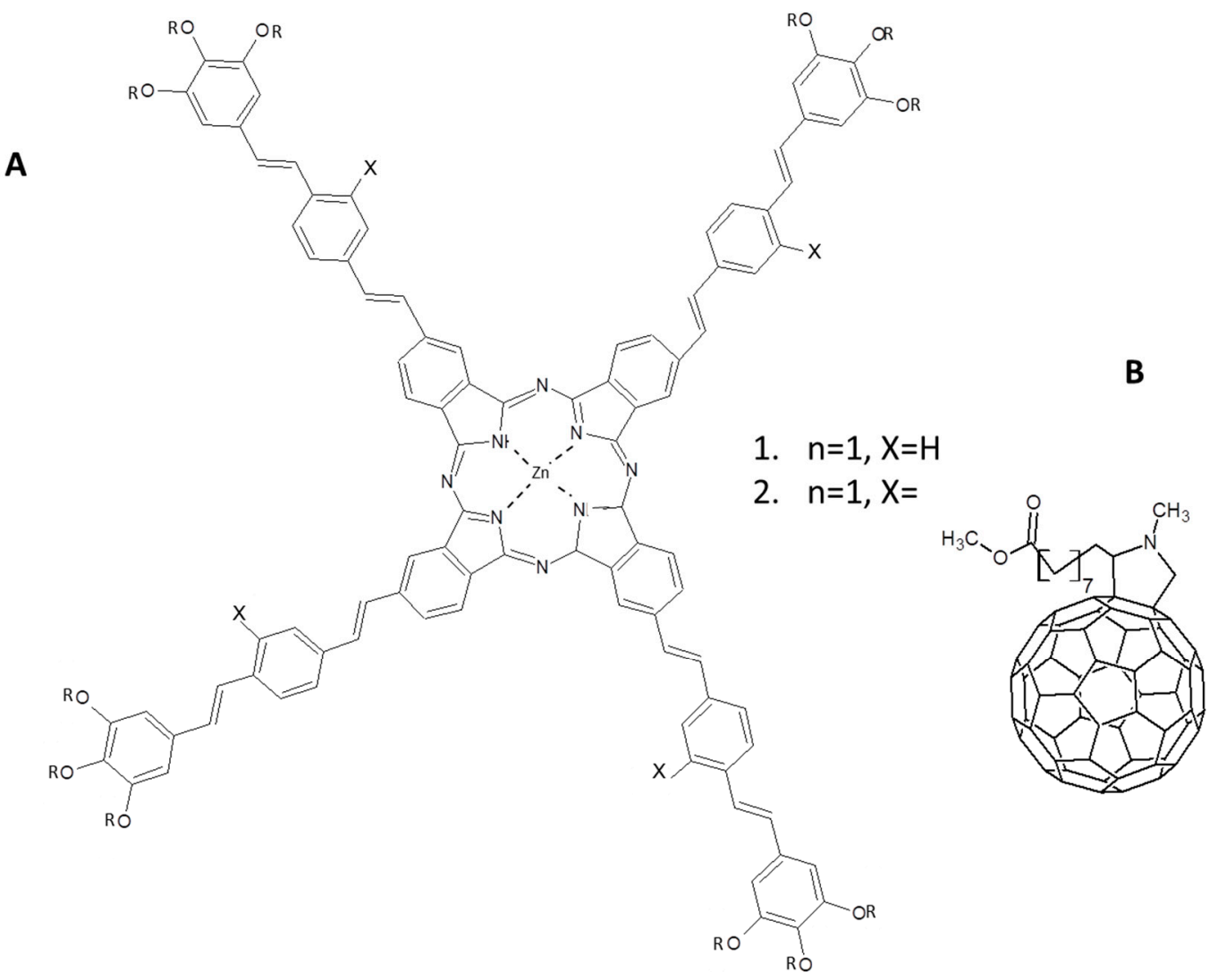

Figure 15. (A) Star-shaped zinc phthalocyanines and (B) fulleropyrrolidine derivative chemical structures used in [99].

Another allotropic form of carbon, graphene, has been sometimes used as electron acceptor when coupled with phthalocyanine. As well as $\mathrm{C}_{60}$, graphene energetic levels are suitable for accepting electrons by phthalocyanine when the two species are adequately coupled. $\pi$-stacking interactions between graphene layer and the pyrene substituents appended both to phthalocyanine and porphyrins (Figure 16) ensure the formation of a supramolecular assembly porphyrin-graphene and phthalocyanine-graphene [101].

Photoinduced charge transfer are observed for both the systems with comparable charge separation and charge recombination rates $\left(1.4 \times 10^{11} \mathrm{~s}^{-1}\right.$ and $5.2 \times 10^{9} \mathrm{~s}^{-1}, 3.5 \times 10^{12} \mathrm{~s}^{-1}$ and $7.4 \times 10^{9} \mathrm{~s}^{-1}$ for the porphyrin-graphene and Pc-graphene, respectively).

In [102], the phthalocyanine is used as an electron donor in combination with Au-porphyrin in the role of the electron acceptor. Pyridyl substituents attached to the porphyrin have been used, as already reported for many pyridyl $\mathrm{C}_{60}$ derivatives, to coordinate the $\mathrm{Zn}$ central atom of tert-butyl phthalocyanine. The supramolecular complex appears stable enough (a binding constant of $2.94 \times 10^{4} \mathrm{M}^{-1}$ was measured). The electron transfer process from electron donor $\mathrm{ZnPc}$ to porphyrin moiety was evidenced by spectroscopic methods with a rapid charge separation process and charge recombination with a relatively slow rate $\left(4.10 \times 10^{9} \mathrm{~s}^{-1}\right)$.

A saddle distorted dodecaphenyl-substituted porphyrin was used, in supramolecular combination with a 8-times phenyl substituted ZnPc, as electron acceptor [103]. In particular, the saddle distortion of porphyrin macrocycle facilitates the protonation of pyrrole nitrogen atoms and it promotes the acceptor feature of this macrocycle and, in this particular case, it has been used to supramolecularly interact with carboxylate group of a 4-pyridincarboxylate $\left(4-\mathrm{PyCOO}^{-}\right)$. Pyridin termination of 4-PyCOO${ }^{-}$ was used to bind $\mathrm{Zn}$ atom of $\mathrm{Pc}$ and the supramolecular assembly has been obtained. By means of photophysical characterizations the authors evidenced that, under $410 \mathrm{~nm}$ photoexcitation, both porphyrin and phthalocyanine are excited. Then, the porphyrin transfers energy on Pc and a very efficient electron transfer takes place from Pc LUMO towards the dicationic porphyrin. 
A

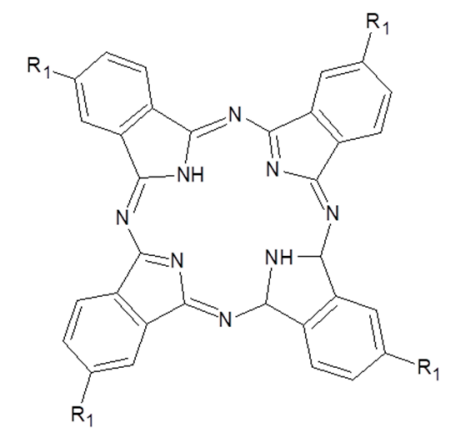<smiles></smiles>

B

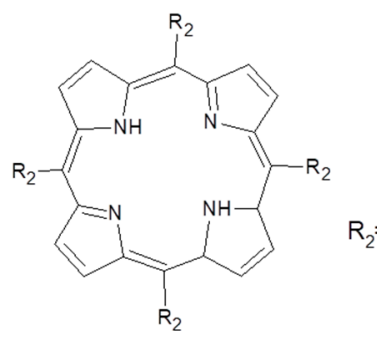<smiles>O=C(CCCC1C=Cc2ccc3c4c(ccc1c24)CC=C3)Oc1ccccc1</smiles>

Figure 16. Structures of (A) phthalocyanine directly linked to four pyrene entities and (B) porphyrin linked to four entities of pyrene [101].

The same mechanism has been not only observed in [104] but tuned by changing the length of the ligand used to link porphyrin and phthalocyanine. Supramolecular assemblies were obtained using a tetrasulfonated porphyrin and several silicon(IV) phthalocyanines axially substituted with permethylated $\beta$-cyclodextrin (CD) (Figure 17) with different molecular bridges. As well as in the other porphyrins/Pcs systems, an energy transfer occurs from Pc to porphyrins and a charge transfer takes place from Pc to porphyrins. Both these mechanisms are strongly influenced by spatial conformation and length of the spacer.

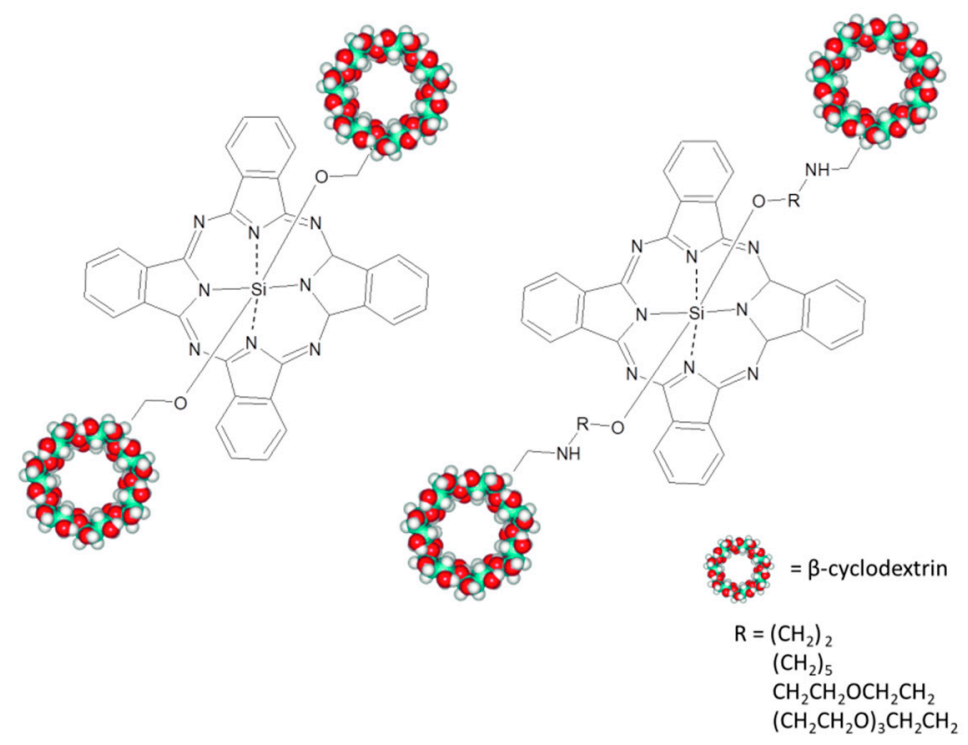

Figure 17. Silicon(IV) phthalocyanines axially substituted with permethylated $\beta$-cyclodextrin used in [104]. 
Same Pcs were used to form supramolecular triads in the presence of both porphyrins and a $\beta$-cyclodextrin conjugated subphthalocyanine [105]. The absorption bands of the three chromophores are well-separated and this allows to separately excite them. According with the author conclusions, it can be supposed that the triad is arranged as followed: subphthalocyanine moiety complexes the tetrasulfonated porphyrin and, on the other side, the phthalocyanine supramolecular binds the porphyrin derivative. When the subphthalocyanine is excited an energy transfer towards $\mathrm{ZnPc}$ is observed and the porphyrin derivative acts as a molecular bridge. Further energy transfer is observed from porphyrin to ZnPc when the porphyrin's Soret band is excited. In addition to the energy transfer phenomenon, the same authors demonstrated that an electron transfer takes place in the supramolecular triad formed by $\beta$-cyclodextrin conjugated subphthalocyanine/tetrasulfonated porphyrin/permethylated $\beta$-cyclodextrin SiPc [106].

With similar philosophy, a supramolecular dyad represented by a $\mathrm{Zn}$ anionic substituted phthalocyanine and a $\mathrm{Zn}$ cationic porphyrin derivative was used to modify a $\mathrm{SnO}_{2}$ electrode. The two macrocycles are photo-active in very large range of visible spectrum and the device obtained by the deposition of the electrostatically bounded porphyrin/Pc dyad on $\mathrm{SnO}_{2}$ showed an efficiency of $0.5 \%$ under AM 1.5 illumination [107]. Finally, ruthenium(II) phthalocyanine was coordinated by six different dendritic oligothiophene ligands (Figure 18) [108].

In this study, the energy and charge transfer phenomena were evaluated changing the solvent polarity and the dendritic oligothiophene, highlighting that polar solvents promote the charge transfer process while non-polar solvents induce an almost exclusive energy transfer. Energy transfer is the process that allows to obtain an IPCE\% of about $5 \%$ in a supramolecular dyad formed by a pyridine-substituted sub-phthalocyanine that coordinates the $\mathrm{Zn}$ central atom of a zinc phthalocyanine derivative [109]. The supramolecular dyad is interfaced with $\mathrm{TiO}_{2}$ to build up a DSSC and short circuit current of $11.6 \mathrm{~mA} \mathrm{~cm}^{-2}$ and open circuit voltage of $589 \mathrm{mV}$ are obtained when the photodevice is illuminated under a solar simulator.

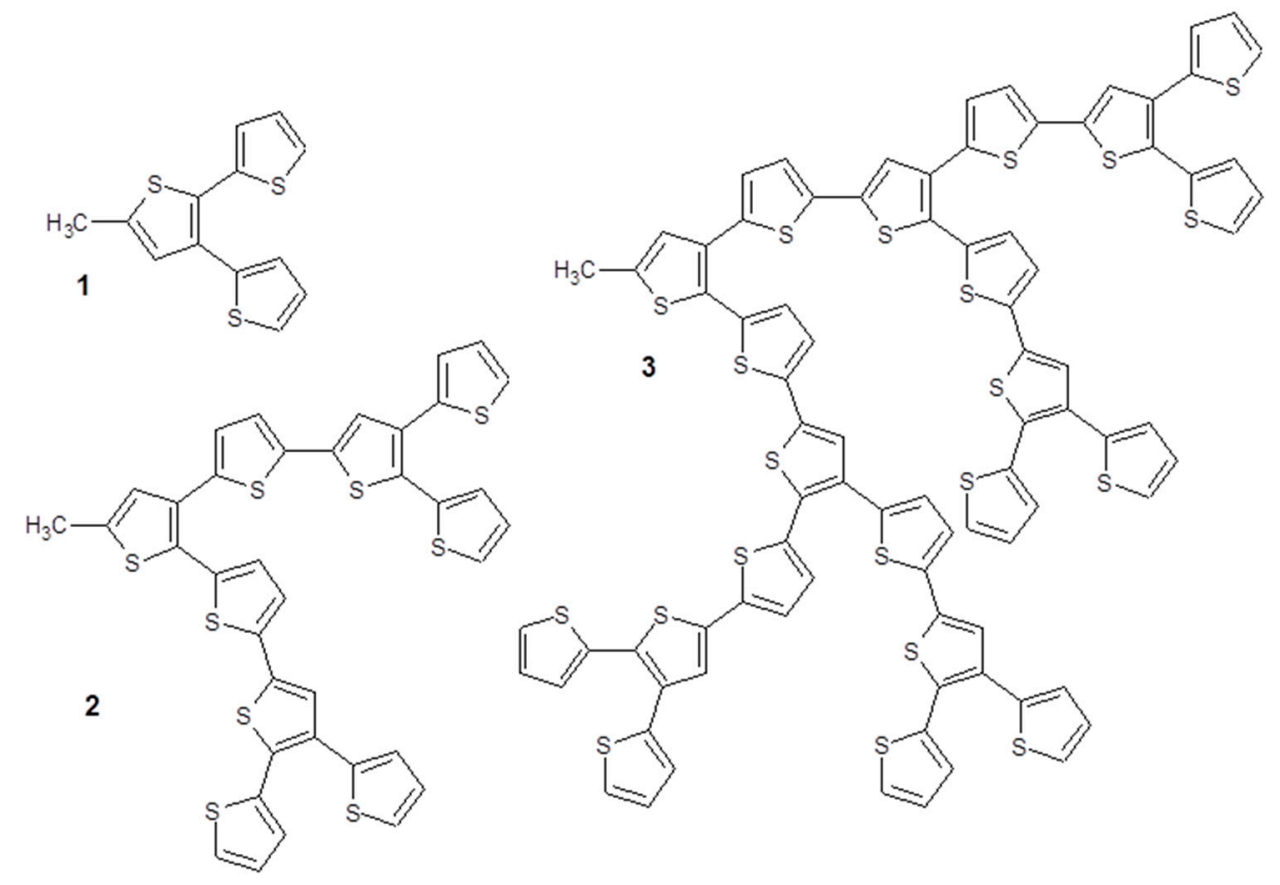

Figure 18. Molecular structures of the oligothiophene ligands used in [108]. 
Few examples of (supra)molecular assemblies of Pcs and carbon nanotubes are reported. It is mainly due to the energetic HOMO-LUMO levels position and to their highly attitude to aggregate in all solvents. Nevertheless it is interesting to consider two different cases: in the first one the phthalocyanine derivatives play the role of electron donor towards the nanotubes [110], in the second case a phthalocyanine derivative is used in the uncommon role of electron acceptor [7]. In both cases the attitude of the carbon nanotubes to aggregate was overcome using the $\pi$-electron cloud of Pc that interacts with the $\pi$-electrons of CNTs enhancing their solubility. This approach is often preferred to the covalent functionalization of the carbon nanotubes since the covalent approach can induce important modifications to electronic and spectroscopic features of CNTs [39,111,112]. In an another system [113] ZnPc derivative was coupled with CNTs by means of the use of a pyrene (magenta colored in Figure 19) functionalized with the imidazole entity. $\pi-\pi$ stacking between pyrene moiety and CNTs allows to solubilize the carbon nanotubes, furthermore the imidazole moiety is able, according to the several examples already reported, to coordinate $\mathrm{Zn}$ atom in the Pc derivative ring. The photoinduced charge transfer was evidenced from Pc derivative to CNTs throughout the pyrene-based bridge.

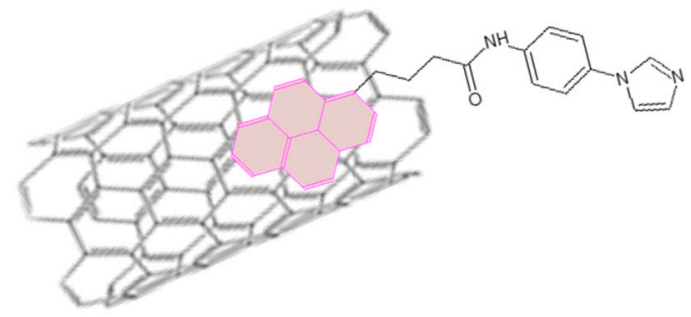

Figure 19. Interaction between $\mathrm{CNT}$ and pyrene functionalized with the imidazole entity according to the mechanism proposed in [113].

Furthermore, the supramolecular functionalization of CNTs can be obtained by means of photo-active molecules or polymers as already reported for other cases of study. It allows to control the distance and the geometry of the supramolecular adduct. In particular, ZnPc laterally substituted with conjugated poly( $p$-phenylenevinylene) oligomers (Figure 20) were dispersed in presence of single walled carbon nanotubes (SWCNTs) in THF and in dimethylformaldehyde [114].

All the functionalized Pcs shown in Figure 20 allow to obtain very stable and highly concentrated single walled CNTs suspension. Fluorescence studies demonstrated that shortest oligomer (Figure 20A) and the Pc with the most flexible structure $\left(\mathrm{X}: \mathrm{O}-\left(\mathrm{CH}_{2}\right)_{6}-\mathrm{O}\right.$ and $\left.n=27\right)$ better interact with SWCNTs and in both cases a charge transfer from the photoexcited ZnPc to SWCNTs was observed by time-resolved transient absorption measurements.

In order to confer electron acceptor features to a phthalocyanine, it needs to be functionalized with highly electron withdrawing substituents. On the other side, the suitability of SWCNTs as electron donors have been already reported when they are coupled with molecules such as fullerenes and perylenes [114,115]. A strategy to have simultaneously a Pc with electron acceptor characteristic and a phthalocyanine able to interact and dissolve SWCNTs in aqueous solution was proposed in [7]. In Figure 21 the chemical structure of the zinc phthalocyanine derivative used to suspend the nanotubes and to form the photoactive supramolecular dyad is presented. 

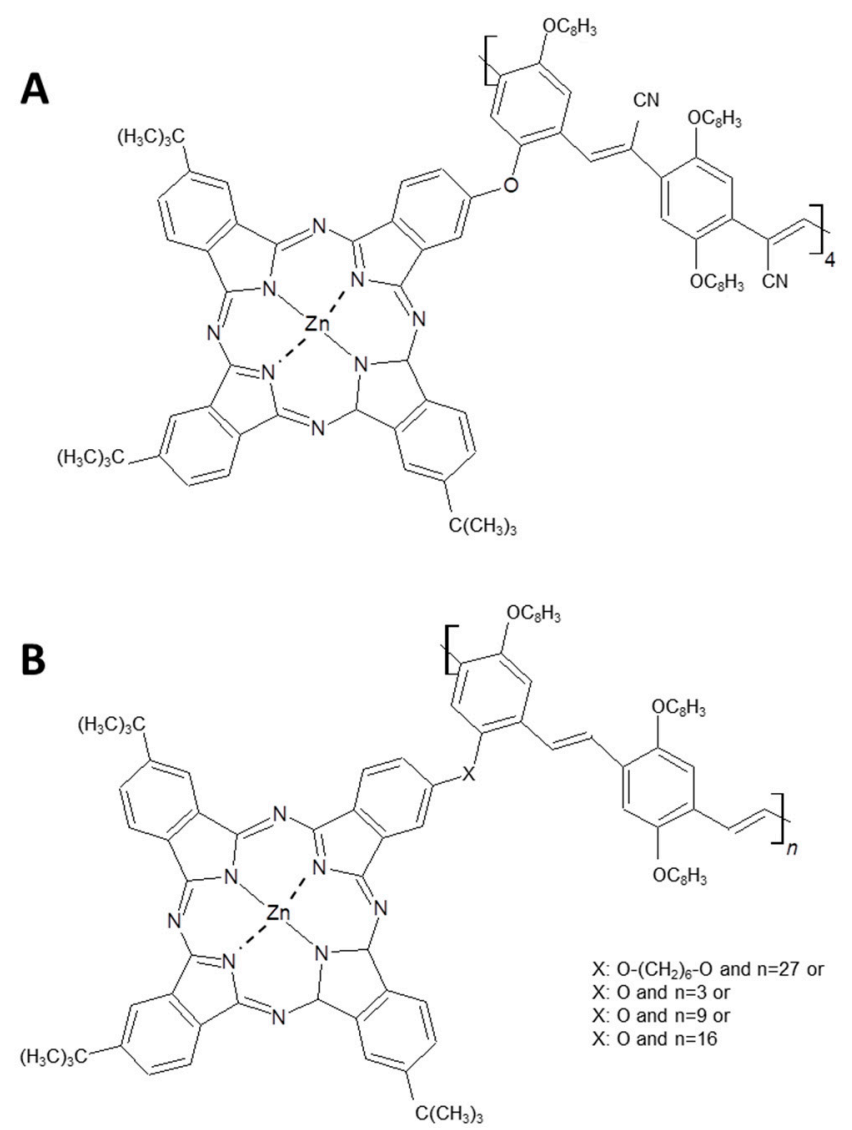

Figure 20. Six different $\mathrm{ZnPcs}$ chemical structures used to interact and to improve CNTs solubilization. $\mathrm{ZnPc}$ derivative (A) and $\mathrm{ZnPc}$ with $\mathrm{X}=\mathrm{O}-\left(\mathrm{CH}_{2}\right)_{6}-\mathrm{O}$ and $n=27$, reported in (B), appear particularly efficient in the SWCNTs solubilization [114].

Spectro-electrochemical experiments were reported, confirming the photo-induced electron transfer from SWCNTs to Pcs and a solar device using the dyad ZnPc/SWCNTs dyad was carried out. Short circuit current and open circuit voltage value depend on the photoactive layer thickness with a maximum of $0.37 \mathrm{~mA} \mathrm{~cm}^{-2}$ and $16 \mathrm{mV}$, respectively.

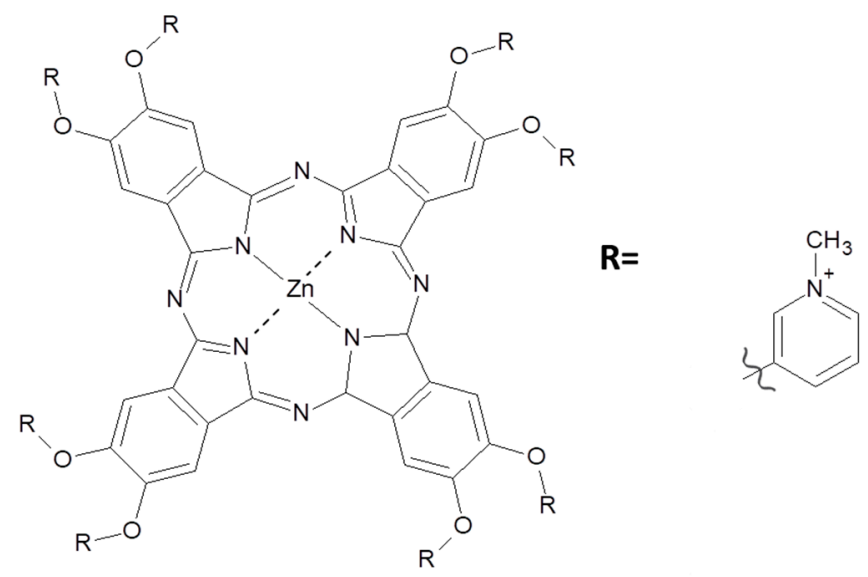

Figure 21. Cationic zinc phthalocyanines used to improve SWCNTs solubilization in water [7].

A case where the $\mathrm{ZnPc}$ is used as an energy acceptor was reported some years ago by Brühwiler and co-workers [116]. In the sake of truth, the aim the research was to explore the possibility to obtain a very efficient charge transfer from a dye molecule (thionine) to the $\mathrm{ZnPc}$ in a zeolite channel. 
The authors induced the absorption of ZnPc derivatives with different functionalizations in the zeolite. According to the Pc functionalization, the absorption process is ruled by Van der Waals, electrostatic or covalent bindings. Electrostatic forces appear more suitable to build the structure up and an energy transfer was photo-induced from thionine molecule to ZnPc by means of FRET along the zeolite channel.

The possibility to use metallic and semiconducting nanoparticles was explored to enhance the photo-induced charge transfer and energy transfer phenomena in the presence of organic molecules [117], in particular dyes [118] and macrocycles like porphyrins and phthalocyanines, even though few examples are strictly connected to solar devices for converting photons in electric current. Gold nanoparticles were used to build up a supramolecular dyad with tert-butyl substituted ZnPc and a charge transfer in toluene solution between the two species was evidenced by spectrophotometric approaches [119]. Furthermore, the presence of the nanoparticles does not influence the formation of the supramolecular triad with $\mathrm{PC}_{70} \mathrm{BM}$ that shows interesting and efficient charge transfer phenomenon.

\section{Pcs-Based Supramolecular Assemblies for Photocatalyst Applications}

The mechanisms ruling the photodegradation and/or more in general the photocatalysis is very similar to the photo-generation of the charge-separated state in a photo-active material. As reported in the previous paragraph, the exciton is promoted by the absorption of a photon of appropriate energy, then the hole-electron photo-generated pair can be separated at the interface with an appropriate material. In a typical photo-catalytic process, an appropriate photon promotes the electron excitation from the HOMO level (or from the valence band) to the LUMO level (or to the conduction band) [120]. As well as in the case of a photovoltaic device, electron and hole migrate toward the catalyst surface to recombine or to promote a redox reaction with the compounds adsorbed on the catalyst. The positive hole reacts with water molecule promoting the formation of the hydroxyl radical $\left(\mathrm{OH}^{\bullet}\right)$ and the electron reduces the oxygen molecules adsorbed, forming the radical O2 ${ }^{\bullet-}$ (Figure 22) [121]. Superoxide and hydroxyl radicals are very reactive species that interact with interesting molecules inducing their modification.

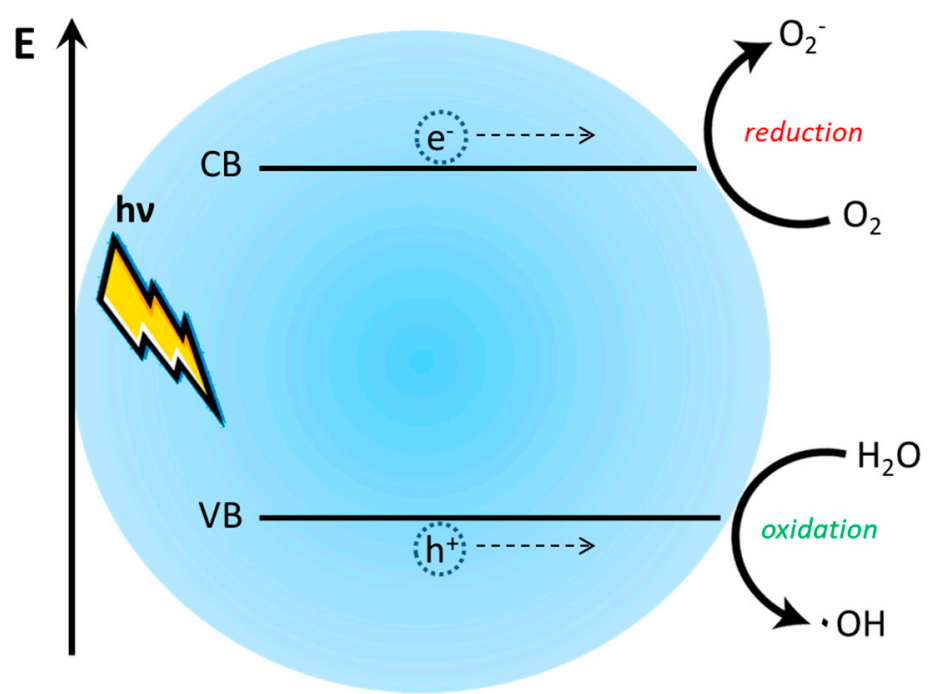

Figure 22. Schematization of the photo-induced formation of the radical $\mathrm{O}_{2}{ }^{\bullet-}$ and the formation of the hydroxyl radical $\left(\mathrm{OH}^{\bullet}\right)$.

In light of this, it is easy to understand that many compounds and supramolecular architectures used in the photovoltaic devices are employed for obtaining efficient photocatalytic system and, as in the case of the photovoltaic devices, the supramolecular arrangement is crucial [122,123]. For example, in the present section, dyads formed by phthalocyanine derivatives and functionalized perylenes, as well as $\mathrm{C}_{60}$, porphyrins and carbon nanotubes will be examined. As a consequence, the strategies 
used to obtain the supramolecular dyads are, in many cases, very similar to those ones already examined. Therefore, analogously to the approach used in Section 3, we will start examining the photocatalytic systems based on Pcs/PDI derivatives.

The perylene derivative illustrated in Figure 23 was used in combination with unsubstituted free-based [124] and Co-metallated Pc [125]. It is interesting to observe that, even though the energetic levels of the two Pcs are very similar, no evolution of $\mathrm{O}_{2}$ has been observed in the case of the free-base Pc/PDI supramolecular assembly. On the contrary, when CoPc is used, an interaction between $\mathrm{OH}^{-}$(in alkaline environment, $\mathrm{pH}=11$ ) and $\mathrm{Co}(\mathrm{III})$ can be predicted. So, under illumination, an electron transfer is induced from Pc to PDI. The hole-doped CoPc can efficiently activate $\mathrm{OH}^{-}$for dioxygen evolution.

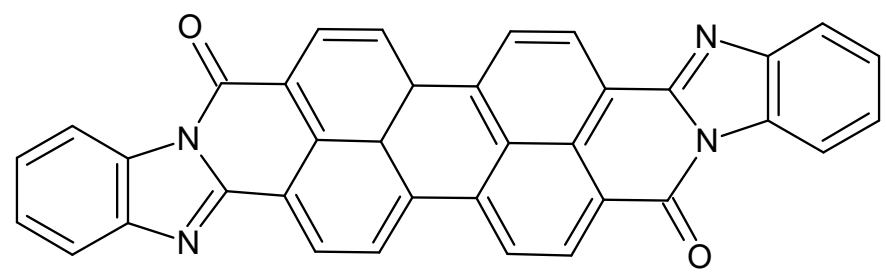

Figure 23. Chemical structures of the perylene derivative PDI used in [124].

The supramolecular nature of the assembly obtained between a tetrasubstituted copper Pc ( $p$-type organic semiconductor) and an asymmetrically substituted PDI ( $n$-type) appears particularly important for the photocatalytic activity. The pyridine substituent was attached on the imide of a PDI derivative (PDI-P) promoting the formation of a hydrogen bonded supramolecular adduct with -COOH group of a 2,9,16,23-tetrakis (4' -carboxyphenoxy) phthalocyanine copper (CuTPc) after a simple procedure [126]. The photocatalytic performances of PDI-P/CuTPc supramolecular assembly were evaluated by monitoring the photodegradation of Rhodamine $\mathrm{B}(\mathrm{RhB})$ aqueous solutions under visible light illumination. It is interesting to observe that the RhB photodegradation efficiency is equal to $23 \%$ in the presence of CuTPc and 27\% when CuTPc and PDI-P are simply mixed. On the contrary, when the supramolecular adduct PDI-P/CuTPc is obtained the efficiency increases up to $80 \%$. In order to explain the photodegradation mechanism, the role of three different scavengers was tested, i.e., $p$-benzoquinone (used to quench the formation of superoxide radical $\cdot \mathrm{O}_{2}{ }^{-}$), $\mathrm{KI}$ (as hole quencher) and isopropanol for quenching the $\cdot \mathrm{OH}$ formation. The charge separation enhancement obtained when $\mathrm{KI}$ is added to the solution is an obvious consequence of the increased number of free electrons; $p$-benzoquinone does not influence the photocatalytic process efficiency and isopropanol almost completely quenches the $\mathrm{RhB}$ photodegradation, suggesting that the photocatalytic process is driven by the $\cdot \mathrm{OH}$. Starting from these considerations, the following mechanism is proposed. As known, the electrons of both CuTPc and PDI-P can be excited on the respective LUMO levels when irradiated by visible light. The promoted electron on electronic excited level of the Pc derivative moves to the LUMO of PDI-P when reaches the interface between the $p$ - and the $n$-semiconductor. The electrons on the PDI-P excited level react with $\mathrm{O}_{2}$ forming $\cdot \mathrm{O}_{2}{ }^{-}$that induces the formation of . $\mathrm{OH}$ and then the $\mathrm{RhB}$ degradation takes place. On the other side, the electron role in the $\cdot \mathrm{O}_{2}{ }^{-}$formation reduces the $\mathrm{e}^{-}-\mathrm{h}^{+}$recombination rate, the holes can migrate from HOMO level of $n$-type molecule towards the HOMO level of CuTPc and directly reacts to degrade RhB [126]. Tetrasulfonated copper Pc was coupled to the 3,4,9,10-perylenetetracarboxylate [127]. As known, the energetic levels of the two organic species are suitable to form an electron donor/electron acceptor dyad and furthermore, in the particular case, the molecular dimensions of both the species perfectly fit if arranged in an edge-on configuration. It allowed to form a sandwich configuration between two layered double hydroxide (LDHs). Under visible illumination, electron transfer is promoted from cationic Pc to PDI derivative and the obtained holes can be used for the degradation of organic dyes. 
The well-known ability to obtain a charge separated specie in the presence of $\mathrm{C}_{60}$ (and derivatives) using Pc as electron donor was employed even to induce photodegradation of organic molecules. As already stressed in the previous paragraph, intermolecular arrangement plays a crucial role in the charge separation phenomenon. In fact, the efficiency of a composite nanoarchitecture obtained by means of $\mathrm{AlPc}$ chloride and $\mathrm{C}_{60}$ appeared two times higher than the simply mixture of AlPc and $\mathrm{C}_{60}$ in the $\mathrm{CO}_{2}$ production and triethylamine photodegradation [128]. The enhancement of photocatalytic features is a consequence of the interface optimization among the AlPc nanostructures and $\mathrm{C}_{60}$ nanoaggregates. It improves the charge separation process generating free charges available for interacting with organic molecules. An improvement of $\mathrm{CO}_{2}$ photogeneration was obtained by the substitution of $\mathrm{CoPc}$ to AlPc [129]. In fact, the same procedure was used to obtain $\mathrm{CoPc}_{\mathrm{C}} / \mathrm{C}_{60}$ nanoclusters and their photocatalytic activity appeared more performing than the one recorded using $\mathrm{AlPc} / \mathrm{C}_{60}$ adduct when irradiated by a low power $\left(\sim 1 \mathrm{~mW} \mathrm{~cm}^{-2}\right)$ visible light source. Furthermore, the authors evidenced that the proposed dyad gave $\mathrm{CO}_{2}$ four times larger than that of well-known inorganic commercial $\mathrm{WO}_{3}$ when the systems were illuminated by $600 \mathrm{~nm}$ wavelength. A further confirmation of the most performing photocatalytic features of $\mathrm{CoPc}$, if compared with other metallated Pcs, is given in [130] where the authors supramolecularly assembled dyads of $\mathrm{Zn}, \mathrm{Cu}, \mathrm{Co}$ and free-based Pcs (and porphyrins) with a bipyridylfulleropyrrolidine. The obtained adducts were used to decorate the titanium dioxide surface and the efficiency of phenol photocatalytic degradation was evaluated for each system. In the sake of the truth, the system that uses Co porphyrin as electron donor appeared the most performing one. Anyway, for all the adducts, an electron transfer under visible light stimulus from Pc (or porphyrin) to $\mathrm{C}_{60}$ derivative, and from the fulleropyrrolidine to $\mathrm{TiO}_{2}$ can be predicted. The injected electrons can react with the dissolved oxygen molecules promoting the formation of superoxide and hydroxyl radicals, very reactive species involved in the phenol degradation.

In the field of the photocatalysis, Pcs are often coupled with nanoparticles for several reasons: for example nanoparticles with magnetic features can be used to easily remove Pc catalyst [131], metallic plasmonic nanoparticles can work as plasmonic antennas to transfer energy on Pc catalyst [132] or phthalocyanines derivative can be used to shift the photocatalytic activity toward the visible range [133]. A ZnPc derivative functionalized with a carboxyl group and three 15-crown-5 ether substituents (Figure 24) was designed and used as a photosensitizer for a Pt-loaded graphitic carbon nitride for $\mathrm{H}_{2}$ photoproduction with visible illumination [134]. The $-\mathrm{COOH}$ substituent binds the $\mathrm{ZnPc}$ derivative on the Pt nanostructure in cooperation with $\pi-\pi$ interaction of the delocalized electrons of Pc and the planar structure of the graphitic carbon nitride. The crown-ethers are used to complex alkaline ions, in particular the addition of $\mathrm{K}^{+}$strongly improves the photoactivity for $\mathrm{H}_{2}$ production.

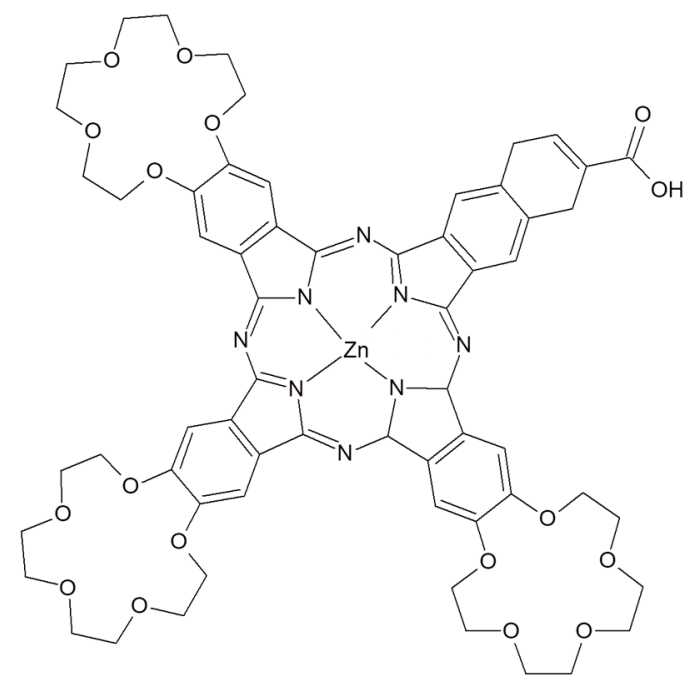

Figure 24. Chemical structure of $\mathrm{ZnPc}$ with three 15-crown-5 ether functional groups and one carboxyl group [134]. 
In a recent system, $\mathrm{Ni} / \mathrm{NiO}$ was decorated with Cobalt $\mathrm{Pc}$ and it was demonstrated that the photocatalytic reduction of $\mathrm{CO}_{2}$ of the supramolecular system appears enhanced if compared with $\mathrm{Ni} / \mathrm{NiO}$ and CoPc separated components [135]. The chemical physical interpretation of this phenomenon is very similar to the one previously proposed for full organic systems, such as for example $\mathrm{C}_{60} / \mathrm{Pc}_{\mathrm{c}}$ derivative adducts. Furthermore, the $\mathrm{Ni} / \mathrm{NiO}$ nanosystem is able to perform photocatalytic reduction of $\mathrm{CO}_{2}$ when irradiated with an opportune wavelength and, simultaneously, it works as electron acceptor from CoPc.

\section{Pcs-Based Supramolecular Assemblies for Photodynamic Therapy (PDT) Applications}

The peculiar physical chemical features of Pc derivatives make them suitable for PDT applications. PDT, in detail, is a therapeutic approach which ensures the inactivation of cancer cells thanks to the production of toxic singlet oxygen by employing photosensitizers (PS), as Pc molecules, porphyrins, perylene bisimide compounds, etc $[59,136]$. Basically, the PS absorbs light in the ground state, $\mathrm{S}_{0}$, promoting electrons to the excited state, $S_{1}$. At this point, PS molecule could undergo the non-radiative process of Intersystem Crossing (ISC) generating the triplet excited state, $\mathrm{T}_{1}$ (Figure 25). Although ISC is a forbidden process requiring a spin inversion, good PS compounds are characterized by efficient ISC. In particular, from $\mathrm{T}_{1}$, PS could relax by phosphorescence decay or by spin exchange with another triplet state molecule [137], as molecular oxygen ${ }^{3} \mathrm{O}_{2}$, which is in its natural triplet state, generating ${ }^{1} \mathrm{O}_{2}$ by Type II Photoprocess (Figure 25) [138].

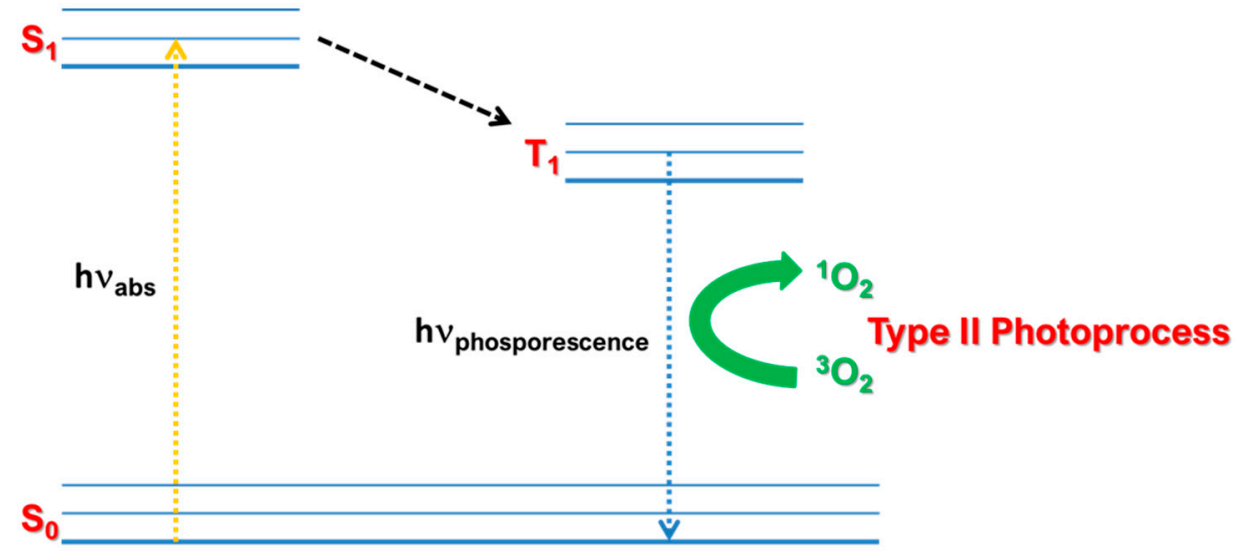

Figure 25. Schematized Jablonski's diagram for a typical PS.

A good PS is supposed to have several characteristics, i.e., appropriate light absorption features, rather in red spectral region $(\lambda>650 \mathrm{~nm})$, low dark toxicity, photo-stability, high quantum yield of photogenerated ${ }^{1} \mathrm{O}_{2}\left(\Phi_{\Delta}\right)$ and relative long lifetime of triplet state [138]. Pcs are good PS taking in account such features; unfortunately they are well-known to be not water soluble, reducing the possibility for in vivo applications and increasing the risk of self-quenching phenomena due to the stacking events [138]. A possibility to overcome such a drawback is to supramolecular self-assemble Pcs moieties with cyclodextrins (CD) as proposed by Ravoo and collaborators [139]. A Pc derivative ad hoc functionalized by adamantane groups was supramolecularly assembled with cyclodextrin unilamellar vesicles (CDVs) made by modified $\beta$-CDs, improving singlet oxygen photogeneration in aqueous environment. They developed the synthetic route to obtain both an amphiphilic $\beta$-CDs with alkyl chains on the secondary face and oligoethylene glycol units on the primary face and an octaoxosubstituted ZnPc bearing two adamantane groups (Figure 26). The obtained amphiphilic $\beta$-CDs were reported to self-assemble into CDVs $[140,141]$. 


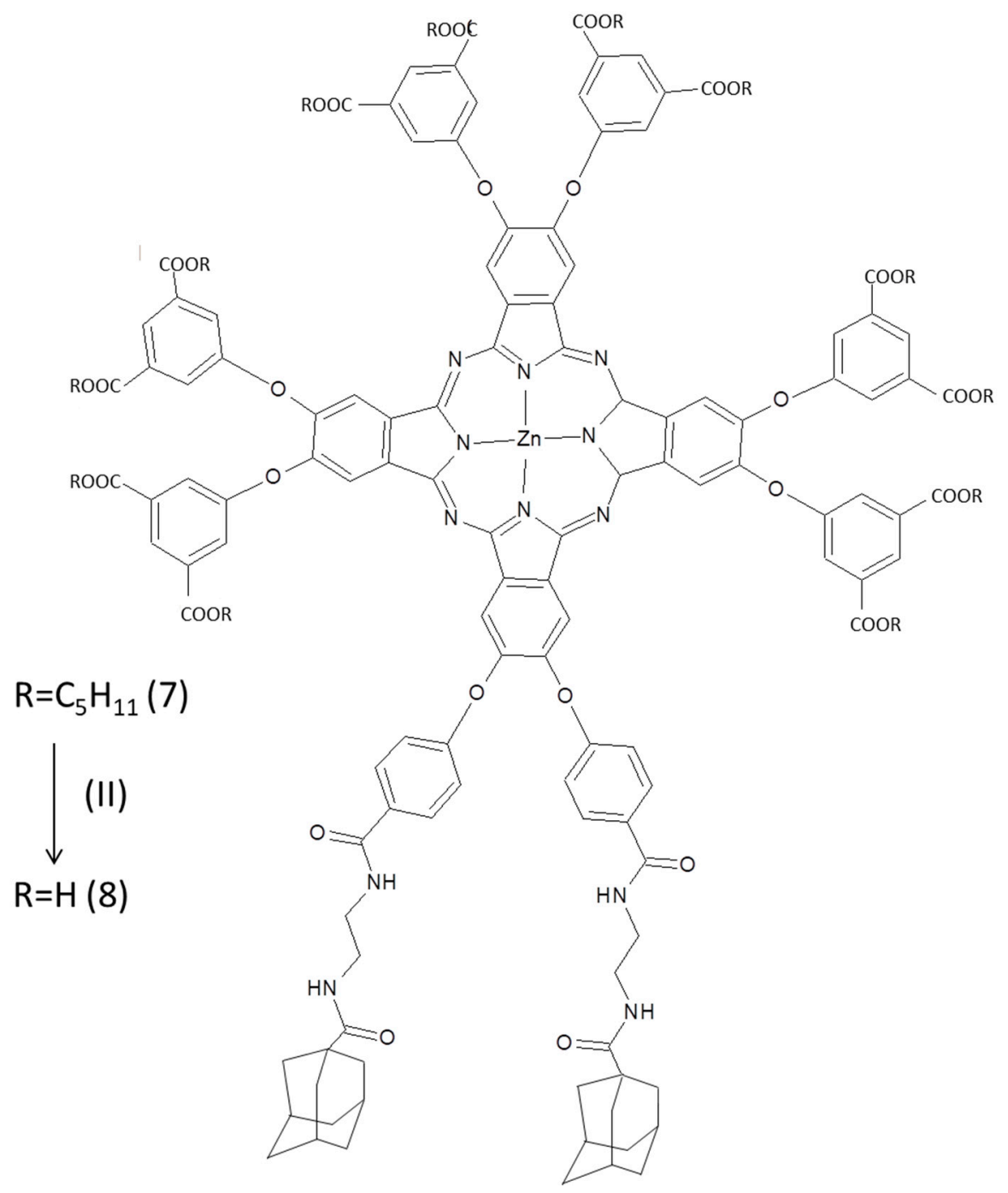

Figure 26. Octahoxosubstituted $\mathrm{ZnPc}$ bearing two adamantane groups [140].

The adsorption of $\mathrm{ZnPc}$ moieties on CDV surface was supposed to be driven by the adamantane groups, according to the literature $[142,143]$ and was supported by the drop to more negative value of the $\zeta$-potential measured: the presence of several free carboxylic groups of ZnPc contributes to lower such a value. Dynamic light scattering (DLS) measurements demonstrated that bare CDVs and ZnPC-CDVs supramolecular assembly diameters were comparable (about $100 \mathrm{~nm}$ ), suggesting that in the presence of $\mathrm{ZnPc}$ the strong electrostatic repulsion among CDVs ensured to avoid aggregation phenomena in aqueous media. This is particularly interesting for the photophysical features of the proposed supramolecular assembly. In fact, absorption spectra of aqueous solution of $\mathrm{ZnPc}$ and $\mathrm{ZnPc-CDVs}$ were recorded and showed the typical bands of a Pc derivative in both cases [144]. It is worth highlighting that the shoulder located at about $620 \mathrm{~nm}$, mainly due to Pc aggregates [139], disappears in the ZnPc-CDVs spectrum, suggesting that the supramolecular assembly permits to preserve the monomeric form of the $\mathrm{ZnPc}$ derivative in aqueous matrices. Even, the emission features were similar and in good agreement with the literature [145]. Then, the fluorescence and the singlet oxygen quantum yield $\left(\Phi_{\mathrm{F}}\right.$ and $\left.\Phi_{\Delta}\right)$ were evaluated and between $\mathrm{ZnPc}$ and $\mathrm{ZnPc}-\mathrm{CDVs}$ aqueous solution interesting differences were underlined. $\Phi_{\mathrm{F}}$ was enhanced by more than twice and $\Phi_{\Delta}$ resulted four times increased in the adduct. Basically, the supramolecular ZnPc-CDVs adduct prepared was characterized by enhanced ${ }^{1} \mathrm{O}_{2}$ photogeneration properties thanks to the monomerization of the $\mathrm{ZnPc}$ derivative and, presumably, by good biocompatibility features thanks to the presence of the $\mathrm{CD}$, so can 
be thought for PDT applications. Starting from these observations, Strassert and collaborators (2016) optimized a supramolecular system based on such CDVs and an asymmetric Si(IV)Pc derivative ad hoc modified (Figure 27) with both an axial pyridinium and an axial adamantane moiety in order to achieve a higher control on the behavior in aqueous matrices and on the interaction with CDVs surface [146].

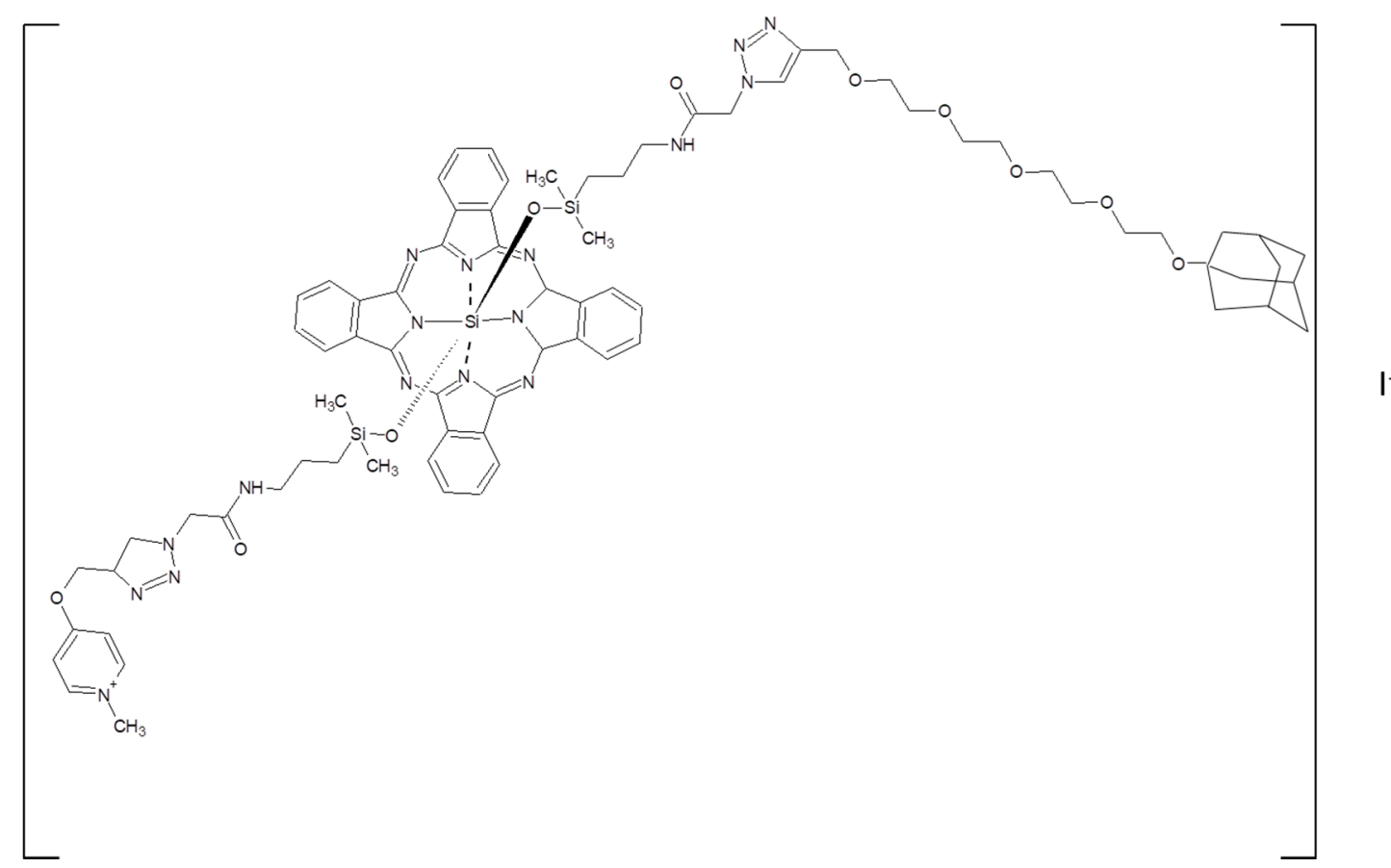

Figure 27. Chemical structure of $\mathrm{Si}(\mathrm{IV}) \mathrm{Pc}$ derivative modified with an axial pyridinium and an axial adamantane moiety used in ref [146].

The positively charged pyridinium bearing axial substituent was expected to improve water solubility and the adamantane bearing chain was exploited for the adsorption of the Pc onto the surface of the CDVs due to their reported affinity [147]. Further, SiPc were reported to have some advantages for PDT applications if compared with $\mathrm{ZnPc}$ mainly related to higher $\Phi_{\mathrm{F}}$ and $\Phi_{\Delta}$, thanks to a reduced tendency to aggregation [148]. The photophysical features of SiPc in dichloromethane (DCM), in water and in water in the presence of an increasing concentration of CDVs were compared. SiPc is present as monomer with interesting $\Phi_{\mathrm{F}}$ and $\Phi_{\Delta}$ value in DCM and in presence of CDVs upon supramolecular assembly formation and was organized in J aggregates when it is dissolved in water. Then, they calculated the binding constant exploiting the Langmuir fitting of the fluorescence (at $675 \mathrm{~nm}$ ) titration at increasing CDVs molar concentration from $0.02 \mathrm{mM}$ to $0.2 \mathrm{mM}$ finding a value of $33 \times 10^{-3} \mathrm{M}^{-1}$ [149]. This value is in good agreement with a host-guest interaction between the adamantane group and the vesicles surface, considering some additional interactions between the positive charged pyridinium moieties and negative charged CDVs surface and some hydrophobic-hydrophobic interactions among SiPc and CDVs bilayer [150]. The system was tested on a methicillin resistant Staphylococcus aureus strain (MRSA) and no dark toxicity was detected for bare SiPc and SiPc-CDVs. Instead, upon illumination, both systems induced relevant bacterial inactivation in $150 \mathrm{~min}$. This could mean that J aggregates are still useful for singlet oxygen photogeneration but also that the binding to the bacteria surface could somehow induce the monomer formation. Nonetheless, the fact that the supramolecular adduct worked as well can represent a good starting point for biological applications in order to have the possibility to introduce another therapeutic agent, for a bimodal approach, or some targeting molecules to deliver the assembly in a specific site by using CDVs as delivery systems. In the context of a bimodal therapeutic approach, based on CDs and a Pc derivative as photosensitizers, Sortino and collaborators developed a 
supramolecular assembly for combining the production of singlet oxygen and nitric oxide under light stimulus [151]. The system was based on a tetrasulfonate ZnPc derivative, an epichlorohydrin- $\beta-C D$ copolymer and an adamantyl functionalized NO photodonor (Figure 28). The chosen copolymer was expected to form in water nanoparticles of about $25 \mathrm{~nm}$ of diameter thanks to the formation of glyceryl cross-linkers among $\beta-C D$ units, characterized by high biocompatibility. The folded polymer configuration is characterized by the presence of hydrophobic nanodomains [152,153] which ensured the encapsulation of the $\mathrm{ZnPc}$ derivative through the benzene ring. The supramolecular interaction of the first aromatic ring induces further interactions in a cooperative way [151]. Absorption and emission spectra of aqueous solution of $\mathrm{ZnPc}$ and of $\mathrm{ZnPc}$ in presence of increasing concentration of the epichlorohydrin- $\beta-C D$ network were obtained. The Pc derivative tends to form aggregates and not to fluoresce in water (becoming no active as PS), whilst, upon encapsulation, the monomerization was induced restoring red light emission. So, the obtained supramolecular system was also proposed for two photon excitation (TPE) fluorescence microscopy applications permitting to monitor the uptake by cancer cells.
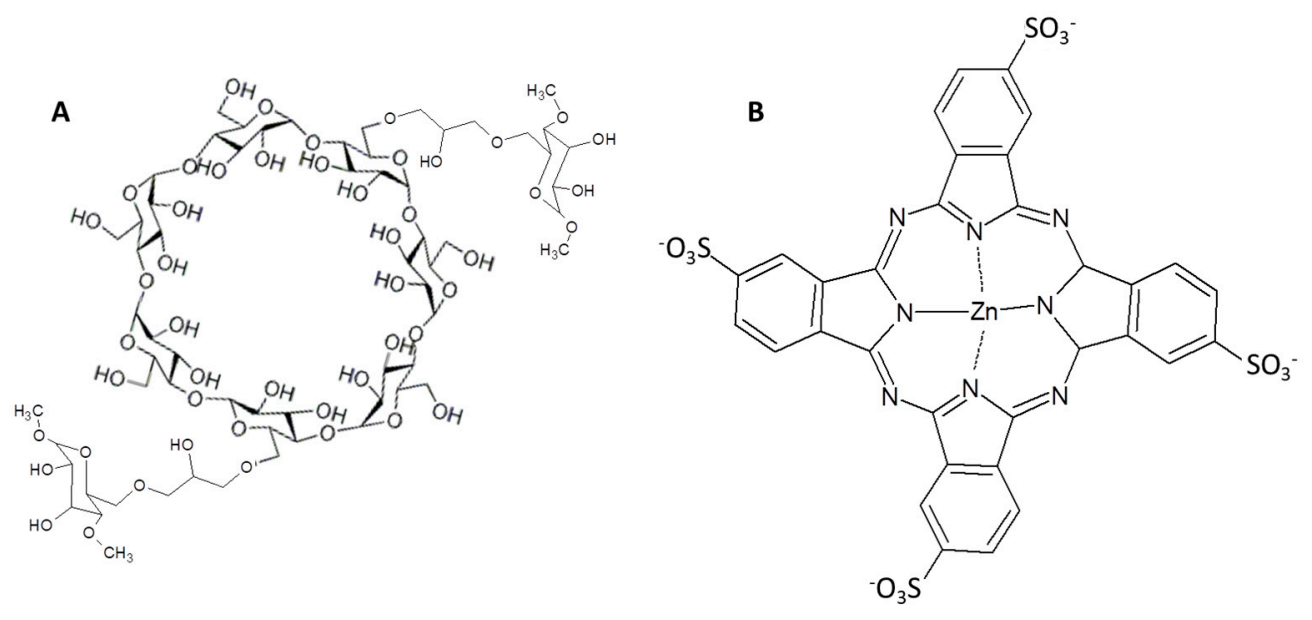

C

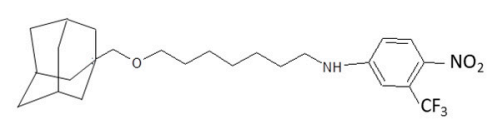

Figure 28. Chemical structures of poly- $\beta$-cyclodextrin (A), zinc phthalocyaninetetrasulfonate (B) and adamantylnitroaniline $(\mathbf{C})$ derivatives [151].

The system epichlorohydrin- $\beta-\mathrm{CD} /$ tetrasulfonate $\mathrm{ZnPc}$ was demonstrated to be characterized by high binding constant value in a 1:1 stoichiometry suggesting that the benzenesulfonate moieties can interact with the 3D CDs network due to the high density of cavity favoring the binding as monomer of the Pc, fundamental requirement for the ${ }^{1} \mathrm{O}_{2}$ photogeneration and for TPE applications. Then, the chosen NO donor, characterized by an adamantyl moiety linked to a nitroaniline commercial derivative, was encapsulated in the CDs exploiting the well-known affinity of the adamantane for CDs [147], avoiding the internalization of the entire chromophore. The tilted configuration of the nitro group with respect to the aromatic ring plane guarantees the NO photorelease and this binding mechanism is able to prevent from the planarization [59]. The final assembly was characterized and, upon $532 \mathrm{~nm}$ excitation, both the $\mathrm{ZnPc}$ transient triplet state decay at $500 \mathrm{~nm}$ and the ${ }^{1} \mathrm{O}_{2}$ phosphorescence decay at $1270 \mathrm{~nm}$ were monitored confirming the great potential of this hybrid nanostructured assembly. Moreover, NO photogeneration was confirmed by means of an amperometric sensor. The cellular internalization was checked by TPE imaging in vitro on an epidermal cancer cell line (A431) and, even, ex vivo on human skin. The cell viability was strongly reduced by the 
combination of photoreleased $\mathrm{NO}$ and ${ }^{1} \mathrm{O}_{2}$, demonstrating that the three component system has very interesting features for this kind of applications.

In the same perspective, the same tetrasulfonate $\mathrm{ZnPc}$ was encapsulated by using a $\beta$-cyclodextrin-based polymer [154], which is reported to assemble in water into $30 \mathrm{~nm}$ nanoparticles [153]. As in the previous example [151], the encapsulation restored both the red light emission and the transient spectrum of the triplet state of the PS, suggesting the presence of the monomer. Indeed, the $680 \mathrm{~nm}$ absorption band was restored as well [155]. Even in this case, the system was thought for a bimodal approach further encapsulating a green emitting NO photodonor, preserving the photoactivation of this compound. The developed hybrid system was tested in vitro on a melanoma cells line both as platform for the monitoring of the internalization by means of Confocal Laser microscopy and as a platform to kill cancer cells upon light irradiation. Moreover, in the above frame, the tetrasulfonate $\mathrm{ZnPc}$ and the $\mathrm{NO}$ photodonor were encapsulated in a supramolecular assembly based on the $\beta$-cyclodextrin-based polymer and a dextran modified with alkyl side chain into a photoreleasing $\mathrm{NO}$ and ${ }^{1} \mathrm{O}_{2}$ high biocompatible hydrogel [156].

Another proposed approach based on supramolecular assembly of natural polymer to exploit singlet oxygen production by Pc derivatives dealt with the use of nanocellulose crystals (CNC) [41]. $\mathrm{CNC}$ were obtained by a sulphuric acid hydrolysis procedure which permits to have negative charged CNC due to the presence of sulfate groups [157]. In this way, two cationic Pcs bearing eight pyridinium moieties were electrostatically linked to CNC surface. In particular, one of the two used derivatives was quaternized by methoxy(triethylenoxy) chains and presents tert-butylphenyl substituents at the 5-position of the pyridinium units. Basically, this second derivative was less water soluble than the first one. The obtained supramolecular adducts were demonstrated to have higher photo-antimicrobial activity due to singlet oxygen production with respect to bare Pcs. It is worth noting that suspensions of both the adducts in phosphate saline buffer ( $\mathrm{pH}$ 7.4) actually were no more able to photorelease ${ }^{1} \mathrm{O}_{2}$, due to strong aggregation phenomena. Nonetheless, once the biocompatible systems were placed in contact with Gram-negative and Gram-positive bacteria and a pathological yeast, thanks to the supramolecular interaction, the Pcs could be supposed to be released from CNC restoring ${ }^{1} \mathrm{O}_{2}$ production. In fact, the photo-antimicrobial activity resulted improved for these supramolecular adducts if compared with porphyrin-based systems, but covalently linked [158,159].

In the same frame of biopolymers supramolecular assemblies for Pcs delivery in PDT applications, curdlan (CUR) based nanoparticles were even proposed with interesting results [160]. CUR (Figure 29) is a $\beta$-(D)-glucan polymer able to spontaneously assemble in aqueous media into right-handed triple helices (t-CUR) [161]. The possibility to interconvert t-CUR into single strand CUR (s-CUR) in dimethyl sulfoxide (DMSO) was exploited to encapsulate a Pc derivative, creating CUR-Pc based nanoparticles of about $760 \mathrm{~nm}$ with a red-shifted Q band located at about $752 \mathrm{~nm}$. There is a great result for biomedical applications, due to the deeper penetration of tissues guaranteed by the red region of the light spectrum. CUR-Pc systems were tested on HeLa cells showing no dark toxicity and interesting capability to kill cancer cells upon long-wavelength light irradiation.

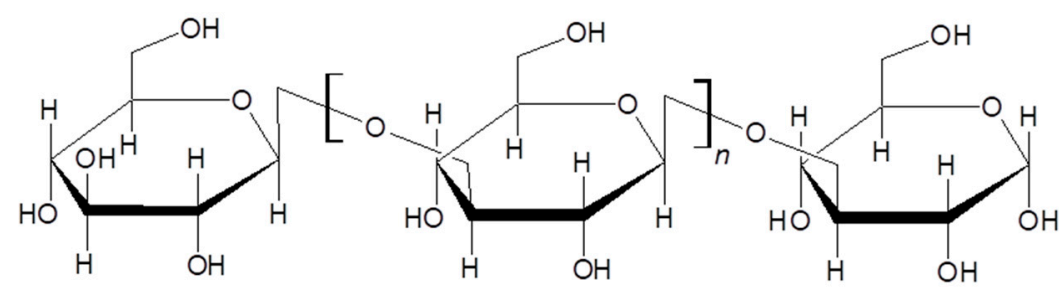

Figure 29. Curdlan chemical structure [161].

Another particularly interesting approach to develop bio-inspired hybrids for PDT applications based on Pc derivative is the employment of virus capsid proteins allowing to obtain a platform able to deliver Pcs derivative and to preserve the photoproduction of ${ }^{1} \mathrm{O}_{2}$ [162-164]. Virus like particles (VLP) produced from the coat protein (CP) of cowpea chlorotic mottle virus (CCMV) are reported as 
versatile nanosystems for drug delivery applications [165-167]. CCMV is a single-strand RNA plant virus characterized by a capsid of ca. $28 \mathrm{~nm}$ diameter, where $\mathrm{CP}$ are supramolecularly organized in 90 dimers in a icosahedral conformation [168]. Basically, CP can be released, disassembling the virus, and re-assembled, once RNA is separated, into VLP encapsulating chemical species, such as PS moieties. Tuning the composition (i.e., ionic strength) and the $\mathrm{pH}$ of the medium, different conformation of VLP can be obtained [163]. In this way, Cornelissen, Torres and collaborators were able to encapsulate a tetrasulfonate $\mathrm{ZnPc}$ in VLP as $\pi-\pi$ stacked dimers [164]. The ZnPc dimers loaded VLP cellular internalization was checked inside RAW264.7 macrophage cells and the red light irradiation was confirmed to induce cell death [164] underlining the good potential of such systems. The supramolecular formation of ZnPc dimers nanosphere inside VLP was even theorized [163]. By changing the route to re-assemble VLP in presence of the Pc derivative, an important hypsochromic shift from $635 \mathrm{~nm}$ (typical of dimer configuration [169]) to $613 \mathrm{~nm}$ of $\mathrm{ZnPc}$ absorption band was recorded, suggesting the $\mathrm{H}$ aggregation of the molecules inside the VLP. Cryo-TEM images of the obtained ZnPc loaded VLP suggested the presence of high ZnPc density with the molecules organized as empty nanosphere in the inner part of the particle. Indeed, protein cages can thought as building blocks to develop systems encapsulating molecules with low water solubility [170]. Among these proteins, also apoferritin (aFt) from Pyrococcus furiosus was reported as an interesting biological system to be loaded for biomedical applications able to organize into hierarchical supramolecular assemblies [162]. aFt was mixed with a supramolecular assembly based on an octacationic $\mathrm{ZnPc}$ derivative (octakis(1-methyl-3-pyridiniumoxy)-ZnPc) and a tetra-anionic pyrene derivative (1,3,6,8-pyrenetetrasulfonic acid), reported in Figure 30 [51]. The $\pi$ - $\pi$ stacking between $\mathrm{ZnPc}$ and pyrene drove the assembly formation in a 1:1 stoichiometry. An important red shift of $\mathrm{ZnPc} Q$ band from $635 \mathrm{~nm}$ to $680 \mathrm{~nm}$ suggested the formation of the monomeric form of ZnPc upon pyrene complexation. This configuration would have preserved 4 positive charges on the ZnPc-pyrene supramolecular adduct. The electrostatic interactions allowed a hierarchical self-assembly process with the formation of ternary (ZnPc-pyrene-aFt) face-centered cubic (fcc) packed crystals.

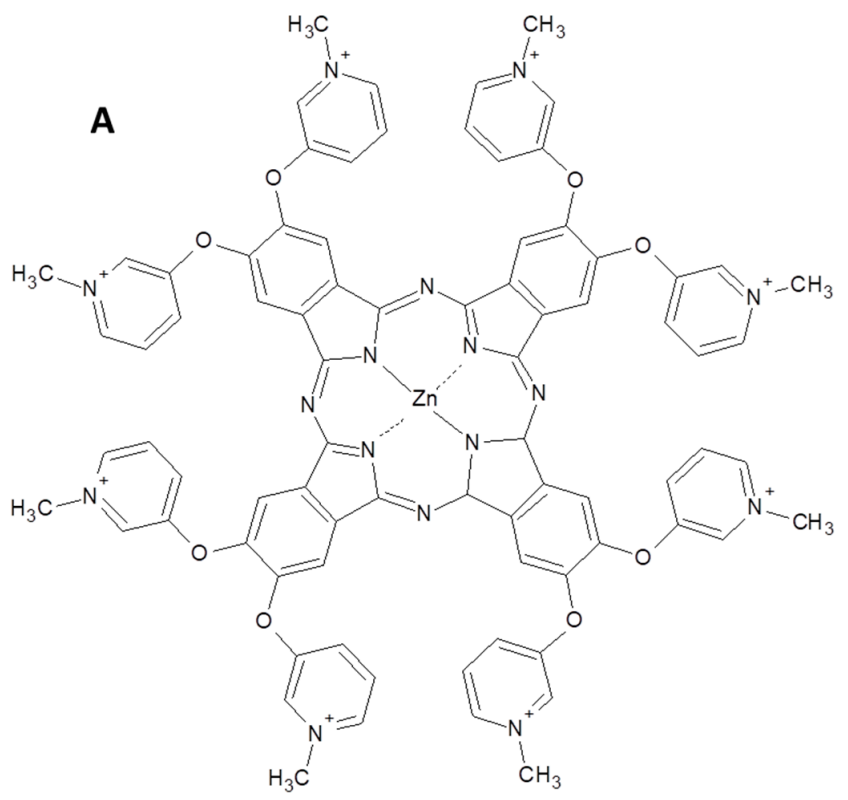

B

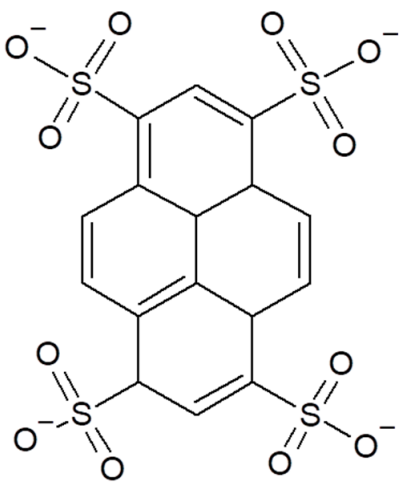

Figure 30. (A) Octacationic ZnPc derivative (octakis(1-methyl-3-pyridiniumoxy)-ZnPc) [51] and (B) tetra-anionic pyrene derivative (1,3,6,8-pyrenetetrasulfonic acid) [170].

This ternary complex was characterized in terms of $\Phi_{\Delta}$ and represents the first example of crystalline supramolecular adduct preserving the photosensitizing features of the embedded PS [51].

Always in order to improve Pc water solubility and delivery in biological media, Kataoka and collaborators [171-173] reported about the possibility to synthesize dendrimers encapsulating Pc, 
as photoactive centre, and bearing ionic peripheral groups. Such dendrimeric moieties, represented by poly(benzyl ether) dendrons, were demonstrated to form supramolecular polyionic complex micelles (PIC) through electrostatic interactions with oppositely charged copolymers [174,175].

Figure 31 shows the chemical structure of the employed anionic dendrimeric $\mathrm{ZnPc}$ (panel A) and of poly(ethylene glycol)-poly(L-lysine) (PEG-PLL, panel B) used as copolymer to obtain PIC.

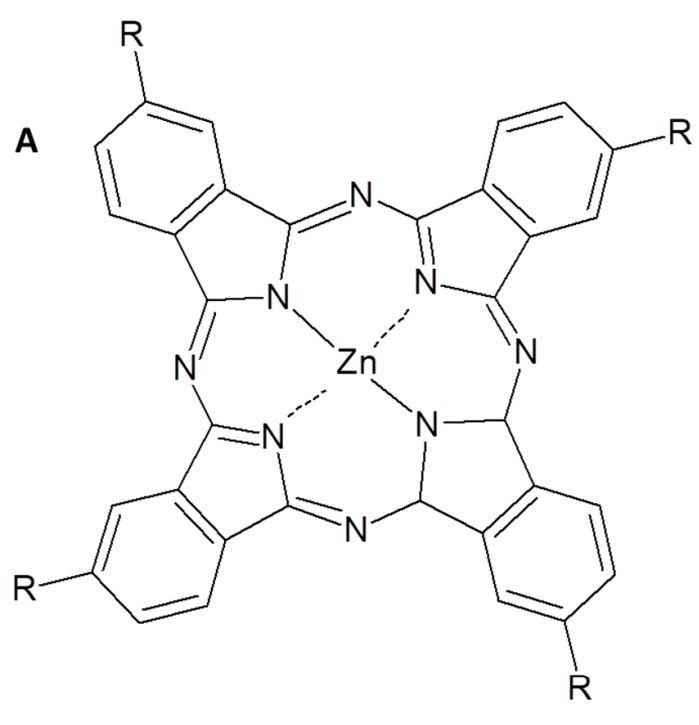
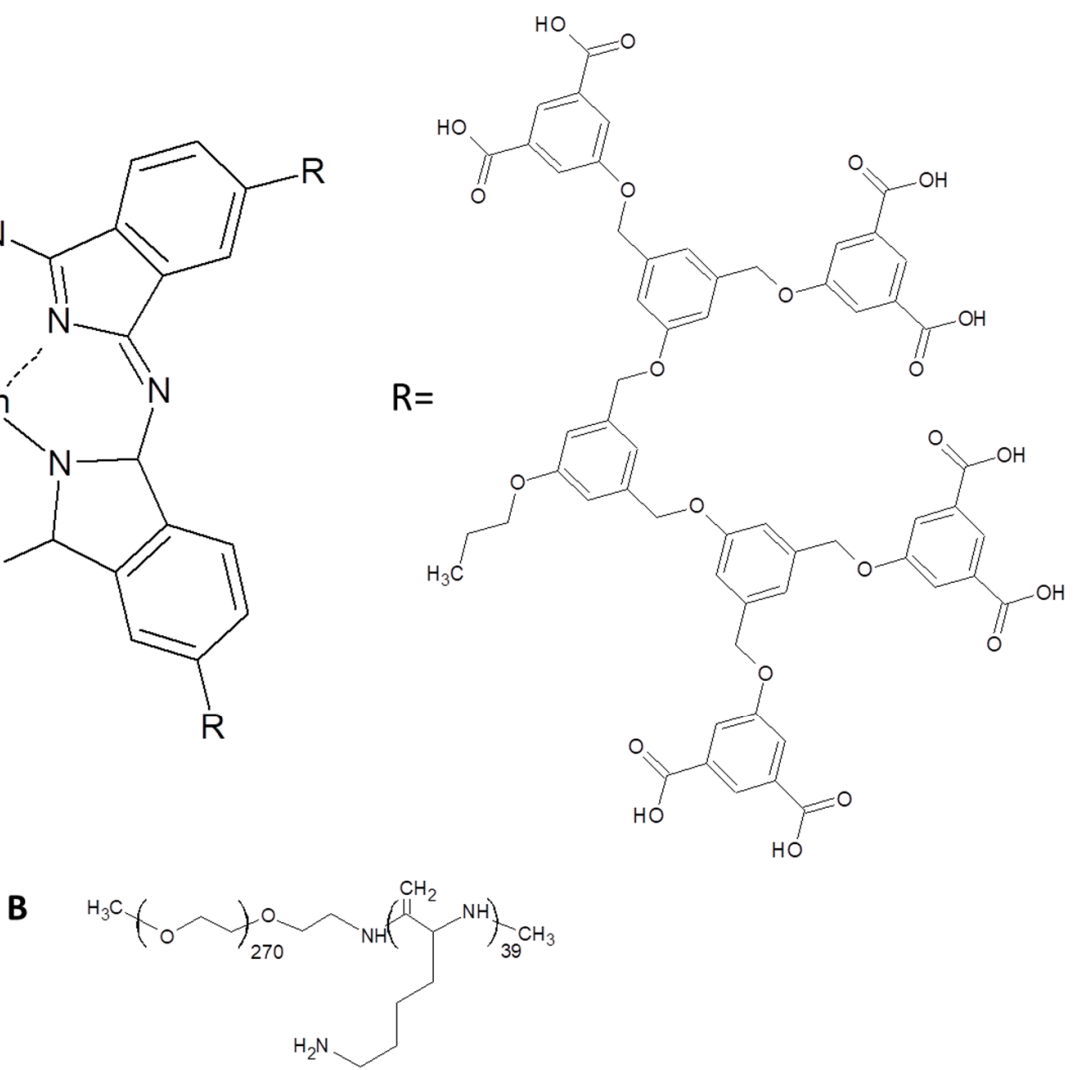

Figure 31. (A) dendrimeric ZnPc; (B) PEG-PLL used in [171].

The dendrimers encapsulating $\mathrm{Pc}_{\mathrm{c}}$ (DPc) based PIC, thanks to the steric hindrance of the dendrimer chains, were characterized by reduced $\mathrm{ZnPc}$ aggregation restoring fluorescent emission and singlet oxygen photo-generation, even if a hypsochromic shift of ZnPc peculiar absorption band from $685 \mathrm{~nm}$ to $630 \mathrm{~nm}$ was observed [173]. In particular, DPc micelles photo-cytotoxicity against HeLa cells was tested and compared to free DPc and it was found that, after $60 \mathrm{~min}$ irradiation, PIC were remarkably more toxic than DPc. Basically, free DPc had better performance as photosensitizing agent in terms of ${ }^{1} \mathrm{O}_{2}$ production, but cellular internalization process seemed to be improved by the micelles. The system was indeed tested in vitro against A459 lung cancer cells [172] and the time-dependent morphological changes during PIC uptake were checked suggesting a unique pathway mediated by endocytosis. Micelles reach mitochondria inducing a huge photo-damage.

Another kind of micelles reported to enhance ZnPc properties for PDT applications was obtained thanks to supramolecular assembly of sodium deoxycholate (SDC) and D- $\alpha$-tocopherol acid polyethylene glycol succinate (TPGS) in specific molar ratios in order ensure the encapsulation of $\mathrm{ZnPc}$ in the hydrophobic core [176]. By changing SDC amounts, different mixed micelles morphologies were obtained, i.e spherical and rod-shaped. All the micelles were characterized by high Pc loading efficiency, good colloidal stability in physiological conditions, good $\Phi_{\Delta}$ and remarkable ability of $\mathrm{ZnPc}$ release during the time, an important feature in a drug delivery system. The light-induced cytotoxicity of ZnPc loaded mixed micelles was investigated on A549 cells with interesting results. Also Poly( $N$-vinylpyrrolidone) (PVP) was mixed with Pc derivatives in order to obtain micelles [177]. 
In particular, crown-ether Pc and different phosphoryl containing Pc (Figure 32A,B respectively) were tested and the role of the metal ion to induce the monomer formation in presence of PVP in the case of the phosphoryl-containing Pc was underlined. Crown-ether derivative aggregation, instead, was not suppressed even with PVP, but slightly reduced by further SDC addition. Nonetheless, the crown-ether derivative based supramolecular assembly was demonstrated to be cytotoxic in vitro against HeLa cells and to reach the perinuclear region. The phosphoryl-containing ZnPc, instead, remained in the cell periphery.

A

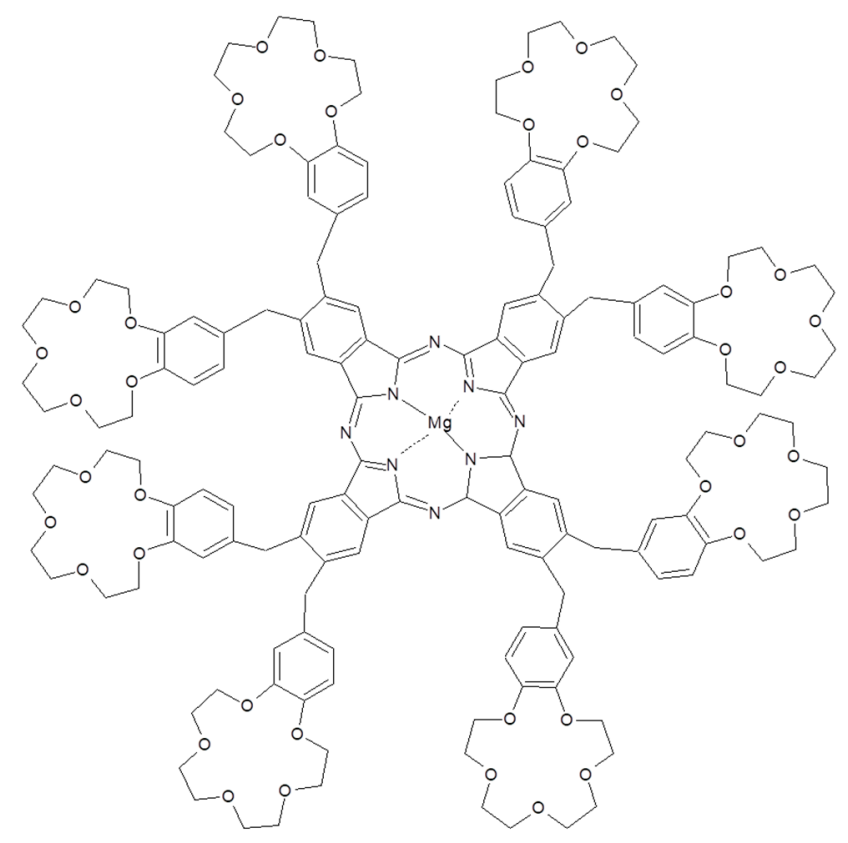

B

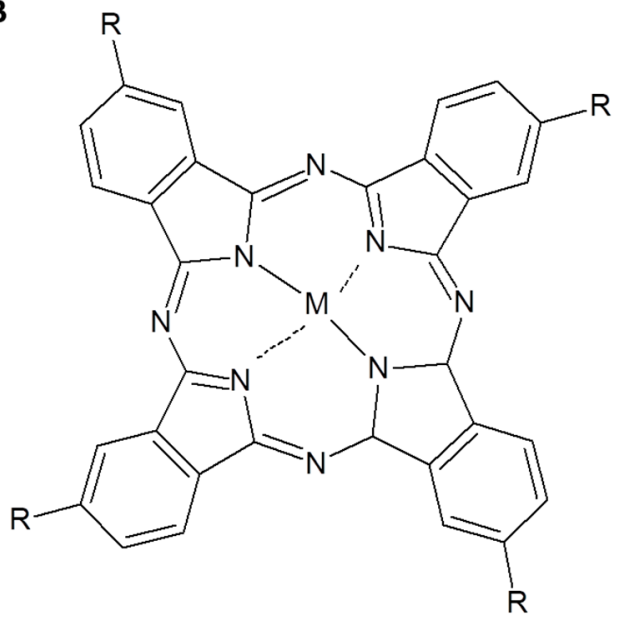<smiles>CCc1cc(F)ccc1P(=O)(O)O</smiles>

Figure 32. (A) crown-ether and (B) phosphoryl-containing derivatives [177].

Moreover, nanoparticles assembled by mixing a ZnPc derivative (4-sulfonatophenoxy-substituted $\mathrm{ZnPc})$ and different azobenzene amphiphiles were reported as very appealing nanoplatform for antibacterial PDT [178].

In particular, the compound Azo 1 (Figure 33) was found to induce the greatest change in the UV-Vis spectrum of ZnPc suggesting a strong host-guest interaction mediated by $\pi-\pi$ stacking phenomena, as even confirmed by the recorded fluorescence quenching upon nanoparticles formation. 


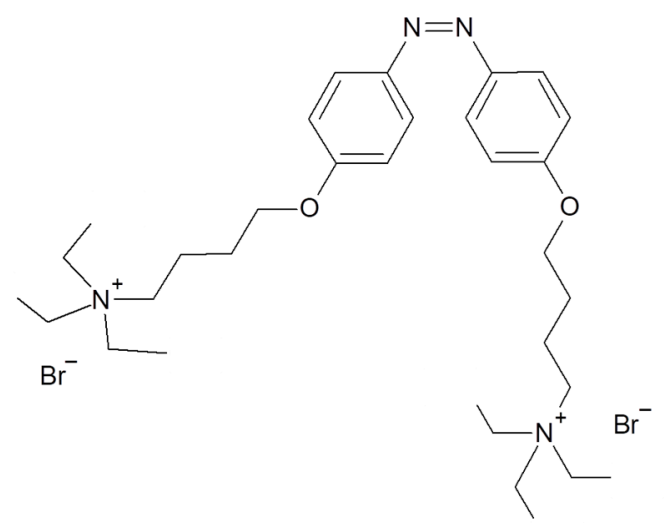

Figure 33. Schematic structure of compound Azo 1 [178].

It is worth highlighting that thanks to the superior features of azobenzene, the nano-assembly can be assembled and disassembled by using light as external trigger [179], locking and unlocking the $\mathrm{ZnPc}$ in a form able to photogenerate singlet oxygen or not. Upon 1 min UV irradiation $(365 \mathrm{~nm})$, nanoparticles were disassembled and became able to kill bacterial cells, in particular E. coli and S. aureus, under red light irradiation.

Another reported approach to overcome Pc drawbacks as PS agent envisaged the chemical modification of Pc derivatives by developing novel synthetic routes and in order to tune Pc molecules aggregation and supramolecular organization $[180,181]$. Huang and collaborators [180] synthetized two ZnPc derivatives, a tetra- and a di- $\alpha$-substituted ZnPc. A triethylene glycol (TEG) chain was used to form a hybrid aza-/oxa-crown-substituted phthalocyanine. The two derivatives displayed interesting self-assembly and photophysical features. Crown ether-substituted Pc, in fact, are known to self-assemble into $\pi-\pi$ columnar aggregates which could lead to liquid-crystalline phases, highly ordered thin films or a gel [182]. The substitution induces a strong red shift of $Q$ band to $699 \mathrm{~nm}$ in the case of the tetrasubstituted Pc and to $685 \mathrm{~nm}$ for the di-substituted Pc. Both molecules are characterized by good $\Phi_{\Delta}$ values, especially the di-substituted one (0.74) calculated in dimethyl formamide. The induced J aggregation of the two Pc molecules was deeply investigated in $\mathrm{CHCl}_{3}$ and $\mathrm{CH}_{2} \mathrm{Cl}_{2}$ in presence of different metal ions demonstrating that singlet oxygen production reduced, if $\mathrm{J}$ aggregation took place. Finally, the cytotoxicity and the cellular uptake tests carried out on HepG2 human hepatocarcinoma cells clearly indicated the di- $\alpha$-substituted ZnPc was characterized by good properties as PS. More recently, Zengin and collaborators [181] reported the synthesis of a novel ball-type ZnPc. This derivative showed an interesting $\Phi_{\Delta}$ value of 0.89 , much higher than the value reported for the un-substituted $\mathrm{ZnPc}$ but, unfortunately, the investigations were performed only in DMSO.

The possibility to develop nano-assemblies of photosensitizers with a switchable design was even investigated $[183,184]$. In particular, regarding Pc molecules, a ZnPc derivative and a SiPc derivative were further modified in order to bear biotin (Figure 34) moieties allowing the "turn on" of Pc photoactivity specifically in the tumor site. Biotin, in fact, is a growth cell promoter and the demand for biotin in cancer tissues is abnormal. So, biotin receptor is overexpressed in these cells and can be used to specifically internalize biotin based supramolecular assemblies [185].

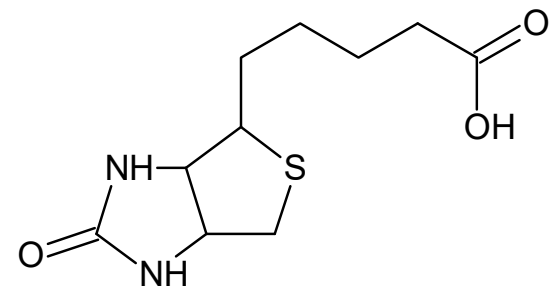

Figure 34. Biotin chemical structure [185]. 
Basically, a ZnPc derivative was modified with triethylene glycol (TEG) linker (Pc-TEG and the hydroxyl group of TEG was further functionalized with biotin [184]. 4 different derivatives were obtained: Pc-1-TEG (with one TEG unit), Pc-2-TEG (with 2 TEG units), Pc-4-TEG (with 4 units) and Pc-4-TEG-B (with 4 TEG units bearing biotin). The first two derivatives did not self-assemble into nanostructures in water, whilst Pc-4-TEG and Pc-4-TEG-B formed spherical nanoparticles. Pc-4-TEG-B, in particular, was demonstrated to form high stable nanoparticles of size ranging between 100 and $200 \mathrm{~nm}$ (NanoPcTB). Photophysical characterization of NanoPcTB in water and of Pc-4-TEG-B monomer in DMSO, clearly, indicated that the assembly quenched the fluorescent emission of the embedded $\mathrm{ZnPc}$, which resulted strongly aggregated with an important blue shift of the $\mathrm{Q}$ band in the absorption spectrum. The possibility to restore the photoactivity of NanoPcTB was tested in vitro by adding increasing amount of avidin, a biotin-specific binding protein. The system disassembled, thanks to the biotin-avidin interaction, allowing the generation of singlet oxygen. The addition of biotin, instead, permitted to re-assemble the nanoparticles, confirming the switchable behavior. NanoPcTB were tested in vivo in A549 tumor (biotin receptor positive) bearing mice by means of fluorescence imaging, confirming the restoring of the fluorescent emission even if in the starting solution was totally quenched. Furthermore, the cell viability assays on A549 and HeLa cells (both positive for biotin receptor) confirmed the outstanding potential of the system. Analogously, an amino-modified SiPc was functionalized with biotin moieties [183], and in presence of different amount of Cremophor EL (CEL) used as surfactant in water, nanoparticles with narrow size distribution of 10, 20, 40 and $90 \mathrm{~nm}$ (NanoPc10, NanoPc20, NanoPc40, NanoPc90) were obtained. By increasing the size of the NanoPc, the fluorescent emission quenching was stronger, but the addition, in vitro, of avidin, again, allowed to restore the photoactivity even for NanoPc90. Cytotoxicity assays and intracellular fluorescence imaging performed on HepG2 cells confirmed the "switch on" of the nanoparticles both in the case of NanoPc20 and NanoPc90. Nonetheless, NanoPc20 was revealed to be much more toxic of NanoPc90 due to mitochondria localization highlighted by in vivo fluorescence imaging upon NanoPc administration via tail in mice bearing $\mathrm{H} 22$ murine hepatocellular tumors.

Pc derivatives were also super-assembled with carbon based materials in order to obtain hybrid materials with peculiar photophysical characteristics $[186,187]$. Carbon based materials, such as carbon dots, graphene quantum dots, carbon nanotubes, have attracting always more interest due to their unique properties that make them suitable for several applications including bio-imaging, sensing, photocatalysis, drug delivery [188-190]. Hybrid materials based on graphene quantum dots and Pc derivatives are reported as interesting nanoplatforms with higher triplet state quantum yield $\Phi_{\mathrm{T}}$, longer fluorescence lifetime and enhanced ${ }^{1} \mathrm{O}_{2}$ photogeneration if compared to bare Pc derivatives. Nyokong and collaborators developed a one-step hydrothermal synthesis route of GQDs in presence of ascorbic acid and the Pc derivative reported in Figure 35, both the free base and the metallated one (Zn) [191]. The system was assembled by $\pi-\pi$ interactions, which did not allow to observe the monomeric form of the free base Pc in the supramolecular nanostructures.

Anyway, the two obtained hybrid materials were characterized, in aqueous media, and in both cases the triplet quantum yield increased, underlining that GQDs support intersystem crossing from excited singlet to triplet state. This promoted, of course, an enhancement in the production of singlet oxygen. Further, Nyokong and collaborators, in another work, proposed ad hoc modified GQDs with BODIPY moieties to tune the interaction with a $\mathrm{ZnPc}$ derivative by means again of $\pi-\pi$ interactions [187]. Even in this case, the supramolecular adduct was characterized by improved singlet oxygen generating ability, fundamental characteristic for the developing of PDT systems. 


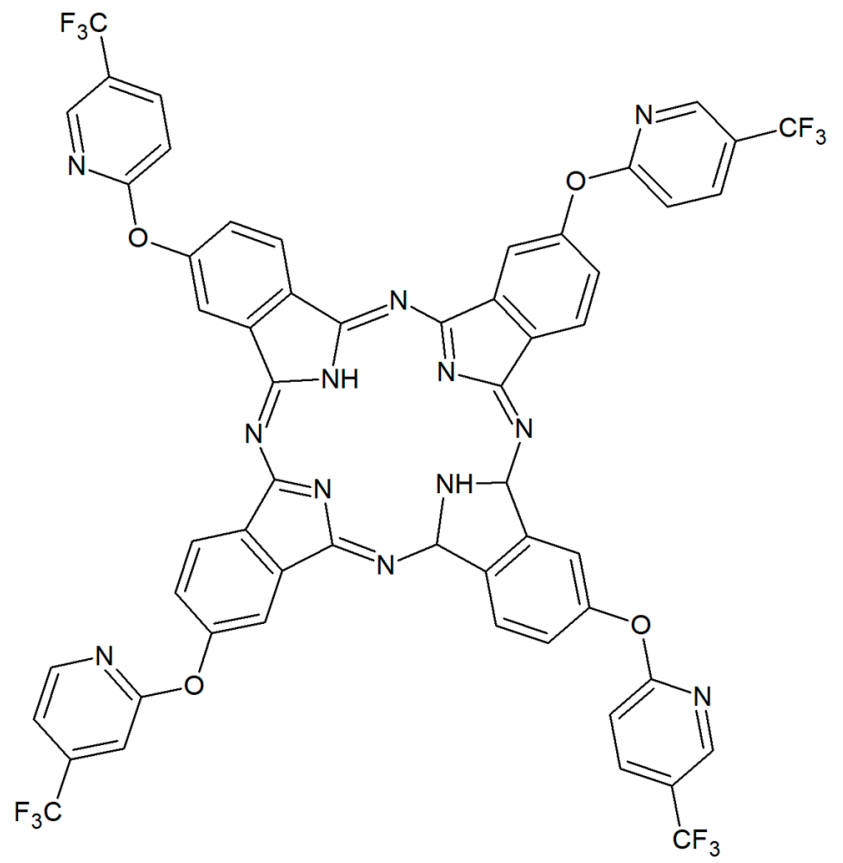

Figure 35. Chemical structure of the free base 4-((5-(trifluoromethyl)pyridin-2-yl)oxy)phthalocyanine utilized to assemble the hybrid structures with GQDs in the ref. [191].

In another approach, a polyfluoroalkyl substituted SiPc derivative (SiPc-F) was synthetized and used to assemble a switchable hybrid system with single walled carbon nanotubes [186]. The supramolecular assembly was built up exploiting, first, host-guest interactions among SiPc-F and pyrene decorated $\beta-C D(p-\beta-C D)$, synthetized according to the literature [192] and supposed to bear two pyrene moieties each CD. Such an interaction was confirmed by the red shift of SiPc-F Q band from $683 \mathrm{~nm}$ to $730 \mathrm{~nm}$. Then, pyrene substituents were exploited to drive $\pi-\pi$ interactions with CNTs sidewalls, generating the supramolecular complex. In this case, the presence of CNTs had a dual role. Thanks to the photothermal capability, which can be used as therapeutic approach [193], the hybrid system was able to induce a localized temperature enhancement: upon $12 \min$ irradiation at $680 \mathrm{~nm}$ $\left(400 \mathrm{~mW} \mathrm{~cm}^{-2}\right)$ the temperature reached $50^{\circ} \mathrm{C}$. CNTs alone did not show the same temperature increase. Simultaneously, the temperature increase induced probably both the thermal expansion of CNTs in the hybrid system and a change in the chemical equilibrium of the complex with the consequent release "light-stimulated" of SiPc-F. Fluorescence emission of SiPC-F was quenched in the complex by CNTs, so its release restored the fluorescence and the possibility to generate singlet oxygen. The antibacterial properties were checked against $E$. coli and the hybrid system showed good results in an aqueous solution containing $10 \%$ of DMSO. The higher toxicity of the assembly if compared with SiPc-F alone or SWNTs could be attributed to the synergic effect of photothermal and photodynamic effect.

In the context of developing supramolecular assembly that can exploit synergic effect of more than one component, supramolecular nanovehicles (SNVs) were assembled encapsulating a tetrasulfonate $\mathrm{ZnPc}$ derivative, as PDT agent, and doxorubicin (DOX), as chemotherapeutic agent, into an ad hoc designed copolymer, folic acid chemically-modified polyvinylpyrrolidone-b-polyacrylic acid (PVP-b-PAA-g-FA) [194]. Folic acid receptor is overexpressed in several cancer cells and folic acid can be thought as a specific target molecule [195]. The developed superior supramolecular assembly ensured synergistic chemotherapy-PDT targeted cancer imaging and therapy. The copolymer had the key role to ensure the formation of micelles like structures in presence of DOX; in fact, acidic DOX groups partially neutralize the ionic folic acid chains guaranteeing the formation of an inner hydrophobic core. The remaining ionized folic acid moieties combining with PVP allows the formation of an external shell exposed to the hydrophilic environment. SNVs, so, had an amphiphilic behavior. $\mathrm{ZnPc}$, then, was internalized in such a shell by hydrogen bonds formation with PVP terminations [196]. 
The obtained SNVs ensured to have $\mathrm{ZnPc}$ in monomeric form optimizing ${ }^{1} \mathrm{O}_{2}$ production in situ. The system was tested in vitro on HepG2 cells and in vivo in HepG2 tumor-bearing mice by intravenous injection into the tails. The synergistic effect confirmed higher anticancer activity than that of each single component of the assembly with a very low drug dose of $1 \mathrm{mg} \mathrm{kg}^{-1}$ considering both the dose of $\mathrm{ZnPC}$ and the dose of DOX.

Also, the possibility to super-assemble nanoparticles of Pc derivative with mitoxantrone was investigated [197]. Mitoxantrone (MA) is a anthracenedione anticancer agent characterized by a conjugated aromatic ring system and two amine groups. These chemical characteristics are important to permit $\pi-\pi$ stacking events and metal-ligand interactions in the complex formation with Pc derivatives. An anionic $\mathrm{ZnPc}$ was chosen to drive the formation of such an assembly, and, by UV-Vis characterization, a 1:1 stoichiometry of the complex was found with a binding constant of $\mathrm{K}=(4.3 \pm 0.8) \times 10^{5}$. Morphological characterization allowed to find nanoparticles of about $60 \mathrm{~nm}$. Other drugs were tested, including DOX, but did not permit to form nanoparticles so well-dispersed as MA with the selected $\mathrm{ZnPc}$. In the assembly, $\mathrm{ZnPc}$ photo-activity is quenched by the formation of $\mathrm{H}$ aggregates, but the supramolecular nature of the interaction allowed to disassemble the nanoparticles. In fact, MA anticancer activity was reported to be due to MA intercalation into DNA. This means that MA affinity towards DNA (binding constant is about $10^{5}-10^{6}$ ) could be used to release ZnPc upon DNA competition with the interactions between $\mathrm{ZnPc}$ and MA. The switchable behavior of the system was tested in vitro by adding nucleic acid in solution and, indeed, at increasing concentration of DNA, $\mathrm{ZnPc}$ fluorescence was found to increase restoring singlet oxygen generation. In this way, promising results in vitro and in vivo were obtained by investigating the anticancer activity on MCF-7 cells and MCF-7 tumors bearing mice.

\section{Conclusions}

Pc derivatives are organic compounds with intriguing physical chemical characteristics which make them suitable for different kinds of applications, especially when their peculiar photophysical features are concerned. Consequently, several examples of Pc molecules employed for driving photo-induced charge and energy transfer phenomena, singlet oxygen and other radical species photo-production, fluorescent sensing devices are reported in the literature. In particular, the possibility to supramolecularly assemble together different Pc derivatives and/or also with other species, such as other molecules, carbon allotropes, nanovesicles, etc., has been deeply investigated in this context. We, indeed, focused in the peculiar mechanisms that rule the above listed photoinduced phenomena when Pcs are supramolecularly arranged. This approach allows to build up even complex molecular architectures for selective analyte sensing based on specific aggregation states. Moreover, optimized charge and/or energy transfers for realizing photo-voltaic devices and photo-catalytic systems have been achieved and explored in this contribution underlining the advantages of the non-covalent interactions. Analogously, singlet oxygen generation has been preserved by the explored supramolecular assemblies guaranteeing in most cases the realization of interesting on-off systems, characteristic that can be almost exclusively reached upon supramolecular approach.

Funding: This research was supported by PRIN 2017 (protocol number 2017PBXPN4_003) and by INITIO-FET Project (Horizon 2020, Grant agreement ID: 828779).

Conflicts of Interest: The authors declare no conflict of interest. 


\section{References}

1. Auyeung, E.; Morris, W.; Mondloch, J.E.; Hupp, J.T.; Farha, O.K.; Mirkin, C.A. Controlling Structure and Porosity in Catalytic Nanoparticle Superlattices with DNA. J. Am. Chem. Soc. 2015, 137, 1658-1662. [CrossRef] [PubMed]

2. Torsi, L.; Farinola, G.M.; Marinelli, F.; Tanese, M.C.; Omar, O.H.; Valli, L.; Babudri, F.; Palmisano, F.; Zambonin, P.G.; Naso, F. A sensitivity-enhanced field-effect chiral sensor. Nat. Mater. 2008, 7, $412-417$. [CrossRef] [PubMed]

3. Horn, D.; Rieger, J. Organic Nanoparticles in the Aqueous Phase-Theory, Experiment, and Use. Angew. Chem. Int. Ed. 2001, 40, 4330. [CrossRef]

4. Bettini, S.; Bonfrate, V.; Madaghiele, M.; Salvatore, L.; Syrgiannis, Z.; Giancane, G.; Valli, L. On-Demand Release of Hydrosoluble Drugs from a Paramagnetic Porous Collagen-Based Scaffold. Chem. A Eur. J. 2016, 23, 1338-1345. [CrossRef]

5. Li, K.; Liu, B. Polymer-encapsulated organic nanoparticles for fluorescence and photoacoustic imaging. Chem. Soc. Rev. 2014, 43, 6570-6597. [CrossRef]

6. Conoci, S.; Guldi, D.M.; Nardis, S.; Paolesse, R.; Kordatos, K.; Prato, M.; Ricciardi, G.; Vicente, M.G.H.; Zilbermann, I.; Valli, L. Langmuir-Shäfer Transfer of Fullerenes and Porphyrins: Formation, Deposition, and Application of Versatile Films. Chem. A Eur. J. 2004, 10, 6523-6530. [CrossRef]

7. Anaya-Plaza, E.; Oliva, M.M.; Kunzmann, A.; Romero-Nieto, C.; Costa, R.D.; De La Escosura, A.; Guldi, D.M.; Torres, T. Quaternized Pyridyloxy Phthalocyanines Render Aqueous Electron-Donor Carbon Nanotubes as Unprecedented Supramolecular Materials for Energy Conversion. Adv. Funct. Mater. 2015, 25, 7418-7427. [CrossRef]

8. Bussetti, G.; Violante, A.; Yivlialin, R.; Cirilli, S.; Bonanni, B.; Chiaradia, P.; Goletti, C.; Tortora, L.; Paolesse, R.; Martinelli, E.; et al. Site-Sensitive Gas Sensing and Analyte Discrimination in Langmuir-Blodgett Porphyrin Films. J. Phys. Chem. C 2011, 115, 8189-8194. [CrossRef]

9. Kim, H.-J.; Lee, J.-S.; Kim, T.-H.; Lee, T.S.; Kim, J. Highly Emissive Self-assembled Organic Nanoparticles having Dual Color Capacity for Targeted Immunofluorescence Labeling. Adv. Mater. 2008, 20, 1117-1121. [CrossRef]

10. Royston, E.; Ghosh, A.; Kofinas, P.; Harris, M.T.; Culver, J.N. Self-Assembly of Virus-Structured High Surface Area Nanomaterials and Their Application as Battery Electrodes. Langmuir 2008, 24, 906-912. [CrossRef]

11. Valli, L.; Giancane, G.; Mazzaglia, A.; Scolaro, L.M.; Conoci, S.; Sortino, S. Photoresponsive multilayer films by assembling cationic amphiphilic cyclodextrins and anionic porphyrins at the air/water interface. J. Mater. Chem. 2007, 17, 1660-1663. [CrossRef]

12. Nyokong, T. Electronic Spectral and Electrochemical Behavior of Near Infrared Absorbing Metallophthalocyanines. Family Medicine 2009, 135, 45-87. [CrossRef]

13. Yılmaz, F.; Özer, M.; Kani, I.; Bekaroğlu, Ö. Catalytic Activity of a Thermoregulated, Phase-Separable $\mathrm{Pd}(\mathrm{II})$-perfluoroalkylphthalocyanine Complex in an Organic/Fluorous Biphasic System: Hydrogenation of Olefins. Catal. Lett. 2009, 130, 642-647. [CrossRef]

14. Blanco-Gómez, A.; Cortón, P.; Barravecchia, L.; Neira, I.; Pazos, E.; Peinador, C.; García, M.D. Controlled binding of organic guests by stimuli-responsive macrocycles. Chem. Soc. Rev. 2020, 49, 3834-3862. [CrossRef]

15. Ariga, K.; Li, M.; Richards, G.J.; Hill, J.P. Nanoarchitectonics: A conceptual paradigm for design and synthesis of dimension-controlled functional nanomaterials. J. Nanosci. Nanotechnol. 2011, 11, 1-13. [CrossRef] [PubMed]

16. Đorđević, L.; Marangoni, T.; Liu, M.; De Zorzi, R.; Geremia, S.; Minoia, A.; Lazzaroni, R.; Ishida, Y.; Bonifazi, D. Templating Porphyrin Anisotropy via Magnetically Aligned Carbon Nanotubes. ChemPlusChem 2019, 84, 1270-1278. [CrossRef]

17. Iglesias, M.G.; Peuntinger, K.; Kahnt, A.; Krausmann, J.; Vázquez, P.; González-Rodríguez, D.; Guldi, D.M.; Torres, T. Supramolecular Assembly of Multicomponent Photoactive Systems via Cooperatively Coupled Equilibria. J. Am. Chem. Soc. 2013, 135, 19311-19318. [CrossRef]

18. Hunt, J.N.; Feldman, K.E.; Lynd, N.A.; Deek, J.; Campos, L.M.; Spruell, J.M.; Hernandez, B.M.; Kramer, E.J.; Hawker, C.J. Tunable, High Modulus Hydrogels Driven by Ionic Coacervation. Adv. Mater. 2011, 23, 2327-2331. [CrossRef] 
19. Manno, D.; Rella, R.; Troisi, L.; Valli, L. Langmuir-Blodgett films of Cu(II)-tetrakis (3,3-dimethylbutoxycarbonyl) phthalocyanine: A spectrophotometric and TEM analysis of their structure and morphology. Thin Solid Films 1996, 280, 249-255. [CrossRef]

20. Apetrei, C.; Casilli, S.; De Luca, M.; Valli, L.; Jiang, J.; Rodriguez-Mendez, M.L.; De Saja, J. Spectroelectrochemical characterisation of Langmuir-Schaefer films of heteroleptic phthalocyanine complexes. Potential applications. Colloids Surfaces A: Physicochem. Eng. Asp. 2006, 284, 574-582. [CrossRef]

21. Bettini, S.; Syrgiannis, Z.; Pagano, R.; Dordevic, L.; Salvatore, L.; Prato, M.; Giancane, G.; Valli, L. Perylene Bisimide Aggregates as Probes for Subnanomolar Discrimination of Aromatic Biogenic Amines. ACS Appl. Mater. Interfaces 2019, 11, 17079-17089. [CrossRef] [PubMed]

22. Yasu, Y.; Inagaki, A.; Akita, M. Synthesis of trinuclear Pd-Ru-Pd porphyrin complexes with axially ligated Pd centers. Prominent metal-to-ligand charge transfer band in the visible region. J. Organomet. Chem. 2014, 753, 48-54. [CrossRef]

23. Barin, G.; Frasconi, M.; Dyar, S.M.; Iehl, J.; Buyukcakir, O.; Sarjeant, A.A.; Carmieli, R.; Coskun, A.; Wasielewski, M.R.; Stoddart, J.F. Redox-Controlled Selective Docking in a [2]Catenane Host. J. Am. Chem. Soc. 2013, 135, 2466-2469. [CrossRef] [PubMed]

24. Pérez-Gutiérrez, E.; Ceron, M.; Santos, P.; Ceballos, P.; Venkatesan, P.; Thamotharan, S.; Bernal-Pinilla, W.; Barbosa-García, O.; Percino, M.J.; Perumal, V.; et al. Film morphology of acrylonitrile materials deposited by a solution process and vacuum evaporation. Supramolecular interactions, optoelectronic properties and an approximation by computational calculations. New J. Chem. 2019, 43, 15513-15524. [CrossRef]

25. Pigot, C.; Dumur, F. Recent Advances of Hierarchical and Sequential Growth of Macromolecular Organic Structures on Surface. Materials 2019, 12, 662. [CrossRef] [PubMed]

26. Bertolani, A.; Pirrie, L.; Stefan, L.; Houbenov, N.; Haataja, J.S.; Catalano, L.; Terraneo, G.; Giancane, G.; Valli, L.; Milani, R.; et al. Supramolecular amplification of amyloid self-assembly by iodination. Nat. Commun. 2015, 6, 7574. [CrossRef] [PubMed]

27. Arrigoni, C.; Schull, G.; Bléger, D.; Douillard, L.; Fiorini-Debuisschert, C.; Mathevet, F.; Kreher, D.; Attias, A.-J.; Charra, F. Structure and Epitaxial Registry on Graphite of a Series of Nanoporous Self-Assembled Molecular Monolayers. J. Phys. Chem. Lett. 2009, 1, 190-194. [CrossRef]

28. Jana, A.; Ishida, M.; Kwak, K.; Sung, Y.M.; Kim, D.S.; Lynch, V.M.; Lee, D.; Kim, D.; Sessler, J.L. Comparative Electrochemical and Photophysical Studies of Tetrathiafulvalene-Annulated Porphyrins and Their ZnIIComplexes: The Effect of Metalation and Structural Variation. Chem. A Eur. J. 2012, 19, 338-349. [CrossRef]

29. Volpati, D.; Aléssio, P.; Zanfolim, A.A.; Storti, F.C.; Job, A.E.; Ferreira, M.; Riul, A.; Oliveira, O.N.; Constantino, C.J.L. Exploiting Distinct Molecular Architectures of Ultrathin Films Made with Iron Phthalocyanine for Sensing. J. Phys. Chem. B 2008, 112, 15275-15282. [CrossRef]

30. Hosseini, A.; Taylor, S.; Accorsi, G.; Armaroli, N.; Reed, C.A.; Boyd, P.D.W. Calix[4]arene-Linked Bisporphyrin Hosts for Fullerenes: Binding Strength, Solvation Effects, and Porphyrin-Fullerene Charge Transfer Bands. J. Am. Chem. Soc. 2006, 128, 15903-15913. [CrossRef]

31. Yang, M.-X.; Tang, Q.; Wang, Q.; Tao, Z.; Xiao, X.; Huang, Y.; Yang, M. pH-stimulus response dye-cucurbituril sensor for amino acids in aqueous solution. Spectrochim. Acta Part A Mol. Biomol. Spectrosc. 2020, 230, 118076. [CrossRef] [PubMed]

32. Ming, S.; Feng, Z.; Mo, D.; Wang, Z.; Lin, K.; Lu, B.; Xu, J. Solvent effects on electrosynthesis, morphological and electrochromic properties of a nitrogen analog of PEDOT. Phys. Chem. Chem. Phys. 2016, 18, 5129-5138. [CrossRef] [PubMed]

33. Kasperski, A.; Nieckarz, D.; Szabelski, P. Structure formation in adsorbed overlayers comprising functional cross-shaped molecules: A Monte Carlo study. Surf. Sci. 2015, 641, 269-277. [CrossRef]

34. Kam, A.; Aroca, R.; Duff, J.; Tripp, C.P. Evolution of the Molecular Organization in Bis(n-propylimido)perylene Films under Thermal Annealing. Chem. Mater. 1998, 10, 172-176. [CrossRef]

35. Aléssio, P.; Constantino, C.J.L.; Job, A.E.; Aroca, R.; González, E.R.P. Molecular architecture of thin films fabricated via physical vapor deposition and containing a poly(azo)urethane. J. Nanosci. Nanotechnol. 2010, 10, 3012-3021. [CrossRef]

36. Bottari, G.; De La Torre, G.; Torres, T. Phthalocyanine-Nanocarbon Ensembles: From Discrete Molecular and Supramolecular Systems to Hybrid Nanomaterials. Accounts Chem. Res. 2015, 48, 900-910. [CrossRef] 
37. Mitsunaga, M.; Ogawa, M.; Kosaka, N.; Rosenblum, L.T.; Choyke, P.L.; Kobayashi, H. Cancer cell-selective in vivo near infrared photoimmunotherapy targeting specific membrane molecules. Nat. Med. 2011, 17, 1685-1691. [CrossRef]

38. Khoza, P.; Nyokong, T. Photocatalytic behaviour of zinc tetraamino phthalocyanine-silver nanoparticles immobilized on chitosan beads. J. Mol. Catal. A Chem. 2015, 399, 25-32. [CrossRef]

39. Sgobba, V.; Giancane, G.; Cannoletta, D.; Operamolla, A.; Omar, O.H.; Farinola, G.M.; Guldi, D.M.; Valli, L. Langmuir-Schaefer Films for Aligned Carbon Nanotubes Functionalized with a Conjugate Polymer and Photoelectrochemical Response Enhancement. ACS Appl. Mater. Interfaces 2013, 6, 153-158. [CrossRef]

40. Tang, H.; Yin, H.; Wang, J.; Yang, N.; Wang, D.; Tang, Z. Molecular Architecture of Cobalt Porphyrin Multilayers on Reduced Graphene Oxide Sheets for High-Performance Oxygen Reduction Reaction. Angew. Chem. Int. Ed. 2013, 52, 5585-5589. [CrossRef]

41. Anaya-Plaza, E.; Van De Winckel, E.; Mikkilä, J.; Malho, J.-M.; Ikkala, O.; Gulias, O.; Bresolí-Obach, R.; Agut, M.; Nonell, S.; Torres, T.; et al. Photoantimicrobial Biohybrids by Supramolecular Immobilization of Cationic Phthalocyanines onto Cellulose Nanocrystals. Chem. A Eur. J. 2017, 23, 4320-4326. [CrossRef] [PubMed]

42. Pais, V.F.; Carvalho, E.F.; Tome, J.P.C.; Pischel, U. Supramolecular control of phthalocyanine dye aggregation. Supramol. Chem. 2014, 26, 642-647. [CrossRef]

43. Li, Z.; Zhang, Y.-M.; Chen, Y.; Liu, Y. A Supramolecular Tubular Nanoreactor. Chem. A Eur. J. 2014, 20, 8566-8570. [CrossRef] [PubMed]

44. Takezawa, Y.; Shionoya, M. Metal-Mediated DNA Base Pairing: Alternatives to Hydrogen-Bonded Watson-Crick Base Pairs. Accounts Chem. Res. 2012, 45, 2066-2076. [CrossRef] [PubMed]

45. Weijer, R.; Broekgaarden, M.; Kos, M.; Van Vught, R.; Rauws, E.A.; Breukink, E.; Van Gulik, T.M.; Storm, G.; Heger, M. Enhancing photodynamic therapy of refractory solid cancers: Combining second-generation photosensitizers with multi-targeted liposomal delivery. J. Photochem. Photobiol. C Photochem. Rev. 2015, 23, 103-131. [CrossRef]

46. Tombe, S.; Chidawanyika, W.; Antunes, E.; Priniotakis, G.; Westbroek, P.; Nyokong, T. Physicochemical behavior of zinc tetrakis (benzylmercapto) phthalocyanine when used to functionalize gold nanoparticles and in electronspun fibers. J. Photochem. Photobiol. A Chem. 2012, 240, 50-58. [CrossRef]

47. Ke, M.-R.; Yeung, S.-L.; Fong, W.-P.; Ng, D.K.P.; Lo, P.-C. A Phthalocyanine-Peptide Conjugate with High in Vitro Photodynamic Activity and Enhanced in Vivo Tumor-Retention Property. Chem. A Eur. J. 2012, 18, 4225-4233. [CrossRef]

48. El-Refaey, A.; Shaban, S.Y.; El-Kemary, M.; El-Khouly, M.E. A light harvesting perylene derivative-zinc phthalocyanine complex in water: Spectroscopic and thermodynamic studies. Photochem. Photobiol. Sci. 2017, 16, 861-869. [CrossRef]

49. Kondo, K.; Akita, M.; Yoshizawa, M. Solubility Switching of Metallophthalocyanines and Their Larger Derivatives upon Encapsulation. Chem. A Eur. J. 2016, 22, 1937-1940. [CrossRef]

50. Schaming, D.; Allain, C.; Farha, R.; Goldmann, M.; Lobstein, S.; Giraudeau, A.; Hasenknopf, B.; Ruhlmann, L. Synthesis and Photocatalytic Properties of Mixed Polyoxometalate-Porphyrin Copolymers Obtained from Anderson-Type Polyoxomolybdates. Langmuir 2010, 26, 5101-5109. [CrossRef]

51. Mikkilä, J.; Anaya-Plaza, E.; Liljeström, V.; Castón, J.R.; Torres, T.; De La Escosura, A.; Kostiainen, M.A. Hierarchical Organization of Organic Dyes and Protein Cages into Photoactive Crystals. ACS Nano 2015, 10, 1565-1571. [CrossRef] [PubMed]

52. Jiang, Y.; Liu, C.; Wang, X.; Wanga, T.; Jiang, J. Fluorescent Phthalocyanine Assembly Distinguishes Chiral Isomers of Different Types of Amino Acids and Sugars. Langmuir 2017, 33, 7239-7247. [CrossRef] [PubMed]

53. Rella, R.; Serra, A.; Siciliano, P.A.; Tepore, A.; Valli, L.; Zocco, A. NO2 gas detection by Langmuir-Blodgett films of copper phthalocyanine multilayer structures. Supramol. Sci. 1997, 4, 461-464. [CrossRef]

54. Da Ros, T.; Prato, M.; Carano, M.; Ceroni, P.; Paolucci, F.; Roffia, S.; Valli, L.; Guldi, D. Synthesis, electrochemistry, Langmuir-Blodgett deposition and photophysics of metal-coordinated fullerene-porphyrin dyads. J. Organomet. Chem. 2000, 599, 62-68. [CrossRef]

55. Zhu, C.; Zhuo, S.; Zheng, H.; Chen, J.; Li, D.; Li, S.; Xu, J.-G. Determination of nucleic acids based on shifting the association equilibrium between tetracarboxy aluminum phthalocyanine and poly-lysine. Spectrochim. Acta Part A Mol. Biomol. Spectrosc. 2005, 61, 743-748. [CrossRef] 
56. Gurrieri, S.; Aliffi, A.; Bellacchio, E.; Lauceri, R.; Purrello, R. Spectroscopic characterization of porphyrin supramolecular aggregates on poly-lysine and their application to quantitative DNA determination. Inorganica Chim. Acta 1999, 286, 121-126. [CrossRef]

57. Achadu, O.J.; Nyokong, T. Fluorescence "turn-ON" nanosensor for cyanide ion using supramolecular hybrid of graphene quantum dots and cobalt pyrene-derivatized phthalocyanine. Dye. Pigment. 2019, 160, 328-335. [CrossRef]

58. Giancane, G.; Valli, L. State of art in porphyrin Langmuir-Blodgett films as chemical sensors. Adv. Colloid Interface Sci. 2012, 17-35. [CrossRef]

59. Giancane, G.; Valli, L.; Sortino, S. Dual-Function Multilayers for the Photodelivery of Nitric Oxide and Singlet Oxygen. ChemPhysChem 2009, 10, 3077-3082. [CrossRef]

60. Hiroto, S.; Miyake, Y.; Shinokubo, H. Synthesis and Functionalization of Porphyrins through Organometallic Methodologies. Chem. Rev. 2016, 117, 2910-3043. [CrossRef]

61. De La Escosura, A.; Martínez-Díaz, M.V.; Guldi, D.M.; Torres, T. Stabilization of Charge-Separated States in Phthalocyanine-Fullerene Ensembles through Supramolecular Donor-Acceptor Interactions. J. Am. Chem. Soc. 2006, 128, 4112-4118. [CrossRef] [PubMed]

62. Guldi, D.M.; Zilbermann, I.; Gouloumis, A.; Vázquez, P.; Torres, T. Metallophthalocyanines: Versatile Electron-Donating Building Blocks for Fullerene Dyads. J. Phys. Chem. B 2004, 108, 18485-18494. [CrossRef]

63. Hill, I.; Kahn, A.; Soos, Z.; Pascal, J.R. Charge-separation energy in films of $\pi$-conjugated organic molecules. Chem. Phys. Lett. 2000, 327, 181-188. [CrossRef]

64. Tong, B.; Yang, H.; Xiong, W.; Xie, F.; Shi, J.; Zhi, J.; Chan, W.K.; Dong, Y. Controlled Fabrication and Optoelectrical Properties of Metallosupramolecular Films Based on Ruthenium(II) Phthalocyanines and 4,4'-Bipyridine Covalently Anchored on Inorganic Substrates. J. Phys. Chem. B 2013, 117, 5338-5344. [CrossRef]

65. Lemaur, V.; Steel, M.; Beljonne, D.; Bredas, J.-L.; Cornil, J. Photoinduced Charge Generation and Recombination Dynamics in Model Donor/Acceptor Pairs for Organic Solar Cell Applications: A Full Quantum-Chemical Treatment. J. Am. Chem. Soc. 2005, 127, 6077-6086. [CrossRef]

66. Modugno, G.; Syrgiannis, Z.; Bonasera, A.; Carraro, M.; Giancane, G.; Valli, L.; Bonchio, M.; Prato, M. The supramolecular design of low-dimensional carbon nano-hybrids encoding a polyoxometalate-bis-pyrene tweezer. Chem. Commun. 2014, 50, 4881-4883. [CrossRef]

67. Hardin, B.E.; Hoke, E.T.; Armstrong, P.B.; Yum, J.-H.; Comte, P.; Torres, T.; Fréchet, J.M.J.; Nazeeruddin, K.; Grätzel, M.; McGehee, M.D. Increased light harvesting in dye-sensitized solar cells with energy relay dyes. Nat. Photon. 2009, 3, 406-411. [CrossRef]

68. O’Regan, B.; López-Duarte, I.; Martínez-Díaz, M.V.; Forneli, A.; Albero, J.; Morandeira, A.; Palomares, E.; Torres, T.; Durrant, J.R. Catalysis of Recombination and Its Limitation on Open Circuit Voltage for Dye Sensitized Photovoltaic Cells Using Phthalocyanine Dyes. J. Am. Chem. Soc. 2008, 130, 2906-2907. [CrossRef]

69. Seitz, W.; Jiménez, Á.J.; Carbonell, E.; Grimm, B.; Rodríguez-Morgade, M.S.; Guldi, D.M.; Torres, T. Synthesis and photophysical properties of a hydrogen-bonded phthalocyanine-perylenediimideassembly. Chem. Commun. 2010, 46, 127-129. [CrossRef]

70. Rodriguez-Morgade, M.S.; Torres, T.; Atienza-Castellanos, C.; Guldi, D.M. Supramolecular Bis (rutheniumphthalocyanine)-Perylenediimide Ensembles: Simple Complexation as a Powerful Tool toward Long-Lived Radical Ion Pair States. J. Am. Chem. Soc. 2006, 128, 15145-15154. [CrossRef]

71. Jiménez, Á.J.; Calderón, R.M.K.; Rodríguez-Morgade, M.S.; Guldi, D.M.; Torres, T. Synthesis, characterization and photophysical properties of a melamine-mediated hydrogen-bound phthalocyanine-perylenediimide assembly. Chem. Sci. 2013, 4, 1064-1074. [CrossRef]

72. Céspedes-Guirao, F.J.; Ohkubo, K.; Fukuzumi, S.; Fernández-Lázaro, F.; Sastre-Santos, Á. Supramolecular Zinc Phthalocyanine-Imidazolyl Perylenediimide Dyad and Triad: Synthesis, Complexation, and Photophysical Studies. Chem. Asian J. 2011, 6, 3110-3121. [CrossRef] [PubMed]

73. Bettini, S.; Valli, L.; Santino, A.; Martinelli, C.; Farinola, G.M.; Cardone, A.; Sgobba, V.; Giancane, G. Spectroscopic investigations, characterization and chemical sensor application of composite Langmuir-Schäfer films of anthocyanins and oligophenylenevinylene derivatives. Dye. Pigment. 2012, 94, 156-162. [CrossRef]

74. Bettini, S.; Sawalha, S.; Carbone, L.; Giancane, G.; Prato, M.; Valli, L. Carbon nanodot-based heterostructures for improving the charge separation and the photocurrent generation. Nanoscale 2019, 11, 7414-7423. [CrossRef] 
75. Bettini, S.; Syrgiannis, Z.; Ottolini, M.; Bonfrate, V.; Giancane, G.; Valli, L.; Prato, M. Supramolecular Chiral Discrimination of D-Phenylalanine Amino Acid Based on a Perylene Bisimide Derivative. Front. Bioeng. Biotechnol. 2020, 8, 160. [CrossRef]

76. Panda, D.K.; Goodson, F.S.; Ray, S.; Saha, S. Dye-sensitized solar cells based on multichromophoric supramolecular light-harvesting materials. Chem. Commun. 2014, 50, 5358-5360. [CrossRef]

77. Qi, D.; Zhang, L.; Wan, L.; Zhao, L.; Jiang, J. Design of a Universal Reversible Bidirectional Current Switch Based on the Fullerene-Phthalocyanine Supramolecular System. J. Phys. Chem. A 2012, 116, 6785-6791. [CrossRef]

78. Ray, A.; Santhosh, K.; Bhattacharya, S. Absorption spectrophotometric, fluorescence, transient absorption and quantum chemical investigations on fullerene/phthalocyanine supramolecular complexes. Spectrochim. Acta Part A Mol. Biomol. Spectrosc. 2011, 78, 1364-1375. [CrossRef]

79. Ray, A.; Santhosh, K.; Bhattacharya, S. Photophysical and Theoretical Insights on Fullerene/Zincphthalocyanine Supramolecular Interaction in Solution. J. Phys. Chem. B 2012, 116, 11979-11998. [CrossRef]

80. Ray, A.; Pal, H.; Bhattacharya, S. Photophysical investigations on supramolecular fullerene/phthalocyanine charge transfer interactions in solution. Spectrochim. Acta Part A Mol. Biomol. Spectrosc. 2014, 117, 686-695. [CrossRef]

81. Nefedova, I.V.; Martynov, A.G.; Averin, A.A.; Kirakosyan, G.A.; Tsivadze, A.Y.; Birin, K.P. New Octopus-like Phthalocyanines as Fullerene Receptors: Synthesis and Photophysical Investigation. Isr. J. Chem. 2015, 56, 181-187. [CrossRef]

82. Jurow, M.; Varotto, A.; Manichev, V.; Travlou, N.A.; Giannakoudakis, D.A.; Drain, C.M. Self-organized nanostructured materials of alkylated phthalocyanines and underivatized C60 on ITO. RSC Adv. 2013, 3, 21360. [CrossRef]

83. Varotto, A.; Todaro, L.; Vinodu, M.; Koehne, J.; Liu, G.-Y.; Drain, C.M. Self-organization of a new fluorous porphyrin and C60 films on indium-tin-oxide electrode. Chem. Commun. 2008, 11, 4921-4923. [CrossRef] [PubMed]

84. Kawashima, Y.; Ohkubo, K.; Blas-Ferrando, V.M.; Sakai, H.; Font-Sanchis, E.; Ortiz, J.; Fernández-Lázaro, F.; Hasobe, T.; Sastre-Santos, Á.; Fukuzumi, S. Near-Infrared Photoelectrochemical Conversion via Photoinduced Charge Separation in Supramolecular Complexes of Anionic Phthalocyanines with Li+@C60. J. Phys. Chem. B 2015, 119, 7690-7697. [CrossRef]

85. Lederer, M.; Hahn, U.; Strub, J.-M.; Cianferani, S.; Van Dorsselaer, A.; Nierengarten, J.-F.; Torres, T.; Guldi, D.M. Probing Supramolecular Interactions between a Crown Ether Appended Zinc Phthalocyanine and an Ammonium Group Appended to a C60 Derivative. Chem. A Eur. J. 2016, 22, 2051-2059. [CrossRef] [PubMed]

86. Silvestri, F.; López-Duarte, I.; Seitz, W.; Beverina, L.; Martínez-Díaz, M.V.; Marks, T.J.; Guldi, D.M.; Pagani, G.A.; Torres, T. A squaraine-phthalocyanine ensemble: Towards molecular panchromatic sensitizers in solar cells. Chem. Commun. 2009, 4500-4502. [CrossRef] [PubMed]

87. Zhang, J.; Li, Y.; Wang, L.; Fujiki, M.; Li, X.; Zhang, Z.; Zhang, W.; Zhou, N.; Zhu, X. Supramolecular self-assembly and photovoltaic property of soluble fluorogallium phthalocyanine. RSC Adv. 2014, 4, 29485-29492. [CrossRef]

88. Maggini, M.; Scorrano, G.; Prato, M. Addition of azomethine ylides to C60: Synthesis, characterization, and functionalization of fullerene pyrrolidines. J. Am. Chem. Soc. 1993, 115, 9798-9799. [CrossRef]

89. Koeppe, R.; Sariciftci, N.S.; Troshin, P.A.; Lyubovskaya, R.N. Complexation of pyrrolidinofullerenes and zinc-phthalocyanine in a bilayer organic solar cell structure. Appl. Phys. Lett. 2005, 87, 244102. [CrossRef]

90. Koeppe, R.; Troshin, P.A.; Fuchsbauer, A.; Lyubovskaya, R.N.; Sariciftci, N.S. Photoluminescence Studies on the Supramolecular Interactions Between a Pyrollidinofullerene and Zinc? Phthalocyanine Used in Organic Solar Cells. Full-Nanotub. Carbon Nanostructures 2006, 14, 441-446. [CrossRef]

91. Troshin, P.A.; Koeppe, R.; Peregudov, A.S.; Peregudova, S.M.; Egginger, M.; Lyubovskaya, R.N.; Sariciftci, N.S. Supramolecular Association of Pyrrolidinofullerenes Bearing Chelating Pyridyl Groups and Zinc Phthalocyanine for Organic Solar Cells. Chem. Mater. 2007, 19, 5363-5372. [CrossRef]

92. Rio, Y.; Seitz, W.; Gouloumis, A.; Vázquez, P.; Sessler, J.L.; Guldi, D.M.; Torres, T. A Panchromatic Supramolecular Fullerene-Based Donor-Acceptor Assembly Derived from a Peripherally Substituted Bodipy-Zinc Phthalocyanine Dyad. Chem. A Eur. J. 2010, 16, 1929-1940. [CrossRef] [PubMed] 
93. Chen, X.-F.; El-Khouly, M.E.; Ohkubo, K.; Fukuzumi, S.; Ng, D.K.P. Assemblies of Boron Dipyrromethene/Porphyrin, Phthalocyanine, and C60 Moieties as Artificial Models of Photosynthesis: Synthesis, Supramolecular Interactions, and Photophysical Studies. Chem. A Eur. J. 2018, 24, 3862-3872. [CrossRef] [PubMed]

94. Suanzes, J.A.; Chaurasia, S.; Calderon, R.M.K.; Guldi, D.M.; Bottari, G.; Torres, T. Phthalocyanine-corannulene conjugates: Synthesis, complexation studies with a pyridyl-functionalized C60 fullerene, and photophysical properties. J. Porphyrins Phthalocyanines 2020, 24, 410-415. [CrossRef]

95. Das, S.K.; Mahler, A.; Wilson, A.K.; D'Souza, F. High-Potential Perfluorinated Phthalocyanine-Fullerene Dyads for Generation of High-Energy Charge-Separated States: Formation and Photoinduced Electron-Transfer Studies. ChemPhysChem 2014, 15, 2462-2472. [CrossRef]

96. D'Souza, F.; Maligaspe, E.; Ohkubo, K.; Zandler, M.E.; Subbaiyan, N.K.; Fukuzumi, S. Photosynthetic Reaction Center Mimicry: Low Reorganization Energy Driven Charge Stabilization in Self-Assembled Cofacial Zinc Phthalocyanine Dimer-Fullerene Conjugate. J. Am. Chem. Soc. 2009, 131, 8787-8797. [CrossRef]

97. D'Souza, F.; Chitta, R.; Gadde, S.; Rogers, L.M.; Karr, P.A.; Zandler, M.E.; Sandanayaka, A.S.D.; Araki, Y.; Ito, O. Photosynthetic Reaction Center Mimicry of a "Special Pair" Dimer Linked to Electron Acceptors by a Supramolecular Approach: Self-Assembled Cofacial Zinc Porphyrin Dimer Complexed with Fullerene(s). Chem. A Eur. J. 2007, 13, 916-922. [CrossRef]

98. Ballesteros, B.; De La Torre, G.; Torres, T.; Hug, G.L.; Rahman, G.A.; Guldi, D.M. Synthesis and photophysical characterization of a titanium(IV) phthalocyanine-C60 supramolecular dyad. Tetrahedron 2006, 62, 2097-2101. [CrossRef]

99. Lehmann, M.; DeChant, M.; Holzapfel, M.; Schmiedel, A.; Lambert, C. Fullerene-Filled Liquid-Crystal Stars: A Supramolecular Click Mechanism for the Generation of Tailored Donor-Acceptor Assemblies. Angew. Chem. Int. Ed. 2019, 58, 3610-3615. [CrossRef]

100. Guldi, D.M.; Gouloumis, A.; Vázquez, P.; Torres, T.; Georgakilas, V.; Prato, M. Nanoscale Organization of a Phthalocyanine-Fullerene System: Remarkable Stabilization of Charges in Photoactive 1-D Nanotubules. J. Am. Chem. Soc. 2005, 127, 5811-5813. [CrossRef]

101. KC, C.B.; Das, S.K.; Ohkubo, K.; Fukuzumi, S.; D'Souza, F. Ultrafast charge separation in supramolecular tetrapyrrole-graphene hybrids. Chem. Commun. 2012, 48, 11859. [CrossRef] [PubMed]

102. El-Khouly, M.E.; Fukuzumi, S. Light harvesting a gold porphyrin-zinc phthalocyanine supramolecular donor-acceptor dyad. Photochem. Photobiol. Sci. 2016, 15, 1340-1346. [CrossRef] [PubMed]

103. Kojima, T.; Honda, T.; Ohkubo, K.; Shiro, M.; Kusukawa, T.; Fukuda, T.; Kobayashi, N.; Fukuzumi, S. A Discrete Supramolecular Conglomerate Composed of Two Saddle-Distorted Zinc(II)-Phthalocyanine Complexes and a Doubly Protonated Porphyrin with Saddle Distortion Undergoing Efficient Photoinduced Electron Transfer. Angew. Chem. Int. Ed. 2008, 47, 6712-6716. [CrossRef] [PubMed]

104. Maligaspe, E.; Kumpulainen, T.; Lemmetyinen, H.; Tkachenko, N.V.; Subbaiyan, N.K.; Zandler, M.E.; D'Souza, F. Ultrafast Singlet-Singlet Energy Transfer in Self-Assembled via Metal-Ligand Axial Coordination of Free-Base Porphyrin-Zinc Phthalocyanine and Free-Base Porphyrin-Zinc Naphthalocyanine Dyads. J. Phys. Chem. A 2010, 114, 268-277. [CrossRef] [PubMed]

105. Menting, R.; Lau, J.T.F.; Xu, H.; Ng, D.K.P.; Röder, B.; Ermilov, E.A. Formation and photoinduced processes of a self-assembled subphthalocyanine-porphyrin-phthalocyanine supramolecular complex. Chem. Commun. 2012, 48, 4597. [CrossRef] [PubMed]

106. Menting, R.; Ng, D.K.P.; Ermilov, E.A.; Röder, B. Sequential energy and charge transfer processes in mixed host-guest complexes of subphthalocyanine, porphyrin and phthalocyanine chromophores. Phys. Chem. Chem. Phys. 2012, 14, 14573. [CrossRef]

107. Subbaiyan, N.K.; D'Souza, F. Light-to-electron converting panchromatic supramolecular solar cells of phthalocyanine-porphyrin heterodimers adsorbed onto nanocrystalline $\mathrm{SnO}_{2}$ electrodes. Chem. Commun. 2012, 48, 3641. [CrossRef]

108. Spänig, F.; López-Duarte, I.; Fischer, M.K.R.; Martínez-Díaz, M.V.; Bäuerle, P.; Torres, T.; Guldi, D.M. Charge and energy transfer processes in ruthenium(II) phthalocyanine based electron donor-acceptor materials-Implications for solar cell performance. J. Mater. Chem. 2011, 21, 1395-1403. [CrossRef]

109. Kawata, T.; Chino, Y.; Kobayashi, N.; Kimura, M. Increased Light-Harvesting in Dye-Sensitized Solar Cells through Förster Resonance Energy Transfer within Supramolecular Dyad Systems. Langmuir 2018, 34, 7294-7300. [CrossRef] 
110. Bartelmess, J.; Ehli, C.; Cid, J.-J.; Iglesias, M.G.; Vázquez, P.; Torres, T.; Guldi, D.M. Screening interactions of zinc phthalocyanine-PPV oligomers with single wall carbon nanotubes-a comparative study. J. Mater. Chem. 2011, 21, 8014. [CrossRef]

111. Kobashi, K.; Sekiguchi, A.; Yamada, T.; Muroga, S.; Okazaki, T. Dispersions of High-Quality Carbon Nanotubes with Narrow Aggregate Size Distributions by Viscous Liquid for Conducting Polymer Composites. ACS Appl. Nano Mater. 2020, 3, 1391-1399. [CrossRef]

112. Lucas, A.; Zakri, C.; Maugey, M.; Pasquali, M.; Van Der Schoot, P.; Poulin, P. Kinetics of Nanotube and Microfiber Scission under Sonication. J. Phys. Chem. C 2009, 113, 20599-20605. [CrossRef]

113. Das, S.K.; Subbaiyan, N.K.; D’Souza, F.; Sandanayaka, A.S.D.; Wakahara, T.; Ito, O. Formation and photoinduced properties of zinc porphyrin-SWCNT and zinc phthalocyanine-SWCNT nanohybrids using diameter sorted nanotubes assembled via metal-ligand coordination and $\pi-\pi$ stacking. J. Porphyrins Phthalocyanines 2011, 15, 1033-1043. [CrossRef]

114. Hahn, U.; Engmann, S.; Oelsner, C.; Ehli, C.; Guldi, D.M.; Torres, T. Immobilizing Water-Soluble Dendritic Electron Donors and Electron Acceptors-Phthalocyanines and Perylenediimides-Onto Single Wall Carbon Nanotubes. J. Am. Chem. Soc. 2010, 132, 6392-6401. [CrossRef] [PubMed]

115. D'Souza, F.; Chitta, R.; Sandanayaka, A.S.D.; Subbaiyan, N.K.; D’Souza, L.; Araki, Y.; Ito, O. Supramolecular Carbon Nanotube-Fullerene Donor-Acceptor Hybrids for Photoinduced Electron Transfer. J. Am. Chem. Soc. 2007, 129, 15865-15871. [CrossRef] [PubMed]

116. López-Duarte, I.; Dieu, L.; Dolamic, I.; Martinez-Diaz, M.V.; Torres, T.; Calzaferri, G.; Brühwiler, D. On the Significance of the Anchoring Group in the Design of Antenna Materials Based on Phthalocyanine Stopcocks and Zeolite, L. Chem. A Eur. J. 2010, 17, 1855-1862. [CrossRef]

117. Buccolieri, A.; Bettini, S.; Salvatore, L.; Baldassarre, F.; Ciccarella, G.; Giancane, G. Sub-nanomolar detection of biogenic amines by SERS effect induced by hairy Janus silver nanoparticles. Sensors Actuators B Chem. 2018, 267, 265-271. [CrossRef]

118. Bettini, S.; Pagano, R.; Valli, L.; Giancane, G. Enhancement of Open Circuit Voltage of a ZnO-Based Dye-Sensitized Solar Cell by Means of Piezotronic Effect. Chem. Asian J. 2016, 11, 1240-1245. [CrossRef]

119. Ray, A.; Bhattacharya, S. Chemical physics behind phthalocyanine-gold nanoparticle interaction and its effect over supramolecular interaction between PC70BM and phthalocyanine in solution. Chem. Phys. Lett. 2015, 639, 183-188. [CrossRef]

120. Bettini, S.; Pagano, R.; Semeraro, P.; Ottolini, M.; Salvatore, L.; Marzo, F.; Lovergine, N.; Giancane, G.; Valli, L. $\mathrm{SiO}_{2}$-Coated $\mathrm{ZnO}$ Nanoflakes Decorated with Ag Nanoparticles for Photocatalytic Water Oxidation. Chem. A Eur. J. 2019, 25, 14123-14132. [CrossRef]

121. Pagano, R.; Quarta, A.; Pal, S.; Licciulli, A.; Valli, L.; Bettini, S. Enhanced Solar-Driven Applications of ZnO@Ag Patchy Nanoparticles. J. Phys. Chem. C 2017, 121, 27199-27206. [CrossRef]

122. Alencar, W.S.; Crespilho, F.N.; Martins, M.V.A.; Zucolotto, V.; Oliveira, J.O.N.; Silva, W.C. Synergistic interaction between gold nanoparticles and nickel phthalocyanine in layer-by-layer (LbL) films: Evidence of constitutional dynamic chemistry (CDC). Phys. Chem. Chem. Phys. 2009, 11, 5086-5091. [CrossRef] [PubMed]

123. Alencar, W.S.; Crespilho, F.N.; Santos, M.; Zucolotto, V.; Oliveira, O.N.; Silva, W.C. Influence of Film Architecture on the Charge-Transfer Reactions of Metallophthalocyanine Layer-by-Layer Films. J. Phys. Chem. C 2007, 111, 12817-12821. [CrossRef]

124. Abe, T.; Nagai, K.; Kaneko, M.; Okubo, T.; Sekimoto, K.; Tajiri, A.; Norimatsu, T. A Novel and Efficient System of a Visible-Light-Responsive Organic Photoelectrocatalyst Working in a Water Phase. ChemPhysChem 2004, 5, 716-720. [CrossRef] [PubMed]

125. Abe, T.; Nagai, K.; Kabutomori, S.; Kaneko, M.; Tajiri, A.; Norimatsu, T. An Organic Photoelectrode Working in the Water Phase: Visible-Light-Induced Dioxygen Evolution by a Perylene Derivative/Cobalt Phthalocyanine Bilayer. Angew. Chem. Int. Ed. 2006, 45, 2778-2781. [CrossRef]

126. Wang, H.; Zhao, L.; Liu, X.; Xu, J.; Hou, W.; Wang, J.; He, E.; Zhang, R.; Zhang, H. Novel hydrogen bonding composite based on copper phthalocyanine/perylene diimide derivatives $\mathrm{p}-\mathrm{n}$ heterojunction with improved photocatalytic activity. Dye. Pigment. 2017, 137, 322-328. [CrossRef]

127. Zheng, S.; Lu, J.; Shi, J.; Duan, X. Two-dimensional confined electron donor-acceptor co-intercalated inorganic/organic nanocomposites: An effective photocatalyst for dye degradation. RSC Adv. 2017, 7, 2789-2795. [CrossRef] 
128. Zhang, S.; Sakai, R.; Abe, T.; Iyoda, T.; Norimatsu, T.; Nagai, K. Photoelectrochemical and Photocatalytic Properties of Biphasic Organic p- and n-Type Semiconductor Nanoparticles Fabricated by a Reprecipitation Process. ACS Appl. Mater. Interfaces 2011, 3, 1902-1909. [CrossRef]

129. Arunachalam, P.; Zhang, S.; Abe, T.; Komura, M.; Iyoda, T.; Nagai, K. Weak visible light $(\sim \mathrm{mW} / \mathrm{cm} 2)$ organophotocatalysis for mineralization of amine, thiol and aldehyde by biphasic cobalt phthalocyanine/fullerene nanocomposites prepared by wet process. Appl. Catal. B Environ. 2016, 193, 240-247. [CrossRef]

130. Regulska, E.; Karpińska, J.; Echegoyen, L.; Rivera-Nazario, D.M.; Plonska-Brzezinska, M.E. Enhanced Photocatalytic Performance of Porphyrin/Phthalocyanine and Bis (4-pyridyl)pyrrolidinofullerene modified Titania. ChemistrySelect 2017, 2, 2462-2470. [CrossRef]

131. Ma, X.; Luo, M.; Yan, L.; Tang, N.; Li, J. Preparation of a magnetically recyclable visible-light-driven photocatalyst based on phthalocyanine and its visible light catalytic degradation of methyl orange and p-nitrophenol. New J. Chem. 2019, 43, 9589-9595. [CrossRef]

132. Zvyagina, A.I.; Ezhov, A.A.; Meshkov, I.N.; Ivanov, V.K.; König, B.; Gorbunova, Y.G.; Arslanov, V.V.; Kalinina, M.A.; Birin, K.P.; König, B.; et al. Plasmon-enhanced light absorption at organic-coated interfaces: Collectivity matters. J. Mater. Chem. C 2018, 6, 1413-1420. [CrossRef]

133. Mele, G.; Annese, C.; D’Accolti, L.; De Riccardis, A.; Fusco, C.; Palmisano, L.; Scarlino, A.; Vasapollo, G. Photoreduction of Carbon Dioxide to Formic Acid in Aqueous Suspension: A Comparison between Phthalocyanine $/ \mathrm{TiO}_{2}$ and Porphyrin/ $\mathrm{TiO}_{2}$ Catalysed Processes. Molecules 2014, 20, 396-415. [CrossRef] [PubMed]

134. Liu, Q.; Wang, J.; Liu, N.; Li, R.; Peng, T. Photosensitization of zinc phthalocyanine bearing 15-crown-5 ether moieties on carbon nitride for $\mathrm{H}_{2}$ production: Effect of co-existing alkali metal ions. J. Power Sources 2018, 396, 57-63. [CrossRef]

135. Prajapati, P.K.; Singh, H.; Yadav, R.; Sinha, A.K.; Szunerits, S.; Boukherroub, R.; Jain, S.L. Core-shell Ni/NiO grafted cobalt (II) complex: An efficient inorganic nanocomposite for photocatalytic reduction of $\mathrm{CO}_{2}$ under visible light irradiation. Appl. Surf. Sci. 2019, 370-381. [CrossRef]

136. Giancane, G.; Syrgiannis, Z.; Bettini, S.; Valli, L.; Guerra, F.; Fraix, A.; Bucci, C.; Sortino, S.; Prato, M.; Sortino, S. Singlet oxygen photo-production by perylene bisimide derivative Langmuir-Schaefer films for photodynamic therapy applications. J. Colloid Interface Sci. 2019, 553, 390-401. [CrossRef]

137. Sternberg, E.D.; Dolphin, D.; Brückner, C. Porphyrin-based photosensitizers for use in photodynamic therapy. Tetrahedron 1998, 54, 4151-4202. [CrossRef]

138. Kwiatkowski, S.; Knap, B.; Przystupski, D.; Saczko, J.; Kędzierska, E.; Knap-Czop, K.; Kotlińska, J.; Michel, O.; Kotowski, K.; Kulbacka, J. Photodynamic therapy-mechanisms, photosensitizers and combinations. Biomed. Pharmacother. 2018, 106, 1098-1107. [CrossRef]

139. Voskuhl, J.; Kauscher, U.; Gruener, M.; Frisch, H.; Wibbeling, B.; Strassert, C.A.; Ravoo, B.J. A soft supramolecular carrier with enhanced singlet oxygen photosensitizing properties. Soft Matter 2013, 9, 2453. [CrossRef]

140. Kandoth, N.; Vittorino, E.; Sciortino, M.T.; Parisi, T.; Colao, I.; Mazzaglia, A.; Sortino, S. A Cyclodextrin-Based Nanoassembly with Bimodal Photodynamic Action. Chem. A Eur. J. 2011, 18, 1684-1690. [CrossRef]

141. Mazzaglia, A.; Valerio, A.; Micali, N.; Villari, V.; Quaglia, F.; Castriciano, M.A.; Monsu'scolaro, L.; Giuffrè, M.; Siracusano, G.; Sciortino, M.T. Effective cell uptake of nanoassemblies of a fluorescent amphiphilic cyclodextrin and an anionic porphyrin. Chem. Commun. 2011, 47, 9140. [CrossRef] [PubMed]

142. Uhlenheuer, D.A.; Wasserberg, D.; Haase, C.; Nguyen, H.D.; Schenkel, J.H.; Huskens, J.; Ravoo, B.J.; Jonkheijm, P.; Brunsveld, L. Directed Supramolecular Surface Assembly of SNAP-tag Fusion Proteins. Chem. A Eur. J. 2012, 18, 6788-6794. [CrossRef] [PubMed]

143. Voskuhl, J.; Fenske, T.; Stuart, M.C.A.; Wibbeling, B.; Schmuck, C.; Ravoo, B.J. Molecular Recognition of Vesicles: Host-Guest Interactions Combined with Specific Dimerization of Zwitterions. Chem. A Eur. J. 2010, 16, 8300-8306. [CrossRef] [PubMed]

144. Ogunsipe, A.; Chen, J.-Y.; Nyokong, T. Photophysical and photochemical studies of zinc(ii) phthalocyanine derivatives?effects of substituents and solvents. New J. Chem. 2004, 28, 822. [CrossRef]

145. Ogunsipe, A.; Maree, D.; Nyokong, T. Solvent effects on the photochemical and fluorescence properties of zinc phthalocyanine derivatives. J. Mol. Struct. 2003, 650, 131-140. [CrossRef] 
146. Galstyan, A.; Kauscher, U.; Block, D.; Ravoo, B.J.; Strassert, C.A. Silicon(IV) Phthalocyanine-Decorated Cyclodextrin Vesicles as a Self-Assembled Phototherapeutic Agent against MRSA. ACS Appl. Mater. Interfaces 2016, 8, 12631-12637. [CrossRef]

147. Voskuhl, J.; Stuart, M.C.A.; Ravoo, B.J. Sugar-Decorated Sugar Vesicles: Lectin-Carbohydrate Recognition at the Surface of Cyclodextrin Vesicles. Chem. A Eur. J. 2010, 16, 2790-2796. [CrossRef]

148. Lau, J.T.F.; Lo, P.-C.; Tsang, Y.-M.; Fong, W.-P.; Ng, D.K.P. Unsymmetrical ?-cyclodextrin-conjugated silicon(iv) phthalocyanines as highly potent photosensitisers for photodynamic therapy. Chem. Commun. 2011, 47, 9657. [CrossRef]

149. Jori, G.; Fabris, C.; Soncin, M.; Ferro, S.; Coppellotti, O.; Dei, D.; Fantetti, L.; Chiti, G.; Roncucci, G. Photodynamic therapy in the treatment of microbial infections: Basic principles and perspective applications. Lasers Surg. Med. 2006, 38, 468-481. [CrossRef]

150. Falvey, P.; Lim, C.W.; Darcy, R.; Revermann, T.; Karst, U.; Giesbers, M.; Marcelis, A.T.M.; Lazar, A.; Coleman, A.W.; Reinhoudt, D.N.; et al. Bilayer Vesicles of Amphiphilic Cyclodextrins: Host Membranes That Recognize Guest Molecules. Chem. A Eur. J. 2005, 11, 1171-1180. [CrossRef]

151. Kandoth, N.; Kirejev, V.; Monti, S.; Gref, R.; Ericson, M.; Sortino, S. Two-Photon Fluorescence Imaging and Bimodal Phototherapy of Epidermal Cancer Cells with Biocompatible Self-Assembled Polymer Nanoparticles. Biomacromolecules 2014, 15, 1768-1776. [CrossRef] [PubMed]

152. Gidwani, B.; Vyas, A. Synthesis, characterization and application of Epichlorohydrin- $\beta$-cyclodextrin polymer. Colloids Surfaces B Biointerfaces 2014, 114, 130-137. [CrossRef] [PubMed]

153. Othman, M.; Bouchemal, K.; Couvreur, P.; Desmaële, D.; Morvan, E.; Pouget, T.; Gref, R.; Patrick, C. A comprehensive study of the spontaneous formation of nanoassemblies in water by a "lock-and-key" interaction between two associative polymers. J. Colloid Interface Sci. 2011, 354, 517-527. [CrossRef] [PubMed]

154. Fraix, A.; Kandoth, N.; Manet, I.; Cardile, V.; Graziano, A.C.E.; Gref, R.; Sortino, S. An engineered nanoplatform for bimodal anticancer phototherapy with dual-color fluorescence detection of sensitizers. Chem. Commun. 2013, 49, 4459. [CrossRef] [PubMed]

155. Howe, L.; Zhang, J.Z. Ultrafast Studies of Excited-State Dynamics of Phthalocyanine and Zinc Phthalocyanine Tetrasulfonate in Solution. J. Phys. Chem. A 1997, 101, 3207-3213. [CrossRef]

156. Fraix, A.; Gref, R.; Sortino, S. A multi-photoresponsive supramolecular hydrogel with dual-color fluorescence and dual-modal photodynamic action. J. Mater. Chem. B 2014, 2, 3443-3449. [CrossRef]

157. Edgar, C.D.; Gray, D.G. Smooth model cellulose I surfaces from nanocrystal suspensions. Cellulose 2003, 10, 299-306. [CrossRef]

158. Carpenter, B.L.; Feese, E.; Sadeghifar, H.; Argyropoulos, D.S.; Ghiladi, R.A. Porphyrin-Cellulose Nanocrystals: A Photobactericidal Material that Exhibits Broad Spectrum Antimicrobial Activityt. Photochem. Photobiol. 2012, 88, 527-536. [CrossRef]

159. Drogat, N.; Granet, R.; Sol, V.; Le Morvan, C.; Bégaud-Grimaud, G.; Lallouet, F.; Krausz, P. Cellulose nanocrystals: A new chlorin carrier designed for photodynamic therapy: Synthesis, characterization and potent anti-tumoural activity. Photodiagnosis Photodyn. Ther. 2011, 8, 157. [CrossRef]

160. Liu, Z.; Wang, D.; Sun, X.; Sun, Q.; Wu, Y.; Xu, Y. Construction and Characterization of Phthalocyanine-Loaded Particles of Curdlan and Their Photosensitivity. Int. J. Mol. Sci. 2018, 19, 3323. [CrossRef]

161. Yoshiba, K.; Okamoto, S.; Dobashi, T.; Oku, H.; Christensen, B.E.; Sato, T. Effects of carboxylation of the side chains on the order-disorder transition in aqueous solution of schizophyllan, a triple helical polysaccharide. Carbohydr. Polym. 2017, 168, 79-85. [CrossRef]

162. Мa, Y.; Nolte, R.J.; Cornelissen, J.J. Virus-based nanocarriers for drug delivery. Adv. Drug Deliv. Rev. 2012, 64, 811-825. [CrossRef] [PubMed]

163. Luque, D.; De La Escosura, A.; Snijder, J.; Brasch, M.; Burnley, R.J.; Koay, M.S.T.; Carrascosa, J.L.; Wuite, G.J.; Roos, W.H.; Heck, A.J.R.; et al. Self-assembly and characterization of small and monodisperse dye nanospheres in a protein cage. Chem. Sci. 2014, 5, 575-581. [CrossRef]

164. Brasch, M.; De La Escosura, A.; Ma, Y.; Uetrecht, C.; Heck, A.J.R.; Torres, T.; Cornelissen, J.J.L.M. Encapsulation of Phthalocyanine Supramolecular Stacks into Virus-like Particles. J. Am. Chem. Soc. 2011, 133, 6878-6881. [CrossRef]

165. Stephanopoulos, N.; Carrico, Z.M.; Francis, M.B. Nanoscale Integration of Sensitizing Chromophores and Porphyrins with Bacteriophage MS2. Angew. Chem. Int. Ed. 2009, 48, 9498-9502. [CrossRef] [PubMed] 
166. Prasuhn, D.E.; Kuzelka, J.; Strable, E.; Udit, A.K.; Cho, S.-H.; Lander, G.C.; Quispe, J.D.; Diers, J.R.; Bocian, D.F.; Potter, C.; et al. Polyvalent Display of Heme on Hepatitis B Virus Capsid Protein through Coordination to Hexahistidine Tags. Chem. Boil. 2008, 15, 513-519. [CrossRef] [PubMed]

167. Endo, M.; Fujitsuka, M.; Majima, T. Porphyrin Light-Harvesting Arrays Constructed in the Recombinant Tobacco Mosaic Virus Scaffold. Chem. A Eur. J. 2007, 13, 8660-8666. [CrossRef]

168. Heck, A.J.R. Native mass spectrometry: A bridge between interactomics and structural biology. Nat. Methods 2008, 5, 927-933. [CrossRef]

169. Nyokong, T. Effects of substituents on the photochemical and photophysical properties of main group metal phthalocyanines. Co-ord. Chem. Rev. 2007, 251, 1707-1722. [CrossRef]

170. Zeng, Q.; Wen, H.; Wen, Q.; Chen, X.; Wang, Y.; Xuan, W.; Liang, J.; Wan, S. Cucumber mosaic virus as drug delivery vehicle for doxorubicin. Biomaterials 2013, 34, 4632-4642. [CrossRef]

171. Nishiyama, N.; Jang, W.D.; Kataoka, K. Supramolecular nanocarriers integrated with dendrimers encapsulating photosensitizers for effective photodynamic therapy and photochemical gene delivery. New J. Chem. 2007, 31, 1074-1082. [CrossRef]

172. Nishiyama, N.; Nakagishi, Y.; Morimoto, Y.; Lai, P.-S.; Miyazaki, K.; Urano, K.; Horie, S.; Kumagai, M.; Fukushima, S.; Cheng, Y.; et al. Enhanced photodynamic cancer treatment by supramolecular nanocarriers charged with dendrimer phthalocyanine. J. Control. Release 2009, 133, 245-251. [CrossRef] [PubMed]

173. Jang, W.-D.; Nakagishi, Y.; Nishiyama, N.; Kawauchi, S.; Morimoto, Y.; Kikuchi, M.; Kataoka, K. Polyion complex micelles for photodynamic therapy: Incorporation of dendritic photosensitizer excitable at long wavelength relevant to improved tissue-penetrating property. J. Control. Release 2006, 113, 73-79. [CrossRef] [PubMed]

174. Li, Y.; Jang, W.-D.; Nishiyama, N.; Kishimura, A.; Kawauchi, S.; Morimoto, Y.; Miake, S.; Yamashita, T.; Kikuchi, M.; Aida, T.; et al. Dendrimer Generation Effects on Photodynamic Efficacy of Dendrimer Porphyrins and Dendrimer-Loaded Supramolecular Nanocarriers. Chem. Mater. 2007, 19, 5557-5562. [CrossRef]

175. Jang, W.-D.; Nishiyama, N.; Zhang, G.-D.; Harada, A.; Jiang, D.-L.; Kawauchi, S.; Morimoto, Y.; Kikuchi, M.; Koyama, H.; Aida, T.; et al. Supramolecular Nanocarrier of Anionic Dendrimer Porphyrins with Cationic Block Copolymers Modified with Polyethylene Glycol to Enhance Intracellular Photodynamic Efficacy. Angew. Chem. Int. Ed. 2005, 44, 419-423. [CrossRef]

176. Lu, X.; Zhu, W.; Chen, T.; Peng, Q.; Yu, C.; Yang, M. Exploration of photophysical and photochemical properties of Zinc phthalocyanine-loaded SDC/TPGS mixed micelles. Chem. Phys. Lett. 2019, 735, 136737. [CrossRef]

177. Lapshina, M.A.; Ustyugov, A.; Baulin, V.; Terentiev, A.; Tsivadze, A.; Goldshleger, N.F. Crown- and phosphoryl-containing metal phthalocyanines in solutions of poly(N-vinylpyrrolidone): Supramolecular organization, accumulation in cells, photo-induced generation of reactive oxygen species, and cytotoxicity. J. Photochem. Photobiol. B Boil. 2020, 202, 111722. [CrossRef]

178. Cheng, H.-B.; Li, X.; Kwon, N.; Fang, Y.; Baek, G.; Yoon, J. Photoswitchable phthalocyanine-assembled nanoparticles for controlled "double-lock" photodynamic therapy. Chem. Commun. 2019, 55, 12316-12319. [CrossRef]

179. Cheng, H.-B.; Zhang, Y.-M.; Xu, C.; Liu, Y. Photoresponsive Supramolecular Complexes as Efficient DNA Regulator. Sci. Rep. 2014, 4, 1-6. [CrossRef]

180. Chen, X.-W.; Ke, M.-R.; Li, X.-S.; Lan, W.-L.; Zhang, M.-F.; Huang, J.-D. Synthesis, Supramolecular Behavior, and in Vitro Photodynamic Activities of Novel Zinc(II) Phthalocyanines "Side-strapped" with Crown Ether Bridges. Chem. Asian J. 2013, 8, 3063-3070. [CrossRef]

181. Bilgiçli, A.T.; Bilgiçli, H.G.; Günsel, A.; Pişkin, H.; Tüzün, B.; Yarasir, M.N.; Zengin, M. The new ball-type zinc phthalocyanine with S S bridge; Synthesis, computational and photophysicochemical properties. J. Photochem. Photobiol. A Chem. 2020, 389, 112287. [CrossRef]

182. Engelkamp, H. Self-Assembly of Disk-Shaped Molecules to Coiled-Coil Aggregates with Tunable Helicity. Science 1999, 284, 785-788. [CrossRef] [PubMed]

183. Li, D.; Wang, X.-Z.; Yang, L.-F.; Li, S.-C.; Hu, Q.-Y.; Li, X.; Zheng, B.-Y.; Ke, M.-R.; Huang, J.-D. Size-Tunable Targeting-Triggered Nanophotosensitizers Based on Self-Assembly of a Phthalocyanine-Biotin Conjugate for Photodynamic Therapy. ACS Appl. Mater. Interfaces 2019, 11, 36435-36443. [CrossRef] [PubMed] 
184. Li, X.; Kim, C.-Y.; Lee, S.; Lee, D.; Chung, H.-M.; Kim, G.; Heo, S.-H.; Hong, K.-S.; Yoon, J.; Kim, C. Nanostructured Phthalocyanine Assemblies with Protein-Driven Switchable Photoactivities for Biophotonic Imaging and Therapy. J. Am. Chem. Soc. 2017, 139, 10880-10886. [CrossRef]

185. Ren, W.X.; Han, J.; Uhm, S.; Jang, Y.J.; Kang, C.; Kim, J.-H.; Kim, J.S. Recent development of biotin conjugation in biological imaging, sensing, and target delivery. Chem. Commun. 2015, 51, 10403-10418. [CrossRef]

186. Chen, X.; Wu, S.; Ma, N.; Chen, J.; Guo, Q.; Han, X.; Chen, K.; Yang, H.; Huang, Y.; Peng, Y.; et al. A polyfluoroalkyl substituted phthalocyanine based supramolecular light switch for photothermal and photodynamic antibacterial activity against Escherichia coli. Chem. Commun. 2018, 54, 13279-13282. [CrossRef]

187. Nwahara, N.; Nkhahle, R.; Ngoy, B.P.; Mack, J.; Nyokong, T. Synthesis and photophysical properties of BODIPY-decorated graphene quantum dot-phthalocyanine conjugates. New J. Chem. 2018, 42, 6051-6061. [CrossRef]

188. Dong, J.; Wang, K.; Sun, L.; Sun, B.; Yang, M.; Chen, H.; Wang, Y.; Sun, J.; Dong, L. Application of graphene quantum dots for simultaneous fluorescence imaging and tumor-targeted drug delivery. Sensors Actuators B Chem. 2018, 256, 616-623. [CrossRef]

189. Qu, D.; Zheng, M.; Du, P.; Zhou, Y.; Zhang, L.; Li, D.; Tan, H.; Zhao, Z.; Xie, Z.; Sun, Z. Highly luminescent S, $\mathrm{N}$ co-doped graphene quantum dots with broad visible absorption bands for visible light photocatalysts. Nanoscale 2013, 5, 12272-12277. [CrossRef]

190. Sahoo, A.K.; Kanchi, S.; Mandal, T.; Dasgupta, C.; Maiti, P.K. Translocation of Bioactive Molecules through Carbon Nanotubes Embedded in the Lipid Membrane. ACS Appl. Mater. Interfaces 2018, 10, 6168-6179. [CrossRef]

191. Fomo, G.; Achadu, O.J.; Nyokong, T. One-pot synthesis of graphene quantum dots-phthalocyanines supramolecular hybrid and the investigation of their photophysical properties. J. Mater. Sci. 2017, 53, 538-548. [CrossRef]

192. Guo, Z.; Feng, Y.; Zhu, D.; He, S.; Liu, H.; Shi, X.; Sun, J.; Qu, M. Light-Switchable Single-Walled Carbon Nanotubes Based on Host-Guest Chemistry. Adv. Funct. Mater. 2013, 23, 5010-5018. [CrossRef]

193. Moon, H.K.; Lee, S.H.; Choi, H.C. In Vivo Near-Infrared Mediated Tumor Destruction by Photothermal Effect of Carbon Nanotubes. ACS Nano 2009, 3, 3707-3713. [CrossRef] [PubMed]

194. Liang, R.; You, S.; Ma, L.; Li, C.; Tian, R.; Wei, M.; Yan, D.; Yin, M.; Yang, W.; Evans, D.G.; et al. A supramolecular nanovehicle toward systematic, targeted cancer and tumor therapy. Chem. Sci. 2015, 6, 5511-5518. [CrossRef]

195. Bettini, S.; Giancane, G.; Pagano, R.; Bonfrate, V.; Salvatore, L.; Madaghiele, M.; Buccolieri, A.; Manno, D.; Serra, A.; Maruccio, G.; et al. A simple approach to synthetize folic acid decorated magnetite@SiO ${ }_{2}$ nanostructures for hyperthermia applications. J. Mater. Chem. B 2017, 5, 7547-7556. [CrossRef]

196. Zhou, H.; Jiao, P.; Yang, L.; Li, X.; Yan, B. Enhancing Cell Recognition by Scrutinizing Cell Surfaces with a Nanoparticle Array. J. Am. Chem. Soc. 2011, 133, 680-682. [CrossRef]

197. Li, X.; Yu, S.; Lee, D.; Kim, G.; Lee, B.; Cho, Y.; Zheng, B.-Y.; Ke, M.-R.; Huang, J.-D.; Nam, K.T.; et al. Facile Supramolecular Approach to Nucleic-Acid-Driven Activatable Nanotheranostics That Overcome Drawbacks of Photodynamic Therapy. ACS Nano 2017, 12, 681-688. [CrossRef]

(C) 2020 by the authors. Licensee MDPI, Basel, Switzerland. This article is an open access article distributed under the terms and conditions of the Creative Commons Attribution (CC BY) license (http://creativecommons.org/licenses/by/4.0/). 